\title{
Estudo de variáveis morfológicas e moleculares associadas ao acometimento de linfonodos axilares não-sentinelas no carcinoma infiltrativo inicial de mama
}

Tese apresentada à Faculdade de Medicina da Universidade de São Paulo para obtenção do título de Doutor em Ciências.

Programa de Clínica Cirúrgica

Orientador: Prof. Dr. Alfredo Luiz Jacomo

São Paulo

2020 


\section{Estudo de variáveis morfológicas e moleculares associadas ao acometimento de linfonodos axilares não-sentinelas no carcinoma infiltrativo inicial de mama}

Tese apresentada à Faculdade de Medicina da Universidade de São Paulo para obtenção do título de Doutor em Ciências.

Programa de Clínica Cirúrgica

Orientador: Prof. Dr. Alfredo Luiz Jacomo

São Paulo

2020 
Dados Internacionais de Catalogação na Publicação (CIP)

Preparada pela Biblioteca da

Faculdade de Medicina da Universidade de São Paulo

Creprodução autorizada pelo autor

Andrade, Danúbia Ariana de

Estudo de variáveis morfológicas e moleculares associadas ao acometimento de linfonodos axilares não-sentinelas no carcinoma infiltrativo inicial de mama / Danúbia Ariana de Andrade. -- São Paulo,

2020.

Tese (doutorado)--Faculdade de Medicina da Universidade de São Paulo.

Programa de Clínica Cirúrgica.

orientador: Alfredo Luiz Jacomo.

Descritores: 1.Neoplasias da mama 2.Cirurgia 3. Linfonodo sentinela 4.Biópsia de linfonodo sentinela 5.Metástases linfonodais

USP /FM/DBD $-248 / 20$

Responsável: Erinalva da Conceição Batista, CRB-8 6755 
Ao meu filho Otto, por me ensinar a forma mais pura do amor. Ao meu esposo Tácio, por nos escolhermos todos os dias. Aos meus pais, pelo apoio incondicional. Ao meu irmão lgor, pelo companheirismo e amizade. 


\section{AGRADECIMENTOS}

Ao meu orientador, Prof. Dr. Alfredo Luiz Jacomo, pela inspiração acadêmica, pela oportunidade, incentivo e todo suporte durante a realização do meu doutorado.

Ao Prof. Dr. Alfredo Carlos Simões Dornellas de Barros pelos ensinamentos médicos, acadêmicos e humanos, mas, sobretudo por me estimular a ser uma profissional mais empática e em busca do conhecimento.

À Profa. Dra. Filomena M. Carvalho e ao Dr. Fernando N. Aguiar por todo suporte com a análise anatomopatológica dos casos e pelo exemplo de excelência na especialidade médica. À Dra. Sheila Wludarski pela dedicação na obtenção do material anatomopatológico arquivado.

Às minhas colegas de pós-graduação, Larissa, Priscila e Rebeca pela amizade, parceria e intercâmbio de ideias.

Às minhas colegas de trabalho, Beatriz, Juliana e Carolina, que compartilham as angústias e vitórias do dia a dia.

Às secretárias da Disciplina de Topografia Estrutural Humana da FMUSP, Shirley de Sousa e a Mariliza Ottani, pela disponibilidade e gentileza.

À secretária para assuntos de pós-graduação do Departamento de Clínica Cirúrgica, Eliane Gazeto, pela receptividade e eficiência.

Ao epidemiologista Alex Cassenote pela consultoria estatística.

Às funcionárias da Clínica Prof. Alfredo Barros pelo auxílio na coleta de dados. 


\section{NORMATIZAÇÃO ADOTADA}

Esta tese está de acordo com as seguintes normas, em vigor no momento desta publicação:

Referências: adaptado de International Committee of Medical Journals Editors (Vancouver).

Universidade de São Paulo. Faculdade de Medicina. Divisão de Biblioteca e Documentação. Guia de apresentação de dissertações, teses e monografias. Elaborado por Anneliese Carneiro da Cunha, Maria Julia de A. L. Freddi, Maria F. Crestana, Marinalva de Souza Aragão, Suely Campos Cardoso, Valéria Vilhena. 3a ed. São Paulo: Divisão de Biblioteca e Documentação; 2011.

Abreviaturas dos títulos dos periódicos de acordo com List of Journals Indexed in Index Medicus. 


\section{SUMÁRIO}

\section{LISTA DE ABREVIATURAS, SIGLAS E SÍMBOLOS}

\section{LISTA DE TABELAS}

\section{LISTA DE FIGURAS}

\section{RESUMO}

\section{ABSTRACT}

1. INTRODUÇÃO

2. OBJETIVOS

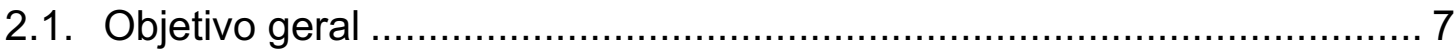

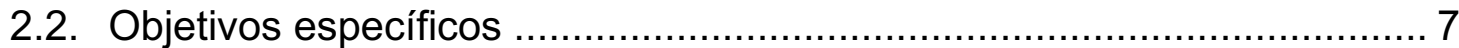

3. REVISÃO DA LITERATURA

3.1. Aspectos epidemiológicos do câncer de mama ...................................... 9

3.2. Mecanismos de formação e desenvolvimento do câncer de mama........... 9

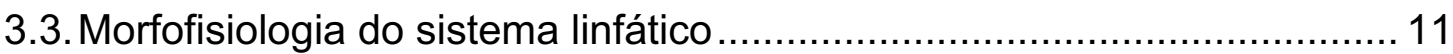

3.4. O sistema linfático na mama ........................................................ 13

3.5. Tratamento cirúrgico do carcinoma mamário invasivo ............................ 15

3.6. Fatores preditores de acometimento de linfonodos não-sentinelas ......... 20

3.7. Nomogramas para predição do status axilar ......................................... 22

3.8. Omissão da linfadenectomia axilar completa após biópsia de

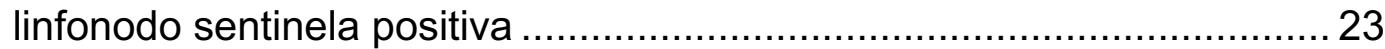

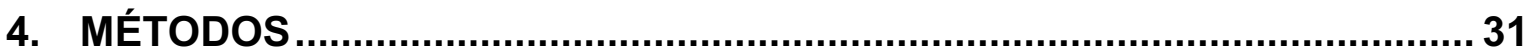

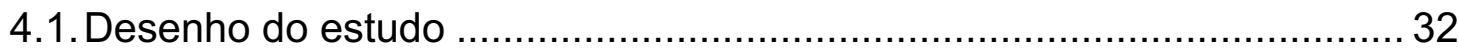

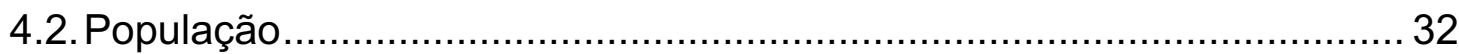

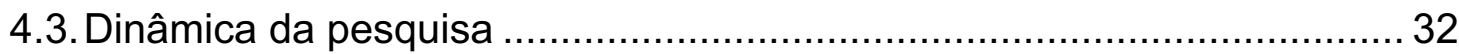

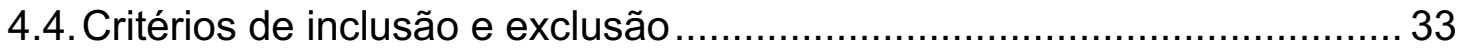


4.5. Variáveis de estudo 34

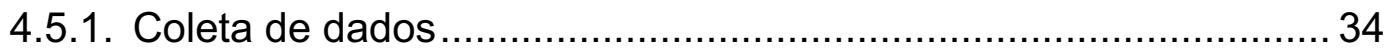

4.5.2. Definições e critérios de positividade ............................................. 35

4.5.3. Mapeamento e retirada do linfonodo sentinela............................. 37

4.5.4. Exame anatomopatológico do linfonodo sentinela ........................ 38

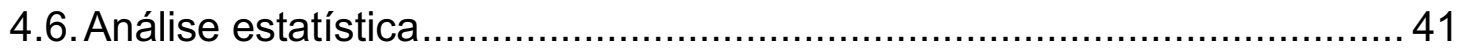

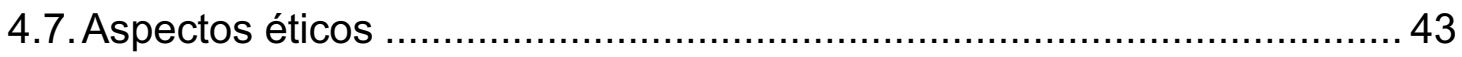

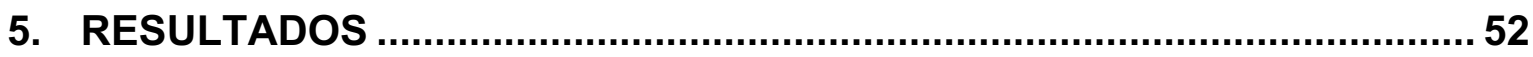

6. DISCUSSÃO

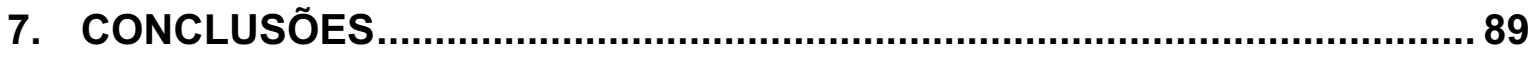

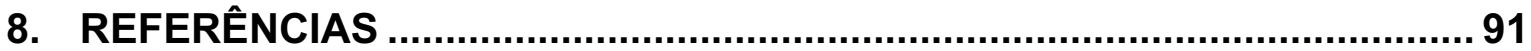

9. ANEXO 


\section{LISTA DE ABREVIATURAS, SIGLAS E SÍMBOLOS}
a.C.
Antes de Cristo
d.C.
Depois de Cristo
BLS
Biópsia do linfonodo sentinela
CLA
Comprometimento linfonodal adicional
$\mathrm{CM}$
Carcinoma de mama
CT
Tamanho tumoral ao exame clínico
DLA
Dissecção linfonodal axilar
DLAC
Dissecção linfonodal axilar completa
DP
Desvio padrão
IC
Intervalo de confiança
IC $95 \%$
Intervalo de confiança de $95 \%$
$\mathrm{FNL}$
Focos neoplásicos nos linfonodos
$\mathrm{HR}$
Hazard ratio
HER-2
Receptor do fator de crescimento epidérmico humano 2
Ki-67
Antígeno marcador de proliferação celular
LN
Linfonodo
LN-S
Linfonodos não-sentinelas
LPS
Linfonodo parassentinela
LS
Linfonodo sentinela
Max
Máximo
Min
Mínimo
$\mathrm{n}$
Número de casos
NO
Axila negativa
OR
Odds ratio
pT
Tamanho tumoral ao exame anatomopatológico
$\mathrm{p}$
Probabilidade de significância ou nível estatístico
RTA
Radioterapia axilar
SOE
Sem outras especificações
nm
Nanômetro
$\mu \mathrm{m}$
Micrômetro
$\mathrm{mm}$
Milímetros 


$\begin{array}{ll}\mathrm{cm} & \text { Centímetros } \\ \mathrm{mm}^{2} & \text { Milímetros quadrados } \\ \% & \text { Porcentagem } \\ = & \text { Igual a } \\ > & \text { Maior que } \\ < & \text { Menor que } \\ \geq & \text { Maior ou igual a } \\ \leq & \text { Menor ou igual a } \\ \pm & \text { Mais ou menos }\end{array}$




\section{LISTA DE TABELAS}

Tabela 1 - Localização dos tumores na mama avaliados pelo exame anatomopatológico em 129 casos de carcinoma mamário infiltrativo

Tabela 2 - Análise descritiva das características tumorais qualitativas estratificadas de acordo com os grupos incluindo frequência absoluta, relativa, intervalo de confiança de $95 \%$

Tabela 3 - Análise descritiva das características moleculares qualitativas estratificadas de acordo com os grupos incluindo frequência absoluta, relativa, intervalo de confiança de $95 \%$ 59

Tabela 4 - Análise descritiva das características linfonodais qualitativas estratificadas de acordo com os grupos incluindo frequência absoluta, relativa, intervalo de confiança de $95 \%$ 60

Tabela 5- Estatísticas descritivas dos fatores quantitativos incluindo média, desvio padrão, mediana, mínimo e máximo

Tabela 6 - Distribuição de parâmetros clínicos e tumorais entre indivíduos com e sem comprometimento linfonodal adicional, incluindo frequência absoluta, relativa, razão de chances com intervalo de confiança de $95 \%$ e nível descritivo

Tabela 7 - Distribuição de parâmetros moleculares entre indivíduos com e sem comprometimento linfonodal adicional, incluindo frequência absoluta, relativa, razão de chances com intervalo de confiança de $95 \%$ e nível descritivo 
Tabela 8 - Distribuição de parâmetros linfonodais entre indivíduos com e sem comprometimento linfonodal adicional não-sentinela, incluindo frequência absoluta e relativa, razão de chances com intervalo de confiança de 95\% e nível descritivo 64

Tabela 9 - Distribuição das variáveis quantitativas entre indivíduos com e sem comprometimento linfonodal adicional, incluindo mediana e nível descritivo 65

Tabela 10 - Modelo de regressão logística ajustado para comprometimento linfonodal adicional, incluindo frequência absoluta e relativa, odds ratio com IC 95\% e nível descritivo 66 


\section{LISTA DE FIGURAS}

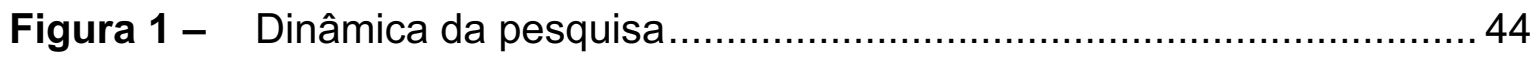

Figura 2 - Linfonodo apresentando micrometástase subcapsular .................. 45

Figura 3 - Linfonodo apresentando envolvimento difuso por macrometástase.

Figura 4 - Injeção peritumoral do radiofármaco tecnécio para marcação do linfonodo sentinela

Figura 5 - Linfocintilografia demonstrando captação de radiofármaco em linfonodo axilar 48

Figura 6 - Identificação do linfonodo sentinela por gama probe 49

Figura 7 - Mensuração da radiação ex-vivo no linfonodo sentinela 50

Figura 8 - Exame citológico por contato

Figura 9 - Distribuição do tamanho tumoral ao exame clínico de acordo com o comprometimento linfonodal adicional

Figura 10 - Distribuição do receptor de estrogênio (\%) entre indivíduos com e sem comprometimento linfonodal adicional

Figura 11 - Distribuição do receptor de progesterona (\%) entre indivíduos com e sem comprometimento linfonodal adicional.

Figura 12 - Distribuição do número de linfonodos sentinelas e parassentinelas comprometidos entre indivíduos com e sem comprometimento linfonodal adicional.

Figura 13 - Distribuição da taxa de comprometimento dos linfonodos sentinelas e parassentinelas entre indivíduos com e sem comprometimento linfonodal adicional. 
Figura 14 - Distribuição do número de focos neoplásicos nos linfonodos entre indivíduos com e sem comprometimento linfonodal adicional

Figura 15 - Distribuição do tamanho da maior metástase $(\mathrm{mm})$ entre indivíduos com e sem comprometimento linfonodal adicional 73

Figura 16 - Distribuição da fração da área do linfonodo ocupada pela metástase (\%) entre indivíduos com e sem comprometimento linfonodal adicional.

Figura 17 - Distribuição do número de linfonodos regionais não-sentinelas dissecados entre indivíduos com e sem comprometimento linfonodal adicional. .75

Figura 18 - Curva ROC dos valores preditos para o modelo de regressão logística ajustado para comprometimento linfonodal adicional não-sentinela 
RESUMO 
Andrade DA. Estudo de variáveis morfológicas e moleculares associadas ao acometimento de linfonodos axilares não-sentinelas no carcinoma infiltrativo inicial de mama [tese]. São Paulo: Faculdade de Medicina, Universidade de São Paulo; 2020.

INTRODUÇÃO: A linfadenectomia axilar completa é tema controverso atualmente após a confirmação de malignidade na biópsia do linfonodo sentinela. Não está claro pela literatura em quais casos existe segurança oncológica para a omissão da linfadenectomia e quais os fatores preditores do acometimento de linfonodos não-sentinelas, que podem ser decisivos para indicar uma ampliação da dissecção. OBJETIVO: Avaliar a possibilidade de predição do envolvimento neoplásico dos linfonodos axilares não-sentinelas com base em parâmetros morfológicos e moleculares. MÉTODOS: Trata-se de um estudo retrospectivo, observacional, transversal e não-controlado. As informações foram obtidas através de dados clínicos e anatomopatológicos de pacientes com carcinomas mamários infiltrativos iniciais tratados com biópsia de linfonodo sentinela, seguida por dissecção linfonodal axilar. Foram incluídos pacientes com tumores estádio I e II. Para análise estatística das variáveis morfológicas e moleculares foram realizadas medidas de frequência, análise por regressão logística binária e regressão logística múltipla. RESULTADOS: Foram avaliados 129 pacientes, sendo que o comprometimento linfonodal adicional não-sentinela foi constatado em 47 casos $(36,4 \%)$. A análise univariada demonstrou que os parâmetros clínicos e tumorais relacionados ao comprometimento linfonodal não-sentinela foram: tamanho tumoral ao exame clínico na categoria clínica T2 (OR $=5,36 ; p=0,005)$, tamanho tumoral ao exame anatomopatológico (sem estimativa de odds ratio, $p=0,001$ ), grau histológico III (OR $=6,33 ; p=0,026)$ e embolização vascular peritumoral presente em área focal (OR 2,42; $p=0,038)$. Os parâmetros relacionados às características linfonodais foram: comprometimento de mais de um linfonodo sentinela/parassentinela ( $O R=3,99 ; p<0,001)$, taxa de comprometimento linfonodal de $100 \%(O R=3,17 ; p=0,003)$, dois ou mais focos neoplásicos nos linfonodos $(\mathrm{OR}=4,1 ; \mathrm{p}<0,001)$, metástase superior a 4,0 mm $(\mathrm{OR}=5,55$; $\mathrm{p}<$ $0,001)$, presença de extensão neoplásica extracapsular $(O R=3,46 ; p=0,011)$, acometimento de gordura perilinfonodal ( $O R=4,63 ; p=0,010)$, envolvimento vascular perilinfonodal ( $O R=4,73 ; p=0,021)$ e 20 ou mais linfonodos nãosentinelas dissecados (OR $=3,94 ; \mathrm{p}<0,001)$. Na análise multivariada, as variáveis que aumentaram a chance de ocorrência do comprometimento linfonodal adicional não-sentinela foram: o tamanho tumoral ao exame clínico na categoria clínica T2 (OR $=9,23 ; p=0,017)$, a presença de dois ou mais focos neoplásicos nos linfonodos (OR $=4,11 ; p=0,039)$ e o tamanho da metástase superior a 4,0 $\mathrm{mm}(\mathrm{OR}=15,42 ; \mathrm{p}=0,019)$ com acurácia de 81\% $(\mathrm{p}<0,001)$. CONCLUSÕES: A acurácia da predição do comprometimento linfonodal regional não-sentinela por parâmetros morfológicos e moleculares é elevada. Os parâmetros tamanho tumoral ao exame clínico na categoria clínica T2, a presença de dois ou mais focos neoplásicos nos linfonodos sentinelas/parassentinelas e o tamanho da metástase superior a $4,0 \mathrm{~mm}$ sugerem a necessidade de complementação da linfadenectomia após biópsia positiva do linfonodo sentinela.

Descritores: Neoplasias da mama; Cirurgia; Linfonodo sentinela; Biópsia de linfonodo sentinela; Metástases linfonodais. 
ABSTRACT 
Andrade DA. Study of morphological and molecular variables associated to the involvement of non-sentinel axillary lymph nodes with initial diagnosis of infiltrating mammary carcinoma [thesis]. São Paulo: "Faculdade de Medicina, Universidade de São Paulo"; 2020.

INTRODUCTION: The complete axillary lymphadenectomy is currently a controversial topic when the malignancy is confirmed through sentinel lymph node biopsy. The literature shows no evidence in what cases there is enough oncological safety to justify the absence of lymphadenectomy or what predictive factors of non-sentinel lymph node involvement may be crucial to suggest an expanded axillary dissection. OBJECTIVE: Evaluate the possibility of predicting neoplastic involvement of the non-sentinel axillary lymph nodes based on morphological and molecular parameters. METHODS: This is a retrospective, observational, cross-sectional and uncontrolled study. All data was collected from clinical and anatomopathological information regarding patients with initial diagnosis of infiltrating mammary carcinomas that were treated with sentinel lymph node biopsy, followed by complete axillary dissection. Patients with cancer in stages I and II were included. The statistical analysis used frequency measures, binary logistic regression and multiple logistic regression. RESULTS: From 129 patients evaluated, the compromise of non-sentinel additional lymph nodes was found in 47 (36.4\%). The univariate analysis showed that clinical and tumoral parameters relating to non-sentinel lymph node compromise were: tumor size in clinical exam of the T2 category $(\mathrm{OR}=$ 5.36; $p=0.005$ ), tumor size in anatomopathological exam (with no estimate of odds ratio, $p=0.001)$, histological grade III (OR $=6.33 ; p=0.026)$ and presence of peritumoral vascular embolism in focal area (OR 2.42; $p=0.038$ ). The parameters relating to lymph node characteristics were: compromise of more than 1 sentinel/para-sentinel lymph node $(O R=3.99 ; p<0.001)$, lymph node compromise rate of $100 \%(O R=3.17 ; p=0.003)$, two or more neoplastic focuses in lymph nodes $(O R=4.1 ; p<0.001)$, metastasis larger than $4.0 \mathrm{~mm}$ $(\mathrm{OR}=5.55 ; p<0.001)$, presence of extracapsular neoplastic extension $(\mathrm{OR}=$ 3.46; $p=0.011)$, perilymphatic fat compromise $(O R=4.63 ; p=0.010)$, perilymphatic vascular involvement $(O R=4.73 ; p=0.021)$ and twenty or more dissected non-sentinel lymph nodes $(O R=3.94 ; p<0.001)$. In the multivariate analysis, the variables that increased the chance of compromise by nonsentinel additional lymph nodes were the tumor size in clinical exams of the T2 category $(O R=9.23 ; p=0.017)$, the presence of two or more neoplastic focuses in the lymph nodes $(O R=4.11 ; p=0.039)$ and metastasis larger than $4.0 \mathrm{~mm}(\mathrm{OR}=15.42 ; \mathrm{p}=0.019)$ with an accuracy of $81 \%(\mathrm{p}<0.001)$. CONCLUSION: The accuracy in predicting the compromise by non-sentinel regional lymph nodes through morphological and molecular parameters is high. Tumor size in clinical exam of the T2 category, presence of two or more neoplastic focuses in the sentinel/para-sentinel lymph nodes and the size of the largest metastasis over $4.0 \mathrm{~mm}$ are parameters that suggest the complete axillary lymphadenectomy when positive sentinel lymph node biopsy.

Descriptors: Breast neoplasms; Surgery; Sentinel lymph node; Sentinel lymph node biopsy; Lymph node metastasis. 
1. INTRODUÇÃO 
A incidência do carcinoma de mama (CM) aumenta progressivamente tanto nos países desenvolvidos, quanto nos países em desenvolvimento. No entanto, a mortalidade está em declínio, sendo reflexo de uma evolução substancial na sua prevenção e no seu tratamento ${ }^{1,2}$.

O cirurgião William Halsted, no final do século XIX, apresentou a técnica de mastectomia radical, oncologicamente correta até hoje, no entanto associada à considerável morbidade ${ }^{3}$. A remoção da mama com extensa área de pele e a ressecção dos músculos peitorais seguida pela linfadenectomia axilar, podem ocasionar prejuízos na qualidade de vida das pacientes, devido à disfunção na motilidade do membro superior, surgimento de linfedema e danos aos nervos axilares ${ }^{4}$.

No início da década de 1970, foram iniciados estudos com o intuito de explorar se uma cirurgia menos agressiva poderia ser tão efetiva para as pacientes quanto a mastectomia ${ }^{5,6}$. Veronesi et al. e Fisher et al. publicaram importantes casuísticas randomizadas, que incluíram pacientes submetidas à mastectomia radical ou ressecção segmentar mamária com dissecção linfonodal axilar completa (DLAC) e, demonstraram claramente, após mais de 20 anos de seguimento, que a cirurgia conservadora associada à radioterapia é tão eficaz quanto a cirurgia radical, em tumores medindo até $3,0 \mathrm{~cm}^{7,8}$.

Diante desses avanços na cirurgia mamária, seguiram-se questionamentos sobre a extensão da cirurgia axilar, pois a linfadenectomia axilar total foi por muito tempo um procedimento de rotina ${ }^{9}$.

$\mathrm{Na}$ prática, o conceito de linfonodo sentinela (LS) foi proposto por Cabanas, que demonstrou que uma biópsia de linfonodo sentinela (BLS) negativa permitiria a omissão da dissecção linfonodal completa em casos de 
carcinomas de pênis ${ }^{10}$. A transposição do conceito de LS para o $\mathrm{CM}$ foi publicada por Krag et al. ${ }^{11}$ e Giuliano et al. ${ }^{12}$. Os pesquisadores identificavam o primeiro linfonodo (LN) que recebia a drenagem linfática da mama e faziam excisão seletiva deste $L N$, seguida por DLAC ${ }^{11,12}$. De fato, comprovou-se que células do carcinoma primário de mama progridem para a axila por um caminho específico via LNs, que não pode ser identificado por meio de amostragem aleatória da axila e a BLS foi capaz de predizer o status linfonodal em mais de $95 \%$ dos $\operatorname{casos}^{11,12}$.

Com a ampla aceitação da BLS, desenvolveram-se análises sobre quais características anatomopatológicas seriam capazes de predizer o acometimento dos demais LNs axilares nos casos de LS positivo. Publicaramse vários nomogramas e escores que contêm diferentes parâmetros para estimar esse risco, mas que apresentam limitações como complexidade do modelo, exigência de um exame anatomopatológico detalhado e por não serem replicáveis em todas as populações ${ }^{13-17}$.

Atualmente é muito oportuna a investigação sobre em quais casos pode se omitir a DLAC, mesmo diante de envolvimento do LS. Algumas importantes pesquisas sobre o tema foram publicadas, como: ACOSOG Z0011 (American College of Surgeons Oncology Group Z0011), AMAROS (After Mapping of the Axilla Radiotherapy or Surgery) e OTOASOR (Optimal Treatment of the Axilla Surgery Or Radiotherapy) ${ }^{18-21}$. No entanto, seus resultados não foram uniformemente aceitos para mudar paradigmas de condutas, devido a inconsistências metodológicas, gerando considerável controvérsia.

O estudo ACOSOG Z0011 avaliou a sobrevida global e sobrevida livre de recorrência locorregional de pacientes com metástases no LS e submetidos 
à cirurgia conservadora da mama, randomizados para receber ou não DLAC. Após seguimento médio de 9,25 anos, não houve diferença significativamente estatística na sobrevida global e sobrevida livre de doença locorregional ${ }^{18,19,22,23}$. No entanto, a investigação apresentou inúmeras falhas no desenho do estudo, na casuística e na análise dos resultados. Houve incoerência no cálculo do tamanho amostral, com isso o recrutamento foi inferior ao planejado e consequentemente reduziu o poder estatístico do estudo. A diferença entre os grupos definida pelo teste de não-inferioridade foi superior ao preconizado pela literatura (considerada $30 \%$ na casuística, sendo habitual uma diferença de no máximo 10\%). Os grupos não foram homogêneos quanto a presença de micrometástases, sendo mais frequente no grupo controle, e houve perda elevada do seguimento clínico. Por fim as análises e conclusões não levaram em conta a heterogeneidade da população como faixa etária, subtipos moleculares e padrões morfológicos.

A pesquisa AMAROS com objetivos semelhantes, comparou a DLAC e a radioterapia axilar (RTA) após LS positivo, demonstrando que os dois procedimentos permitem um excelente e comparável controle axilar em tumores iniciais (menores ou iguais a $5,0 \mathrm{~cm}$ ). Os resultados apontam uma menor morbidade nos casos tratados por radioterapia, entretanto, a avaliação do linfedema foi subjetiva ${ }^{20}$. A casuística foi menor do que o tamanho amostral calculado, consequentemente resultou em baixo poder estatístico e não existiu um grupo controle sem intervenção.

No trabalho OTOASOR, com desenho e conclusões semelhantes ao AMAROS, demonstrou-se novamente, após 8 anos de seguimento, que a RTA 
pode ser um tratamento alternativo para casos selecionados de metástases nos LSs, não havendo grupo controle sem intervenção para comparação ${ }^{21}$.

O assunto é controverso. Esses trials para muitos não foram conclusivos e, isto sim, foram apenas bons trabalhos geradores de hipóteses. Por isto, vários novos estudos clínicos estão em andamento em diversos países, com o objetivo de aclarar a questão: POSNOC (Inglaterra) ${ }^{24}$, SINODAR ONE (Itália $)^{25}$, BOOG 2013-07 (Holanda)26, SENOMAC (Suécia) ${ }^{27}$, SERC (França) ${ }^{28}$, CHINA Z0011 $(\text { China) })^{29}$, INSEMA (Alemanha/Áustria) $)^{30}$ e SOUND (Itália) ${ }^{31}$.

Neste contexto foi idealizada esta pesquisa, visando fornecer bases complementares para uma análise pragmática da justificativa da DLAC após BLS positiva, no carcinoma infiltrativo inicial da mama. 
2. OBJETIVOS 


\subsection{Objetivo geral}

Avaliar a possibilidade de predição do envolvimento neoplásico dos linfonodos não-sentinelas (LN-S), quando o LS for acometido, com base em parâmetros morfológicos e moleculares.

\subsection{Objetivos específicos}

1) Descrever na população do estudo a taxa de comprometimento dos LN-S.

2) Analisar a associação entre as características anatomopatológicas das metástases em LS e linfonodo parassentinela (LPS) e a presença de acometimento dos LN-S: número de LSs/LPSs positivos, taxa de comprometimento linfonodal entre os LSs/LPSs, número de focos neoplásicos, tamanho da metástase, reação fibroinflamatória perimetastática, área do LN ocupada pela neoplasia, presença e dimensão da extensão neoplásica extracapsular, relação entre as neoplasias extracapsular e intraparenquimatosa, acometimento da gordura perilinfonodal, comprometimento vascular perilinfonodal e número de LN-S dissecados.

3) Explorar as associações do acometimento neoplásico dos LN-S com características anatomopatológicas do tumor primário: tamanho, tipo histológico, multiplicidade (multifocalidade e multicentricidade), grau histológico, grau nuclear, presença de embolização vascular peritumoral, positividade para receptores hormonais, superexpressão de HER-2 e expressão de Ki-67.

4) Selecionar as variáveis preditivas de comprometimento linfonodal adicional (CLA), de modo a sugerir situações em que a dissecção linfonodal axilar (DLA) seja mais justificável após um BLS positiva. 
3. REVISÃO DA LITERATURA 


\subsection{Aspectos epidemiológicos do câncer de mama}

As neoplasias malignas têm se comportado como verdadeira epidemia global, sendo estimado o dobro do número de casos de câncer e mortes pela doença ao longo dos próximos 20 a 40 anos. De acordo com a Organização Mundial da Saúde, através da Globocan/Internacional Agency for Research on Cancer, estima-se que em 2030 haverá 27 milhões de casos novos de câncer, 17 milhões de mortes pela doença e 75 milhões de pessoas vivendo com câncer ${ }^{32}$.

O CM é o mais comum entre as mulheres, excetuando o câncer de pele não melanoma, e as estimativas no Brasil para cada ano do triênio 2020-2022, de acordo com o Instituto Nacional de Câncer José Alencar Gomes da Silva (INCA), apontam a ocorrência de cerca de 66.280 casos novos da doença² .

Com relação à sobrevida nos casos de $\mathrm{CM}$, de acordo com dados americanos, houve melhora progressiva ao longo da segunda metade do século XX. As taxas de sobrevida em dez anos entre as mulheres nos Estados Unidos foram de $61 \%$ para $83 \%$ nos casos diagnosticados em 1973 e 1992, respectivamente. Entre os casos diagnosticados no período de 2005 a 2011, a sobrevida em cinco anos foi de $89 \%$ e entre 2009 e 2015 de $90 \%$. Isso se deve ao diagnóstico precoce e aos avanços no tratamento ${ }^{1,32}$.

\subsection{Mecanismos de formação e desenvolvimento do câncer de mama}

A mastectomia radical divulgada por $\mathrm{Halsted}^{3}$, foi apoiada conceitualmente pela teoria centrífuga da permeação, proposta por Handley ${ }^{33}$. Seu trabalho na investigação das rotas de disseminação do CM começou pelo 
questionamento da teoria embólica, expondo inconsistências nesse conceito de disseminação hematogênica da doença. Ele descreveu o processo de crescimento da população de células cancerígenas ao longo dos vasos linfáticos como "permeação linfática".

$\mathrm{Na}$ teoria da permeação, as células cancerígenas conseguem penetrar os plexos anastomóticos periféricos por meio do crescimento centrífugo, ao longo dos pequenos vasos linfáticos adjacentes à neoplasia primária. $\mathrm{O}$ processo foi independente da direção do fluxo linfático. A explicação é que os LNs regionais inicialmente filtravam as células tumorais, mas com o crescimento tumoral essas células seriam capazes de atingir e se disseminar pela corrente sanguínea. Concluiu-se que, embora o carcinoma frequentemente consiga acesso ao sangue quase tão cedo quanto à linfa, sua disseminação ocorre quase inteiramente pelos linfáticos e não pelos vasos sanguíneos ${ }^{33}$.

Na década de 70, ao contrário de Handley e Halsted, Fisher e Fisher difundiram o conceito de infiltração direta do sistema venoso pela neoplasia ${ }^{34}$. A ocorrência de tal evento pode ser deduzida pela evidência histopatológica de extensão intravascular do tumor, bem como a presença de células tumorais em veias tributárias que drenam a mama comprometida pela neoplasia.

$\mathrm{Na}$ década de 90, Tubiana e Koscielny correlacionaram a invasão de LNs axilares com a probabilidade de disseminação hematogênica à distância. As observações realizadas por eles eram compatíveis com um modelo que assumia a existência de volume limite para invasão linfonodal e o envolvimento gradual desses LNs durante o crescimento do tumor, evidenciando padrão ordenado de acometimento, no qual cada tumor progride no seu próprio ritmo. Ressaltaram que os tumores com envolvimento precoce do primeiro LN também são aqueles 
em que a disseminação metastática ocorre prematuramente durante a progressão do tumor e que a capacidade de propagação linfática é adquirida muito antes da capacidade para disseminação hematogênica ${ }^{35}$.

No entanto, os dados apresentados demonstraram que o envolvimento linfonodal e a disseminação à distância não apresentam relação causal. Assim, o envolvimento axilar é um bom índice da propensão de células tumorais adquirirem a capacidade de propagação hematogênica, mas não é a causa dessas se espalharem, existindo um conceito biológico de predeterminação da progressão do câncer ${ }^{35}$.

\subsection{Morfofisiologia do sistema linfático}

O sistema linfático é composto por vasos (capilares e ductos coletores) e LNs que recolhem e filtram a linfa e a direcionam para a corrente sanguínea em direção circulatória centrípeta. Trata-se de sistema unidirecional que capta o fluido intersticial, solução de água com eletrólitos, radicais livres, proteínas e elementos celulares (macrófagos, linfócitos e células dendríticas).

Os canalículos linfáticos originam-se em formações tubulares e apresentam lúmen central. São revestidos por células endoteliais e lâmina basal incompleta. No seu trajeto os capilares mais finos vão se fundindo, determinando os ductos coletores, com paredes mais espessas e fibras elásticas e musculares lisas.

Os linfáticos possuem válvulas no seu interior a cada 2,0 - 3,0 mm, que impedem que o fluxo retroceda. A porção do vaso linfático compreendido entre duas válvulas é denominada linfangion, na qual existe atividade muscular 
pulsátil. Uma combinação de forças extrínsecas - contração da musculatura esquelética - e intrínsecas - contratilidade nos linfangions - impele o fluxo ${ }^{36}$.

Os vasos linfáticos maiores apresentam percurso paralelo ao das veias, ultrapassam os LNs em seu caminho e desaguam em dois grandes troncos coletores: o ducto torácico do lado esquerdo, e o ducto linfático direito. Em cada hemicorpo desembocam nas junções das veias jugular interna e subclávia.

Os LNs são corpúsculos encapsulados de tecido linfoide. Dispõem-se no trajeto dos canalículos linfáticos. Sua conformação lembra um grão de feijão com duas faces, uma convexa e outra com uma reentrância (hilo). Seu tamanho é variável, entre $1,0 \mathrm{~mm}$ e $2,0 \mathrm{~cm}$. Atuam como verdadeiros filtros, removendo por fagocitose microrganismos, moléculas e células estranhas. A linfa atravessa os LNs lentamente, desde o lado convexo, através de linfáticos aferentes, e sai pelo hilo, por vasos eferentes. Pelo hilo passam também a artéria e veia principais do LN.

Logo abaixo da cápsula existe pequeno espaço vazio chamado de seio coletor. A estrutura parenquimatosa pode ser subdividida em regiões cortical e medular: na cortical existem nódulos linfoides, que são condensações de linfócitos, plasmócitos, macrófagos, células reticulares e foliculares dendríticas; a região medular é formada pelos cordões ricos em plasmócitos e linfócitos do tipo $B$, entremeados por seios lacunares, que recebem a linfa vinda da parte cortical e se comunicam com os linfáticos eferentes.

Além da função de filtro, os LNs desempenham papel marcante na imunovigilância. Infecções, neoplasias e estímulos antigênicos diversos incitam a ação linfocítica nos centros germinativos nos nódulos linfoides. Vale recordar 
que os linfócitos são gerados na medula óssea, amadurecidos no timo e armazenados nos LNs.

\subsection{O sistema linfático na mama}

A mama possui rica rede de capilares e vasos linfáticos que drenam para os LNs regionais. Esta rede pode ser subdividida em três porções: superficial, intramamária e profunda ${ }^{37}$.

A porção superficial é formada pelo plexo subcutâneo localizado entre a pele e a fáscia superficial da mama, para onde drena o fluxo da pele e do tecido subcutâneo. A direção de fluxo deste plexo é predominantemente central no sentido da aréola e daí para a axila; uma pequena parte do sistema coleta diretamente para axila ${ }^{38}$.

Na sua porção intramamária a rede é constituída por extenso plexo linfático localizado em volta de cada lóbulo e por um plexo linfático periductal, envolvendo os ductos galactóforos. Esta porção intramamária da rede linfática, de qualquer quadrante, converge para região central da mama, para o plexo linfático subareolar (plexo de Sappey) e daí se dirige para a axila.

$\mathrm{Na}$ parte mais posterior da mama existe o plexo linfático fascial profundo, para onde drenam as estruturas lobulares mais internas, e que se situa sobre a fáscia mamária posterior. O plexo profundo pode dirigir seu conteúdo para o plexo periductal e subareolar e daí para a axila, para os LNs de Rotter dispostos entre os dois músculos peitorais (rota de Groszman), de onde pode fluir para a fossa supraclavicular, para a cadeia de LNs torácicos internos ou para LNs transdiafragmáticos (rota de Gerota). 
A rede linfática axilar apresenta uma vasta quantidade de anastomoses e realiza a drenagem de diversas regiões do membro superior, tórax, abdome e dorso. Os LNs axilares se distribuem em grupos localizados separadamente na região axilar, apresentando uma quantidade variável de LNs, divididos em três níveis distintos, de acordo com a posição relativa ao músculo peitoral menor:

- nível I: LNs axilares anteriores (peitorais ou da mamária externa), LNs axilares posteriores (ou subescapulares), LNs axilares laterais (ou umerais) e LNs paramamários, todos localizados lateralmente ao músculo peitoral menor;

- nível II: LNs axilares centrais (ou intermediários) e LNs interpeitorais (ou LNs de Rotter), que se localizam imediatamente sob o músculo peitoral menor;

- nível III: LNs axilares apicais, posicionados medialmente ao músculo peitoral menor ${ }^{39}$.

No nível I, o grupo axilar anterior é o principal responsável pela drenagem dos quadrantes laterais da mama, o grupo axilar lateral pela drenagem do membro superior, e o grupo axilar posterior pela drenagem do dorso. Num raciocínio simplificado, ao se manter os LNs que drenam o membro superior durante o esvaziamento axilar, no tratamento do $\mathrm{CM}$, poderia se prevenir o linfedema, técnica desenvolvida e intitulada mapeamento axilar reverso. No entanto, esse procedimento é controverso pelos riscos de doença residual ${ }^{39}$.

Um estudo realizado em fetos natimortos, com o intuito de demonstrar a possível independência das vias linfáticas axilares que drenam o membro superior e a região mamária, na verdade sugeriu o oposto. A drenagem linfática do membro superior e mama estão conectadas, principalmente pela proximidade dos LNs e anastomose de vasos linfáticos ${ }^{40}$. 
Atualmente, Pereira et al. e Brown et al. demonstraram que os vasos sanguíneos dos LNs são vias eficazes de disseminação metastática para a circulação sistêmica utilizando modelos animais experimentais, no entanto não há dados se essas descobertas são relevantes para os tumores em humanos $^{41,42}$.

\subsection{Tratamento cirúrgico do carcinoma mamário invasivo}

O CM é uma doença heterogênea que envolve diversos cenários prognósticos e terapêuticos.

A primeira evidência de $\mathrm{CM}$ é descrita no antigo Egito, através dos papiros de Edwin Smith e Ebers ${ }^{43,44}$ que remontam de 3.000 a 2.500 a.C. Naquele período, a cauterização era utilizada para tratar certos problemas mamários, mas não está claro se estes incluíam tumores malignos. Na antiga Grécia, Hippocrates ${ }^{44,45}$ referiu-se à neoplasia como algo "enquistado" ou "escondido", reconhecendo o mau prognóstico desses tumores e não considerando a cirurgia benéfica. Ao longo da era pré-cristã, o tratamento do CM foi observacional, com invocações da ajuda dos deuses. A extirpação da mama foi usada como punição, não desempenhando nenhum papel como um tratamento adequado durante este período ${ }^{44}$.

O início da era cristã testemunhou o início do tratamento cirúrgico para o CM. No século I d.C., Leonides ${ }^{44,46}$ descreveu a técnica operatória para tratamento do $\mathrm{CM}$ e, em 1478, o escritor romano Celsus ${ }^{44}$ apresentou uma descrição clínica completa do CM, sendo "De re medicina in libri octo" o primeiro trabalho médico clássico impresso. 
As descrições anatômicas sobre o CM surgiram no Renascimento com Vesalius $^{44,47}$ (1514-1564); Paré ${ }^{44,48}$ (1510-1590) defendeu a excisão local para pequenos tumores e descreveu a linfadenopatia axilar observada em pacientes com CM; e Severino44,49 (1560-1634) foi o primeiro a remover os LNs axilares.

Em 1757, Le Dran ${ }^{44,50}$ argumentou que o envolvimento linfonodal axilar no $\mathrm{CM}$ era indicativo de mau prognóstico. Ele descreveu que a doença se origina na mama e se espalha através dos linfáticos e sequencialmente para circulação geral. Petit ${ }^{44,51}$ (1674-1750) propôs uma ressecção em monobloco da mama com os LNs palpáveis e o músculo peitoral maior, se associado ao tumor. No entanto, as limitações da cirurgia no período pré-anestésico e préantisséptico restringiram a aplicação desses procedimentos radicais.

A revolução cirúrgica provocada pela anestesia geral, introduzida em 1846, e a prática antisséptica proposta por Lister, em 1867, levaram a esforço escalonado para tratar cirurgicamente $\mathrm{O}^{\mathrm{CM}^{44}}$. Em 1894, Halsted relatou resultados com o tratamento radical do $\mathrm{CM}$ em 50 pacientes $^{3}$. Ele removeu todo o tecido mamário, os músculos peitorais e todos os LNs axilares, realizando uma DLAC. Este procedimento tornou-se conhecido como a mastectomia radical clássica de Halsted. As publicações de Halsted contribuíram para a ampla aceitação da mastectomia radical durante a maior parte do século $\mathrm{XX}$. Antes do tratamento cirúrgico, o $\mathrm{CM}$ foi associado às taxas de recidiva local de 60 a $82 \%$ e taxa de sobrevida em 3 anos de 9 a $39 \%$; Halsted relatou uma taxa de recidiva local de $6 \%$ e taxa de sobrevida em 3 anos de 38 a $42 \%^{3,52}$, e em 10 anos de $12 \%^{53}$. 
As mastectomias radicais no tratamento do $\mathrm{CM}$, embora eficazes, ocasionaram piora da qualidade de vida dos pacientes, o que motivou a pesquisa por procedimentos mais conservadores e terapias adjuvantes.

Com os trabalhos de Veronesi et al. ${ }^{7}$ e Fisher et al. ${ }^{8}$, observou-se a equivalência entre a sobrevida global e a sobrevida livre de doença de mulheres diagnosticadas com carcinomas mamários infiltrativos iniciais tratadas com cirurgia conservadora da mama e DLAC associada a radioterapia versus a mastectomia radical, após 20 anos de seguimento.

Veronesi et al. conduziram estudo randomizado para comparar a eficácia da mastectomia radical com a cirurgia conservadora da mama e DLAC. De 1973 a 1980, 701 mulheres com CM medindo até 2,0 cm de diâmetro foram aleatoriamente designadas para se submeter à mastectomia radical (349 pacientes) ou quadrantectomia e DLAC associada à radioterapia adjuvante (352 pacientes). A incidência cumulativa de recidiva local foi de $8,8 \%$ se quadrantectomia e $2,3 \%$ se mastectomia $(p<0,001)$. Não houve diferença significativa nas taxas de CM contralateral, metástases à distância ou segundo tumor primário. A taxa de mortalidade geral e específica pelo CM foram 41,7\% e $26,1 \%$ no grupo da cirurgia conservadora e DLAC versus $41,2 \%$ e $24,3 \%$ nos casos de mastectomia radical $(p=1,0 \text { e } p=0,8 \text {, respectivamente })^{7}$.

Fisher et al. iniciaram em 1976 um estudo randomizado para determinar se a tumorectomia e DLAC com ou sem radioterapia adjuvante era tão eficaz quanto a mastectomia radical para o tratamento do $\mathrm{CM}$. Um total de 1.851 mulheres, para as quais os dados de acompanhamento estavam disponíveis, foram submetidas aleatoriamente a realizar mastectomia radical, tumorectomia isolada e DLAC ou tumorectomia e DLAC associada à irradiação 
da mama. A incidência cumulativa de recidiva local foi de $14,3 \%$ nas mulheres que se submeteram a tumorectomia e DLAC com irradiação da mama, em comparação com $39,2 \%$ nas submetidas apenas a tumorectomia e DLAC $(p<$ 0,001). Não foram observadas diferenças significativas entre os três grupos com relação à sobrevida livre de doença, sobrevida livre de doença à distância ou sobrevida global ${ }^{8}$.

A terapia conservadora da mama é especialmente importante nos dias atuais, principalmente após a melhoria das técnicas de rastreamento, sendo apropriada para a maioria das pacientes com tumores clínicos em estágios clínicos I ou II. Cumpre os objetivos de cosmese e taxas mínimas de recidiva, devendo-se integrar à irradiação da mama e às terapias adjuvantes sistêmicas.

Com relação ao tratamento linfonodal, a DLAC foi considerada procedimento padrão do manejo cirúrgico por um longo período. Os objetivos são: fornecer informação prognóstica precisa; manter o controle locorregional da doença; embasar racionalmente as decisões sobre a terapia adjuvante.

Como houve necessidade de se estudar terapia mais conservadora para o $\mathrm{CM}$, o tratamento axilar seletivo é tema de recorrente debate na literatura.

O LS é o primeiro LN a drenar o fluxo linfático da região tumoral. O termo foi criado por Gould et al., em 1960, a propósito da drenagem linfática nos esvaziamentos cervicais ${ }^{54}$. Demonstraram que existe um determinado LN que recebe a linfa da área tumoral. Em 1970, Kett et al., através de cintilografia, visualizaram pela primeira vez o LS para a glândula mamária ${ }^{55}$.

Foi criador do conceito da BLS um médico paraguaio, chamado Ramon Cabanas. Em 1977, com base em dissecções no câncer de pênis, postulou a ideia revolucionária de que se o LS estivesse sem comprometimento, não seria 
necessário a remoção dos demais $\mathrm{LNs}^{10}$. Morton et al., depois, difundiram o sucesso da BLS em melanomas ${ }^{56}$.

Especificamente no CM, o pioneiro foi David Krag, que injetou radioisótopo no tumor e fez a BLS usando um contador de radiação gama para orientação. Foi um estudo não randomizado que incluiu 22 pacientes com CM e pesquisa de LS com a técnica de marcação por medicina nuclear com o uso do tecnécio $\left({ }^{99 m} \mathrm{Tc}\right)$. Concluiu-se que a radiolocalização e a ressecção seletiva do LS eram possíveis, e a informação trazida pela análise anatomopatológica desse LN poderia prever o status axilar ${ }^{11}$.

Giuliano et al. popularizaram a BLS, empregando o corante vital azul patente. Entre 1991 e 1994, estudaram 172 pacientes para a análise da identificação do LS marcado pelo azul patente e predição do status axilar. A conclusão foi que o LS era capaz de prever o status axilar em $95 \%$ dos casos, sendo a taxa de falso negativo próxima a $5 \%^{12}$.

No ano de 1998 foram feitas as primeiras BLS no Brasil, em São Paulo: no Hospital Pérola Byngton, utilizando-se radioisótopo (Pinotti, Barros e Piato) e no Instituto Brasileiro de Controle de Câncer, com azul patente (Galeb, Mantovani e Costa).

Para validação da BLS na prática cirúrgica, Veronesi et al. publicaram um estudo clínico com 516 pacientes com CM inicial, randomizados em dois grupos com ou sem DLAC, após BLS negativa para neoplasia. Os pacientes submetidos apenas à BLS apresentavam menor escala de dor e melhor mobilidade do membro superior. Após 10 anos de seguimento não houve diferença em sobrevida livre de doença entre os grupos e concluíram que a 
BLS é um método seguro e preciso de avaliação de metástases axilares em tumores iniciais da mama ${ }^{57,58}$.

O trial multicêntrico americano (NSABP B-32) teve casuística maior (mais de 5.000 pacientes), protocolo semelhante e resultados idênticos. Após follow-up mediano de 95,6 meses não houve diferença de sobrevida global, sobrevida livre de doença e controle regional nos dois grupos ${ }^{59}$.

Atualmente é possível realizar a marcação pré-cirúrgica de lesão não palpável (Radioguided Occult Lesion Localization - ROLL) simultaneamente à pesquisa do linfonodo sentinela (Sentinel Node and Occult Lesion Localization SNOLL) utilizando apenas uma injeção de tecnécio sestamibi (99mTc) dextran ${ }^{60,61}$.

Devido às suas implicações prognósticas e terapêuticas (melhor controle da doença locorregional), a DLAC continua a ser uma conduta padrão nos casos de LS positivo para malignidade. No entanto, as metástases axilares são limitadas ao LS em cerca de $40 \%$ a $70 \%$ dos casos, sendo a DLAC um procedimento sem benefício claro ${ }^{62}$

\subsection{Fatores preditores de acometimento de linfonodos não-sentinelas}

O status axilar permanece como um importante fator prognóstico e, como descrito anteriormente, a BLS é uma técnica bem estabelecida para a previsão do mesmo.

Em 1971, Huvos et al. introduziram uma distinção arbitrária do tamanho da metástase linfonodal em micrometástase (tamanho menor ou igual a 2,0 $\mathrm{mm}$ ) e macrometástase (tamanho maior que 2,0 $\mathrm{mm}$ ) e avaliaram o seu significado. Após oito anos de seguimento de pacientes tratados por $\mathrm{CM}$, as 
taxas de sobrevida foram significativamente melhores no grupo de pacientes que apresentavam micrometástases, quando comparadas à presença de macrometástases ${ }^{63}$.

A avaliação anatomopatológica das metástases linfonodais, descrita pela American Joint Committee on Cancer (AJCC), classifica a carga tumoral linfonodal em três categorias: células tumorais isoladas, micrometástases e macrometástases. As células tumorais isoladas são definidas com um pequeno agrupamento de células tumorais com até $0,2 \mathrm{~mm}$ de extensão ou menos de 200 células em um corte transversal, detectadas por exame histológico ou imunoistoquímica. As micrometástases são depósitos tumorais maiores que 0,2 $\mathrm{mm}$, mas com até $2,0 \mathrm{~mm}$, e metástases superiores a essa medida são consideradas macrometástases ${ }^{64}$.

O exame extensivo dos LSs frequentemente permite detectar altas taxas de micrometástases ou células tumorais isoladas, que demonstram um risco adicional de envolvimento dos LNs regionais de 20 a $24 \% 65$.

Várias características do tumor primário e dos LSs foram investigadas para prever o acometimento dos LN-S.

Com relação ao tumor, parâmetros como tamanho, multiplicidade, grau histológico, invasão linfovascular peritumoral e número de mitoses por $\mathrm{mm}^{2}$ apresentaram associação com o status de comprometimento dos LN-S ${ }^{66-70}$.

Ao considerar as características do LS, o método de detecção da metástase linfonodal foi um fator preditor significativo do envolvimento de LNs adicionais ${ }^{71}$. Também são preditores para a positividade dos LN-S o tamanho da metástase, extensão extracapsular, número de LSs positivos e taxa de 
comprometimento dos LSs (razão entre o número de LSs positivos sobre o número de LSs dissecados $)^{72-84}$.

\subsection{Nomogramas para predição do status axilar}

No intuito de criar ferramentas para tomada de decisão sobre a realização ou não da DLAC foram criados inúmeros nomogramas de predição do comprometimento dos LN-S, mas nenhum deles factíveis na prática clínica. Serão destacados os principais modelos matemáticos.

Em 2003, Van Zee et al. criaram um nomograma a partir de análise multivariada de dados por regressão logística de 702 pacientes, que foram submetidos à DLAC no Memorial Sloan-Kettering Cancer Center. O algoritmo foi construído para predizer o acometimento de LN-S, além dos LSs, e utilizou as seguintes variáveis: tamanho patológico do tumor, tipo histológico, grau nuclear, invasão linfovascular, multifocalidade, status do receptor de estrogênio, método de detecção da metástase no LS e número de LSs positivos e negativos. A acurácia do modelo foi avaliada pelo cálculo da área sob a curva ROC (Receiver Operating Characteristic) e foi superior a $75 \%$ tanto na análise retrospectiva $(76 \%)$, quanto na prospectiva $(77 \%)$. Porém 0 nomograma ao estimar o risco, não estabeleceu o ponto de corte para definição entre realizar ou não a $\operatorname{DLAC}^{13}$. Outras limitações do modelo são: uso da análise anatomopatológica por hematoxilina-eosina ao invés da imunoistoquímica, não incluir o tamanho da metástase na análise e baixa acurácia em pacientes com micrometástases. O estudo com uma coorte 
holandesa realizado por van den Hoven et al. demostrou que o nomograma não era factível em todas as populações ${ }^{85}$.

Hwang et al. revisaram os casos de BLS realizados na Universidade do Texas - M. D. Anderson Cancer Center, entre 1993 e 2001. Os resultados do estudo demonstraram que os tumores maiores que $2,0 \mathrm{~cm}$, as metástases linfonodais maiores que 2,0 $\mathrm{mm}$ e a presença de invasão linfovascular foram fatores prognósticos independentes de doença em LN-S ${ }^{14}$.

Pesquisa realizada na Stanford University School of Medicine também propôs outro modelo matemático para predição de metástases em LN-S, incluindo apenas três variáveis (tamanho tumoral, tamanho da metástase no LS e presença de invasão linfovascular) e demonstrou maior acurácia (83\%) e praticidade quando comparada ao nomograma do Memorial Sloan-Kettering Cancer Center. Porém, no estudo de validação a acurácia foi inferior a $70 \%{ }^{16,86}$.

\subsection{Omissão da linfadenectomia axilar completa após biópsia de linfonodo sentinela positiva}

Atualmente uma discussão frequente na prática clínica gira em torno dos casos em que a DLAC poderia ser omitida, após constatação do LS positivo, se existiriam fatores para influenciar na conduta, e qual a segurança oncológica para essa decisão.

O estudo IBCSG 23-01, conduzido por Galimberti et al. e resultado de pesquisa multicêntrica, randomizada, baseada em teste de não-inferioridade, comparou a DLAC versus observação em pacientes com diagnóstico de micrometástases em LS. Depois de cinco anos de seguimento médio, foram 
observadas taxas de sobrevida livre de doença de $87,8 \%$ e $84,8 \%$ e de sobrevida global de $97,6 \%$ e $97,5 \%(p=0,73)$ respectivamente nos grupos com e sem DLAC ${ }^{87}$.

A pesquisa denominada ACOSOG Z0011 (American College of Surgeons Oncology Group Z0011) conduzida por Giulianno et al. foi um estudo de fase 3, de não-inferioridade, multicêntrico, recrutando-se pacientes de 1999 a 2004. Incluíram mulheres com carcinoma infiltrativo inicial (T1-2 N0), tendo um ou dois LSs infiltrados por observação microscópica. Todas as pacientes foram tratadas por ressecção segmentar de mama e irradiação tangencial do órgão e randomizadas para DLAC ou simples observação ${ }^{18,19}$.

O grupo de DLAC contou com 420 pacientes $(62,5 \%$ com macrometástases no LS e 37,5\% com micrometástases) e o de observação foi constituído por 436 mulheres (55,2\% com macrometástases e 44,8\% com micrometástases). Após follow-up mediano de 9,3 anos, os desfechos apresentados foram sobrevida livre de doença a HR de 0,85 (IC 95\% 0,621,17) e sobrevida global também HR de 0,85 (IC 95\% 0-1,16), sendo considerado, pois, a omissão de DLAC como não inferior. Os autores concluíram que é seguro se preterir a DLAC neste tipo de paciente.

Embora a pesquisa tenha merecido contestações e ensejado outras para sua confirmação, os guidelines da American Society of Clinical Oncology recomendam a BLS exclusiva nos casos que preencherem os critérios de inclusão do ACOSOG Z001188,89. Aplicando esta orientação, no Memorial Sloan Kettering Cancer Center, Morrow et al. analisaram 663 casos que se enquadravam nos critérios do estudo e foram operadas entre 2010 e 2016. 
Depois de cinco anos a sobrevida livre de eventos foi de $93 \%$, a qual foi considerada satisfatória ${ }^{90}$.

Fragilidades metodológicas fizeram com que a conclusão do ACOSOG Z0011 não fosse unanimemente aceita, ao contrário do que quase sempre acontece com os estudos clínicos.

O cálculo amostral estribou-se em premissa equivocada de que a sobrevida global aos cinco anos seria apenas de $80 \%$, quando hoje todos sabem que nos carcinomas mamários iniciais é bem maior. Precisava-se de 500 óbitos na evolução para o estudo ter poder estatístico de $90 \%$ e para atestar a não-inferioridade da conduta observadora. Fecharam o recrutamento com casuística excessivamente menor que a necessária. O poder estatístico ao final resultou muito baixo, em torno de $60 \%$.

O teste de não-inferioridade foi definido para que no grupo controle, só de BLS, a sobrevida global aos cinco anos fosse pelo menos $70 \%$ da observada no grupo DLAC. Esta margem de 30\% de diferença entre os grupos é bastante superior à preconizada em pesquisas deste tipo, que é de no máximo $10 \%$. Isto significa que a não realização de DLAC para estes casos, se levasse a uma diferença de até $30 \%$ na sobrevida, seria considerada segura.

Os dois grupos não foram uniformes em um quesito essencial: a porcentagem de infiltração menor, tipo micrometástases, que foi menor no grupo DLAC (55,2\% versus $62,5 \%)$, favorecendo a conduta niilista.

Ademais, não houve preocupação com personalização das análises e conclusões, não obstante a heterogeneidade da população. É difícil de acreditar que as ilações sejam as mesmas para diferentes subtipos moleculares, faixas de idade e padrões morfológicos. 
Outros pontos a serem criticados são a não consideração da taxa de envolvimento de LS na biópsia (número de LSs comprometidos por LSs dissecados) e a extensão da macrometástase.

Vários outros reparos podem ser feitos à população estudada: mais de $30 \%$ não recebeu quimioterapia apesar de pelo menos um LN positivo; $82 \%$ da população apresentava receptor de estrogênio positivo e apenas 54,5\% recebeu hormonioterapia adjuvante. Houve perda elevada de seguimento, aproximadamente $20 \%$, sendo que as normas das Boas Práticas Clínicas em Pesquisa admitem até $10 \%{ }^{91}$.

Trinta e quatro instituições europeias desenvolveram o estudo AMAROS (After Mapping of the Axilla Radiotherapy or Surgery). Dos casos com LS positivo, 744 pacientes foram randomizados para DLAC e 681 para RTA. Foram incluídos tumores até $5,0 \mathrm{~cm}$ e axila clinicamente negativa, tratados por cirurgia conservadora ou mastectomia entre 2001 e 2010. Após cinco anos de seguimento foram consignadas quatro recidivas axilares no grupo da linfadenectomia axilar e sete casos no grupo da radioterapia $(0,4$ versus $1,1 \%$ ) com diferença estatística não significante, e demostraram a ocorrência de linfedema em $23 \%$ dos pacientes com DLAC e $11 \%$ dos casos que receberam RTA ( $p<0,001)$. Nos dois grupos existiam macrometástases, micrometástases e células tumorais isoladas no LS (cerca de $60 \%, 30 \%$ e 10\%, respectivamente). Os autores concluíram que a RTA promove excelente controle do CM com LS positivo semelhante ao obtido com a DLAC, mas com menor morbidade ${ }^{20}$.

Nesta pesquisa, à semelhança do estudo ACOSOG Z0011, houve problema para se atingir o tamanho amostral calculado e encerrou-se o 
recrutamento antes do momento previsto. Isto resultou em poder estatístico baixo. Entretanto, a recidiva axilar aos cinco anos nos dois grupos foi menos comum do que a prevista, indicando que as duas formas de manejo foram eficientes. Outrossim, por não existir grupo controle sem intervenção, acabou não se sabendo se existe necessidade de RTA para todas as pacientes, ou se a mesma poderia ser subtraída em certos subgrupos.

A alta taxa encontrada de linfedema após DLAC, bem acima da normalmente referida, pode ser questionada ${ }^{92}$. Para Nguyen et al. $^{93}$ a incidência de linfedema após DLAC exclusiva ocorreu em apenas 3,5\%, e no ALMANAC trial ${ }^{94}$, inchaço do membro após DLAC se deu em $14 \%$ das pacientes, quase metade do aqui referido. Este assunto é de difícil comparação, em função dos variados procedimentos para mensuração, das modalidades terapêuticas empregadas e intervenientes e da diversidade de expertise cirúrgica.

Um hospital na Hungria realizou uma investigação com objetivo semelhante, intitulada OTOASOR (Optimal Treatment of the Axilla - Surgery or Radiotherapy) comparando em experiência prospectiva e randomizada DLAC versus RTA, após diagnóstico de LS comprometido por neoplasia em tumores mamários invasivos menores ou iguais a $3,0 \mathrm{~cm}$. Decorridos oito anos de acompanhamento mediano, a incidência da recorrência axilar foi de $2 \%$ no grupo com DLAC e 1,7\% no grupo com RTA ( $p=1,00)$; a sobrevida global foi, respectivamente, de $77,9 \%$ e $84,8 \%(p=0,06)$ e a sobrevida livre de doença de $72,1 \%$ e $77,4 \%(p=0,51)$. Foi inferido que a RTA pode ser considerada uma opção eficiente para casos selecionados de LS comprometido pela neoplasia ${ }^{21}$. 
Novos clinical trials estão em andamento no mundo, com metodologia adequada para contornar as limitações dos estudos citados e/ou acrescentar novas informações.

A pesquisa POSNOC visa comparar DLA ou RTA versus unicamente BLS em pacientes T1-2 N0, com um ou dois LSs envolvidos por macrometástases, tratadas por cirurgia conservadora ou mastectomia. $\mathrm{O}$ objetivo primário é recorrência axilar, os secundários são morbidade no braço, qualidade de vida e sobrevida ${ }^{24}$.

O SINODAR ONE pretende aquilatar o papel terapêutico da DLA seguida de terapia adjuvante, ao compará-la com a terapia adjuvante isolada. As pacientes são estadiadas como T1-2 N0, podem ter um ou dois LSs com macrometástases e recebem cirurgia conservadora ou mastectomia. $\mathrm{O}$ foco fundamental é sobrevida global ${ }^{25}$.

No BOOG 2013-07 estão sendo incluídas pacientes com até três LSs positivos para micrometástases ou macrometástases, estadiadas como T1-2 N0 tratadas por mastectomia. São randomizadas para esvaziamento axilar versus omissão de cirurgia axilar. O objetivo primário é a avaliação de recidiva axilar aos cinco anos e os secundários são sobrevida global, sobrevida livre de doença, morbidade e qualidade de vida ${ }^{26}$.

No SENOMAC mulheres com carcinomas T1-2-3 N0, operadas tanto por ressecção segmentar, como por mastectomia, estão em fase de recrutamento. O LS é avaliado e, diante de uma ou duas estruturas com macrometástases, ocorre a randomização: DLAC versus nenhuma outra abordagem. O objetivo primário é sobrevida específica ao CM. O planejamento estima 3.700 pacientes $^{27}$. 
O ensaio francês Sentinelle Envahi et Randomization du Curage (SERC) é prospectivo e randomizado. Pacientes T1-2 N0 com LS afetado podem ou não receber DLAC, objetivando demonstrar a não-inferioridade da omissão da toillete axilar. Valem mastectomias ou cirurgias conservadoras e macrometástases ou micrometástases. Começaram o estudo em 2014, cerca de 80 instituições estão envolvidas e o plano é abranger mais de 3.000 pacientes $^{28}$.

O desenho do CHINA Z0011 é idêntico ao do estudo ACOSOG Z0011, com alvo na avaliação de sobrevida livre de doença. Iniciaram a inclusão dos casos em 2013. Os dados são comparados conforme idade ( $\leq 50$ e > 50 anos) e tamanho tumoral $(\leq 2,0 \text { e }>2,0 \mathrm{~cm})^{29}$.

No INSEMA pacientes com axila negativa e tumores medindo menos que $5,0 \mathrm{~cm}$, cirurgia conservadora, radioterapia adjuvante e idade $\geq 35$ anos estão sendo randomizadas para nenhuma cirurgia axilar ou BLS (alocação 1:4). Aquelas com LS positivo (só macrometástases em um ou dois LSs) são depois novamente randomizadas para BLS exclusiva ou DLAC. Pretendem contar com quase 7.000 casos e a amostra calculada para a randomização secundária é de 1.968 pacientes. A pesquisa é patrocinada pela Universidade de Rostock da Alemanha ${ }^{30}$.

A investigação SOUND (Sentinel node Observation after axillary UltraSound) foi idealizada com a participação do Prof. Umberto Veronesi, no Instituto Europeu de Oncologia, englobando hospitais italianos, suíços e espanhóis. Visa primeiramente responder se a informação obtida com o exame do LS é realmente necessária. São casos iniciais $(T \leq 2,0 \mathrm{~cm}$ ) com negatividade axilar por exame físico, ultrassonografia e, eventualmente, citologia linfonodal. Na mama o tratamento programado é quadrantectomia e 
radioterapia. A comparação fundamental será entre nenhuma abordagem axilar ou BLS. Na sequência, em LS negativos ou com micrometástases, a BLS será considerada suficiente; havendo macrometástases será executada a DLAC. Iniciaram em 2012; são previstas 780 mulheres em cada braço do estudo de não-inferioridade, com limite de $2,5 \%{ }^{31}$. 
4. MÉTODOS 


\subsection{Desenho do estudo}

Esta pesquisa foi desenvolvida como um estudo retrospectivo, observacional, transversal e não-controlado.

\subsection{População}

Pacientes consecutivos com diagnóstico de carcinoma mamário invasivo inicial, estádios clínicos I e II, submetidos a tratamento cirúrgico primário, atendidos na Clínica Prof. Alfredo Barros, em São Paulo, no período de 2001 a 2018.

Considerando-se a probabilidade entre $21,9 \%$ e $58,8 \%$ de ter $\mathrm{LN}-\mathrm{S}$ comprometidos após BLS positiva ${ }^{95}$, escolheu-se como objetivo a identificação de porcentual máximo desejado de $9 \%$, com margem de erro de $5 \%$ e nível de confiança de $95 \%$. Para essas características, o número mínimo de casos necessários para o estudo foi de $126^{96}$.

\subsection{Dinâmica da pesquisa}

Foram incluídos pacientes que realizaram BLS. Naqueles com resultado positivo para malignidade na avaliação anatomopatológica intraoperatória ou definitiva do LN, procedeu-se à DLA de níveis I e II ou níveis I, II e III (figura 1). Uma vez realizada a linfadenectomia, nos casos de LNs positivos foram analisados macroscopicamente os LN-S para averiguação de eventual contaminação neoplásica. Vale frisar que, para efeitos práticos, nessa pesquisa os LPSs foram agrupados aos LSs para os cálculos estatísticos. 


\subsection{Critérios de inclusão e exclusão}

Foram considerados os seguintes critérios de inclusão:

- diagnóstico de carcinoma mamário invasivo em ambos os sexos,

- tumores estadiados como T1 $(\leq 2,0 \mathrm{~cm})$ ou T2 $(2,0>\mathrm{e} \leq 5,0 \mathrm{~cm})$,

-realização de quadrantectomia mamária, mastectomia ou adenectomia mamária,

- axila clinicamente negativa (cNO),

- realização de biópsia radioguiada de LS,

- avaliação anatomopatológica final, revelando o comprometimento do LS,

- DLA (níveis I e II ou níveis I, II e III), diante do comprometimento do LS,

- avaliação microscópica de todos os LNs excisados.

No que concerne aos critérios de exclusão, estes foram:

- falha na identificação do LS,

- pacientes em curso de recidiva de carcinoma mamário invasivo,

- tratamento sistêmico neoadjuvante,

- indicação primária de linfadenectomia axilar,

- cirurgia axilar e/ou mamária prévia. 


\subsection{Variáveis de estudo}

\subsubsection{Coleta de dados}

Realizou-se a coleta de dados de prontuários e relatórios anatomopatológicos dos pacientes incluídos no estudo. Todos os pacientes foram tratados cirurgicamente pelo mesmo cirurgião (Dr. Alfredo Carlos S. D. de Barros). Os espécimes anatomopatológicos foram analisados pelos laboratórios Dra. Filomena M. Carvalho e Diagnóstika (Dra. Christina H. T. Pelizon e Dra. Cristiane B. A. Nimir).

Do prontuário foram coletados os seguintes dados clínicos:

- idade (anos),

- status menopausal: pré-menopausa, pós-menopausa,

- tamanho tumoral ao exame clínico: em categorias, de acordo com a 8a edição da American Joint Committee on Cancer (AJCC) ${ }^{64}$,

- data do procedimento e tipo de cirurgia mamária: ressecção segmentar, mastectomia, adenectomia.

Dos relatórios anatomopatológicos, foram retiradas as seguintes informações:

- multiplicidade de tumores (multifocalidade e/ou multicentricidade),

- número de focos invasivos na mama,

- tamanho do maior tumor invasivo, apresentado em categorias e em mm no maior eixo, de acordo com a 8a edição da American Joint Committee on Cancer $(\mathrm{AJCC})^{64}$,

- localização do tumor na mama, 
- tipo histológico, segundo a classificação histológica dos tumores da Organização Mundial da Saúde ${ }^{97}$,

- grau histológico, segundo sistema de Nottingham: I, II, III98,

- grau nuclear: 1, 2, $3^{98}$,

- embolização vascular peritumoral, se não identificada, presente em área focal ou presente multifocal,

- receptores de estrogênio, se positivo ou não, com respectiva porcentagem,

- receptores de progesterona, se positivo ou não, com respectiva porcentagem,

- status de HER-2, se positivo ou não,

- Ki-67 em porcentagem,

- número de LSs e LPSs retirados,

- número de LSs e LPSs comprometidos,

- taxa de comprometimento dos LSs e LPSs, que foi calculada pelo quociente entre o número de LSs/LPSs comprometidos pelo número de LSs/LPSs retirados e descrita em porcentagem.

\subsubsection{Definições e critérios de positividade}

Os procedimentos cirúrgicos serão definidos a seguir.

A ressecção segmentar é uma cirurgia que envolve retirada da pele supratumoral, setor mamário subjacente e fáscia do músculo peitoral maior, almejando localizar a área tumoral no centro do espécime e distância tumormargens cirúrgicas laterais, sob o ponto de vista macroscópico, com extensão 
de 2,0 cm. Já a mastectomia implica em ampla retirada de pele, complexo aréolo-papilar e o máximo possível de parênquima mamário. Por fim, a adenectomia mamária, conhecida também pelos nomes de mastectomia subcutânea ou nipple-sparing mastectomy, consistiu na remoção quase completa do corpo glandular da mama, preservando-se totalmente seu envelope cutâneo, incluindo o complexo aréolo-papilar.

A DLA é a retirada dos LNs pelo menos dos níveis I e II, e às vezes do III. Incluiu no mínimo 10 LNs para exame anatomopatológico. A retirada do nível III no ápice da axila, com LNs localizados na região superior e medial a partir da inserção do músculo peitoral menor, foi praticada em tumores muito volumosos, axila extensamente comprometida ou quando a inspeção local digital durante a cirurgia foi suspeita.

O LS foi definido como o elemento de captação mais intensa do radioisótopo, e o LPS como o LN com captação em intensidade inferior, porém acima de $10 \%$ da intensidade de captação basal do primeiro. Ambos podem ser múltiplos.

Foram estabelecidos os seguintes critérios de positividade:

- receptores de estrogênio, como fração de células positivas e categorias positivo (> $1 \%$ de células positivas) ou negativo (ausente ou $<1 \%$ de células positivas) ${ }^{99}$,

- receptores de progesterona, como fração de células positivas e categorias positivo ( $>1 \%$ de células positivas) ou negativo (ausente ou $<1 \%$ de células positivas) ${ }^{99}$, 
- status do HER-2, como negativo (escores 0 ou 1 ) ou positivo (escore 3+ e/ou 2+ com FISH - fluorescence in situ hybridization/teste de hibridização fluorescente in situ - positivo $)^{100}$,

- Ki-67, como a fração de células positivas, avaliada nas áreas de maior densidade de expressão, em pelo menos 500 células.

Definiu-se como BLS positiva o acometimento do LS/LPS tanto por micrometástases (figura 2), quanto por macrometástases (figura 3). Para efeito de cálculos estatísticos os LSs e os LPSs foram agrupados e considerados, na prática, como LSs.

\subsubsection{Mapeamento e retirada do linfonodo sentinela}

Foi utilizado o método radioguiado para a pesquisa do LS no intraoperatório.

O isótopo radioativo aplicado foi o ${ }^{99 \mathrm{~m} T c}$, que apresenta energia para formação de imagem e meia vida de 6 horas, e o veículo utilizado foi uma solução coloidal do polissacarídeo dextran, com peso molecular 500.000

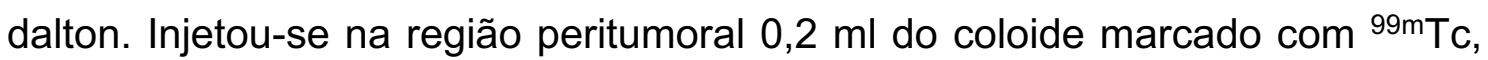
na véspera da cirurgia (figura 4). Após aproximadamente três horas da injeção, procedeu-se à cintilografia em gama câmara para reconhecimento visual do LS, cuja identificação em SPET-CT (Single Photon Emission Computed Tomography - Computed Tomography/Tomografia Computadorizada de Emissão de Fóton Único - Tomografia Computadorizada) favorece o cirurgião ao conferir detalhes topográficos (figura 5). Procurou-se o LS mediante um gama probe, que nada mais é do que um detector portátil de radiação, que a 
mensura e transforma em sinais sonoros (figura 6). O LS (figura 7) é o elemento com maior captação e os denominados LPSs são aqueles com captação de radioatividade menor, porém superior a 10\% do primeiro.

Procedeu-se a dissecção cuidadosa orientada pelo sinal sonoro com o uso de tesoura delicada de Metzenbaum, procurando-se apreender o LN com pinça de Babcock com tração atraumática. Geralmente cauteriza-se o fino pedículo vascular do LN imediatamente antes da sua ressecção com a tesoura. Algumas vezes de forma aleatória são retirados não intencionalmente linfonodos adjacentes, agrupados como fragmentos do nível I. Nesta biópsia são retirados os LSs e eventuais LPSs que são considerados em conjunto.

\subsubsection{Exame anatomopatológico do linfonodo sentinela}

\section{a) Intraoperatório}

A função precípua da análise intraoperatória é fornecer subsídios para possível DLA imediata. O resultado do exame neste momento deve ser considerado para conduta imediata, porém tem acurácia inferior ao exame definitivo; por isto é sempre encarado como preliminar.

A análise intraoperatória foi feita por citologia e/ou histopatologia.

No exame citológico por contato (imprint) as superfícies do LS cortado a cada 1,0 - 2,0 mm, são apoiadas em lâminas de vidro; as células que aderem são coradas pela técnica da hematoxilina-eosina (figura 8). Esta técnica, quando a amostra obtida é representativa, é superior à do raspado da 
superfície do LN com lâmina de bisturi que apresenta o inconveniente de não permitir inferência da distribuição das células no LN.

O complemento por cortes de congelação do LS em criostato, ao longo do seu maior eixo, foi preconizado para tumores com histologia lobular, neoplasias bem diferenciadas ou com células tipo apócrinas que simulam histiócitos e LN com rigidez de consistência ou com macroscopia suspeita.

\section{b) Exame definitivo do linfonodo sentinela por cortes de tecido incluído em parafina}

Os LSs e LPSs foram fixados em formol tamponado, seccionados transversal ou longitudinalmente, a intervalos de $1,5 \mathrm{~mm}$ a $2,0 \mathrm{~mm}$ e inteiramente incluídos em parafina. Os fragmentos foram submetidos a pares de cortes histológicos a cada $100 \mu \mathrm{m}$ até o terceiro nível, cada nível com uma lâmina com cortes submetidos à coloração pela hematoxilina-eosina.

Os preparados histológicos correspondentes aos LSs e LPSs, e os linfonodos axilares regionais não-sentinelas foram revistos para avaliação das seguintes características adicionais:

- número de focos neoplásicos nos linfonodos (FNL), tanto em LNs distintos quanto no mesmo LN,

- tamanho da metástase em $\mathrm{mm}$,

- reação estromal fibroinflamatória intratumoral versus desmoplasia e reação celular inflamatória na neoplasia linfonodal, se ausente, discreta (estroma em menor fração que a neoplasia linfonodal), moderada (estroma em 
proporção similar à da neoplasia linfonodal) e intensa (estroma em maior proporção do que a neoplasia linfonodal),

- fração da área do linfonodo ocupada pela metástase, calculada quantitativamente com auxílio de ocular com retículo com 25 pontos,

- extensão neoplásica extracapsular no linfonodo, se presente ou não, sua extensão em $\mathrm{mm}$ a partir da cápsula e a relação entre componentes extracapsular e intraparenquimatosa (maior eixo em $\mathrm{mm}$ extracapsular/maior eixo em mm intraparenquimatoso),

- acometimento da gordura perilinfonodal, se presente ou não,

- envolvimento vascular perilinfonodal, se presente ou não.

\section{c) Exame microscópico dos outros linfonodos (não-sentinelas) excisados na linfadenectomia complementar}

Os LN-S foram fixados em formol tamponado, seccionados transversal ou longitudinalmente, a intervalos de $1,5 \mathrm{~mm}$ a $2,0 \mathrm{~mm}$ e inteiramente incluídos em parafina. Os fragmentos foram submetidos a pares de cortes histológicos a cada $100 \mu \mathrm{m}$ e submetidos à coloração pela hematoxilina-eosina.

Foram avaliados:

- número de LN-S dissecados,

- presença ou não de LN-S comprometidos,

- total de LN-S comprometidos,

- tamanho das metástases nos LN-S comprometidos. 


\subsection{Análise estatística}

O processo de análise de dados da presente pesquisa iniciou-se com uma exploração descritiva, incluindo frequência absoluta dos atributos qualitativos com valores de média, desvio padrão (DP), mediana, mínimos e máximos também foram calculados. As tabelas descritivas incluindo intervalo de confiança de 95\% (IC 95\%) foram utilizadas para sumarizar os resultados das variáveis qualitativas.

O teste de Kolmogorov-Smirnoff com correção Lilliefors foi utilizado para avaliar a normalidade das variáveis analisadas. Apenas o número de LNs regionais não-sentinelas dissecados e o tamanho das metástases nos LNs regionais comprometidos mostraram seguir distribuição normal, motivo pelo qual o teste de hipótese escolhido na análise entre os grupos no caso das variáveis quantitativas considerou as estatísticas não paramétricas.

Para avaliar a hipótese de que a distribuição das variáveis quantitativas era igual entre os grupos com e sem CLA não-sentinela, o teste $U$ de MannWhitney foi utilizado. Gráficos de boxplot foram gerados para estudar a distribuição das variáveis significativamente associadas. As variáveis quantitativas foram ainda binarizadas com base na mediana para aumentar a possibilidade analítica.

Para testar a hipótese que a distribuição dos fatores qualitativos era homogênea entre as categorias do CLA, uma análise de regressão logística binária foi empregada como exploratória na análise univariada. Tal análise resultou nas estimativas de odds ratios brutas incluindo intervalo de confiança 
de $95 \%$ (IC 95\%) e valor de p calculado pelo método de qui-quadrado, de Wald, ou pelo exato, de Fischer.

A análise multivariada foi realizada por meio de regressão logística múltipla com método de seleção do tipo stepwise forward, com probabilidade de entrada de 0.05, remoção 0,010, corte de classificação de 0,05 e máximo de 19 interações. 0 ajuste final do modelo foi avaliado com método de qualidade do ajuste de HosmerLemeshow. Tal análise resultou nas estimativas de odds ratios ajustadas, incluindo intervalo de confiança de 95\% (IC 95\%) e o valor de p calculado pelo método de qui-quadrado, de Wald. As variáveis avaliadas na regressão stepwise forward foram: dois ou mais FNL, 20 ou mais LN-S dissecados, acometimento da gordura perilinfonodal, embolização vascular peritumoral, envolvimento vascular perilinfonodal, extensão neoplásica extracapsular, grau histológico, grau nuclear, maior metástase $>4,0 \mathrm{~mm}$, mais de um LS e LPS comprometidos, multiplicidade, desmoplasia e reação celular inflamatória na neoplasia linfonodal, receptor de estrogênio, receptor de progesterona, status do HER-2, status menopausal, tamanho tumoral ao exame anatomopatológico, tamanho tumoral ao exame clínico (cT em categorias), taxa de comprometimento linfonodal de 100\% e tipo histológico.

Todos os testes realizados levaram em consideração um a bidirecional de 0.05 e intervalo de confiança (IC) de $95 \%$ e foram realizados com apoio computacional dos softwares IBM SPSS 25 (Statistical Package for the Social Sciences) e Excel $2016^{\circledast}$ (Microsoft Office). 


\subsection{Aspectos éticos}

O protocolo de pesquisa foi aprovado pelo Comitê de Ética e Pesquisa da Faculdade de Medicina da USP, em 23 de agosto de 2018, sob o registro 2.839.142 (anexo).

Foi solicitada e obtida dispensa do termo de consentimento livre e esclarecido, porque o projeto correspondente ao estudo foi retrospectivo e observacional. Foram coletadas apenas informações clínicas dos prontuários e laudos anatomopatológicos de pacientes com carcinoma de mama, obtidas durante o atendimento de rotina. A revisão anatomopatológica não implicou em nenhuma medida de intervenção.

Não foram previstas questões de cunho ético, relativas ao estudo, uma vez que os pacientes já haviam sido tratados no passado e os resultados obtidos não terão impacto na conduta adotada anteriormente para cada paciente. Foi reservado sigilo sobre a identidade dos pacientes envolvidos no estudo. 


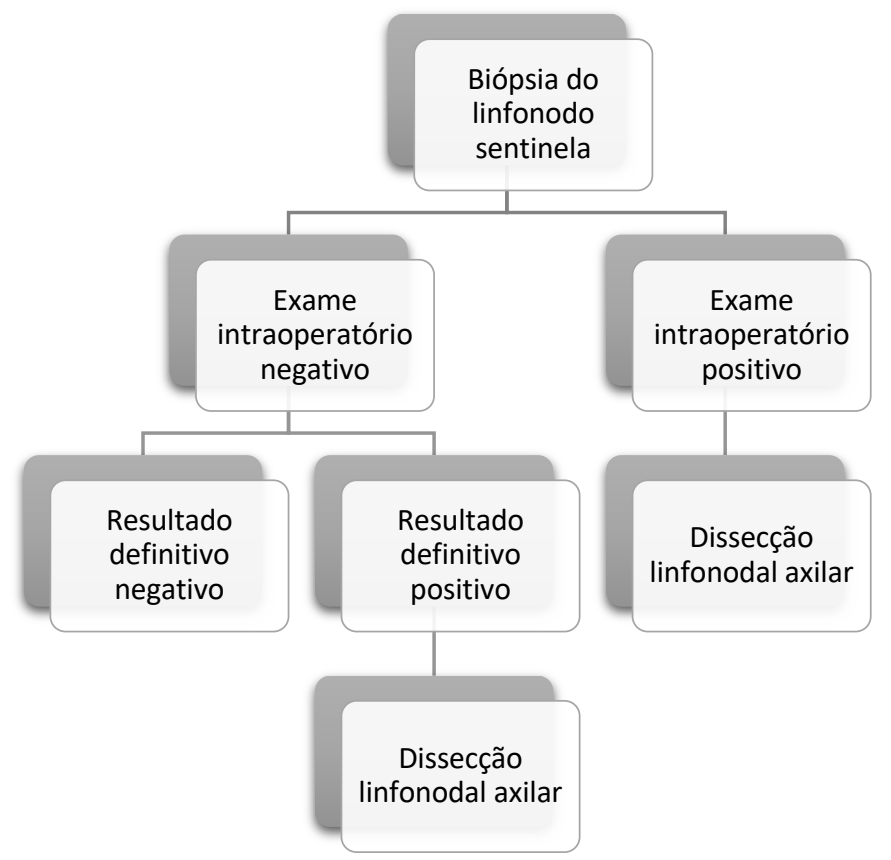

Figura 1 - Dinâmica da pesquisa. 


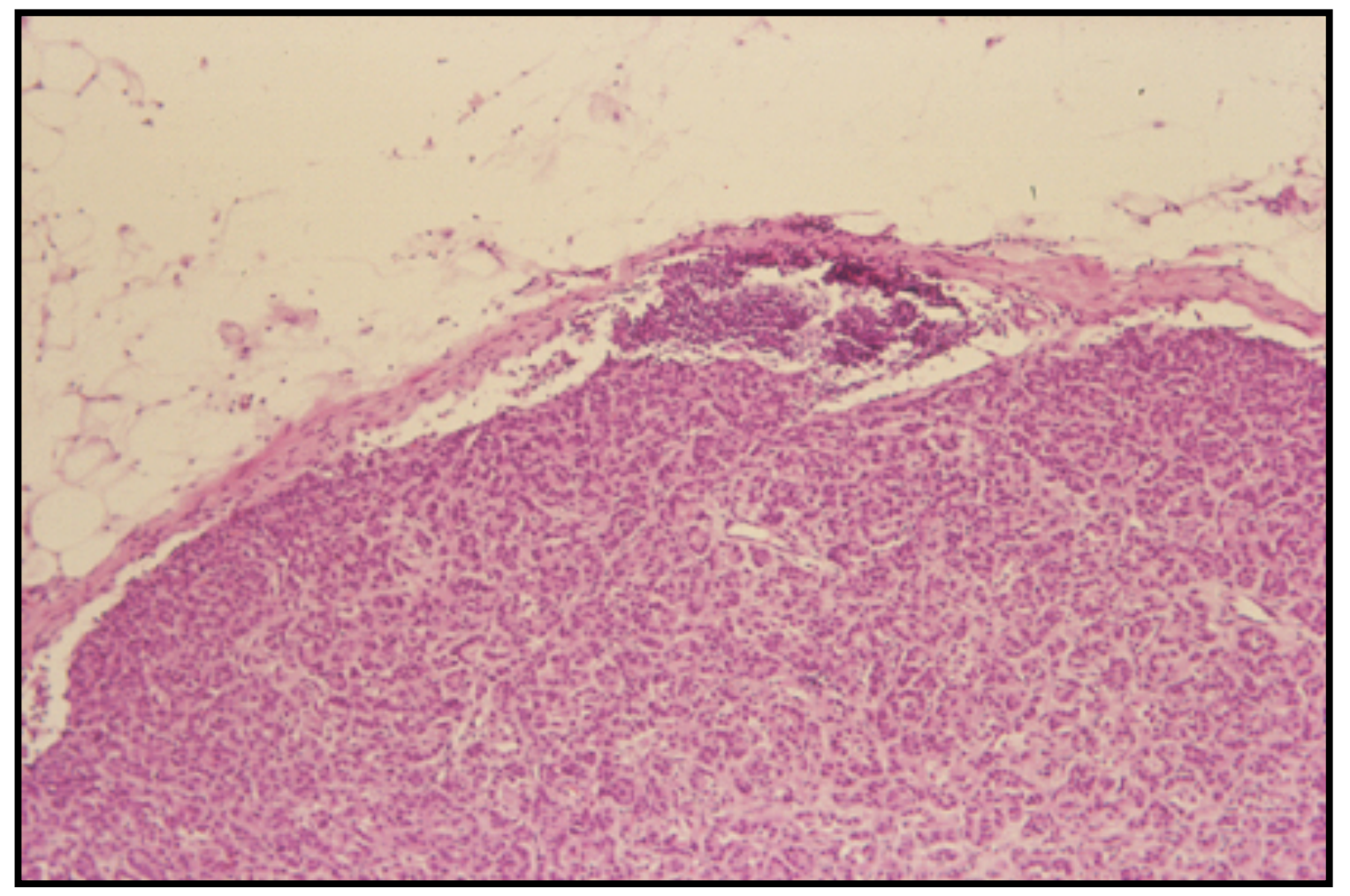

Figura 2 - Linfonodo apresentando micrometástase subcapsular. 


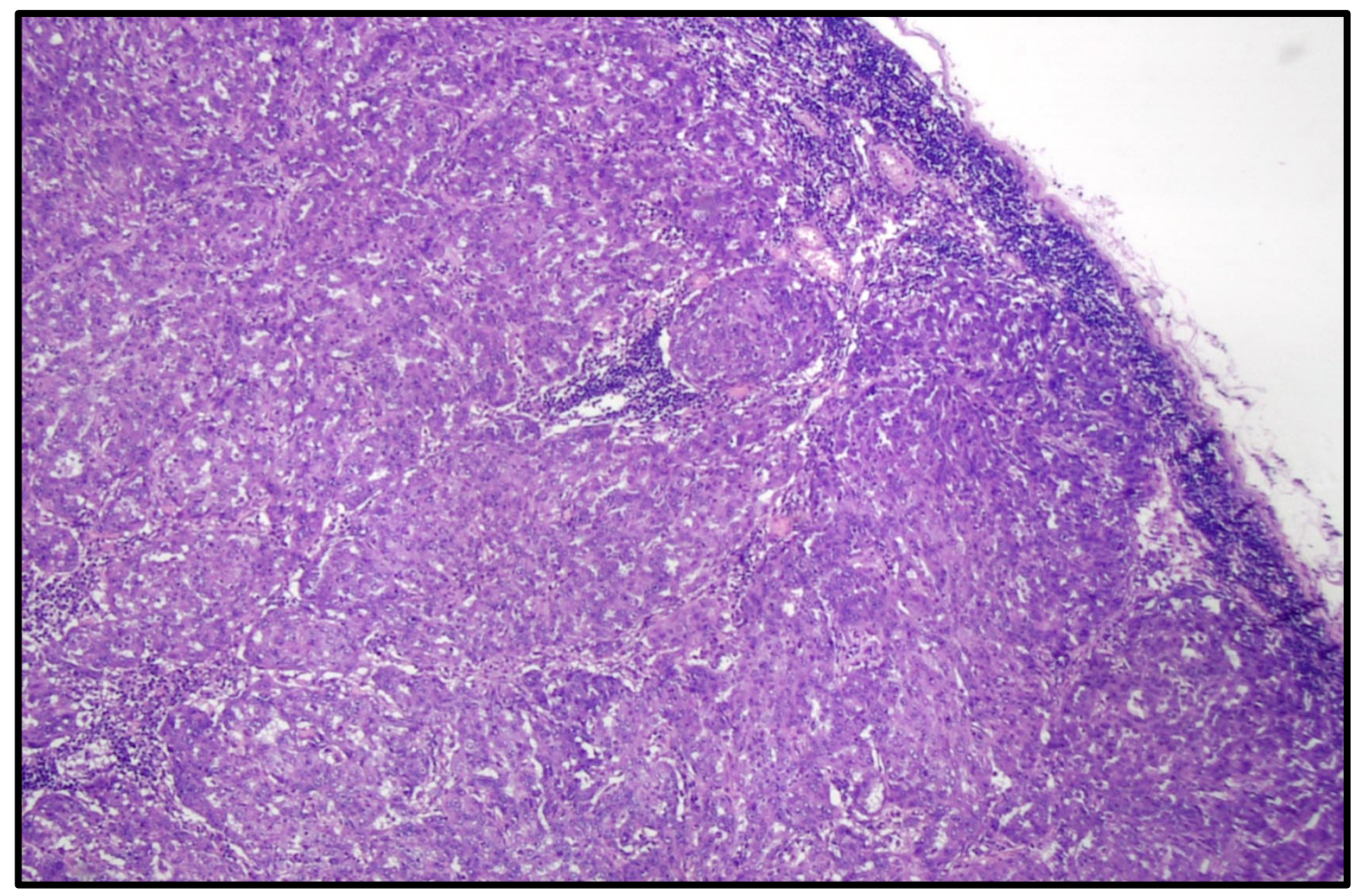

Figura 3 - Linfonodo apresentando envolvimento difuso por macrometástase. 


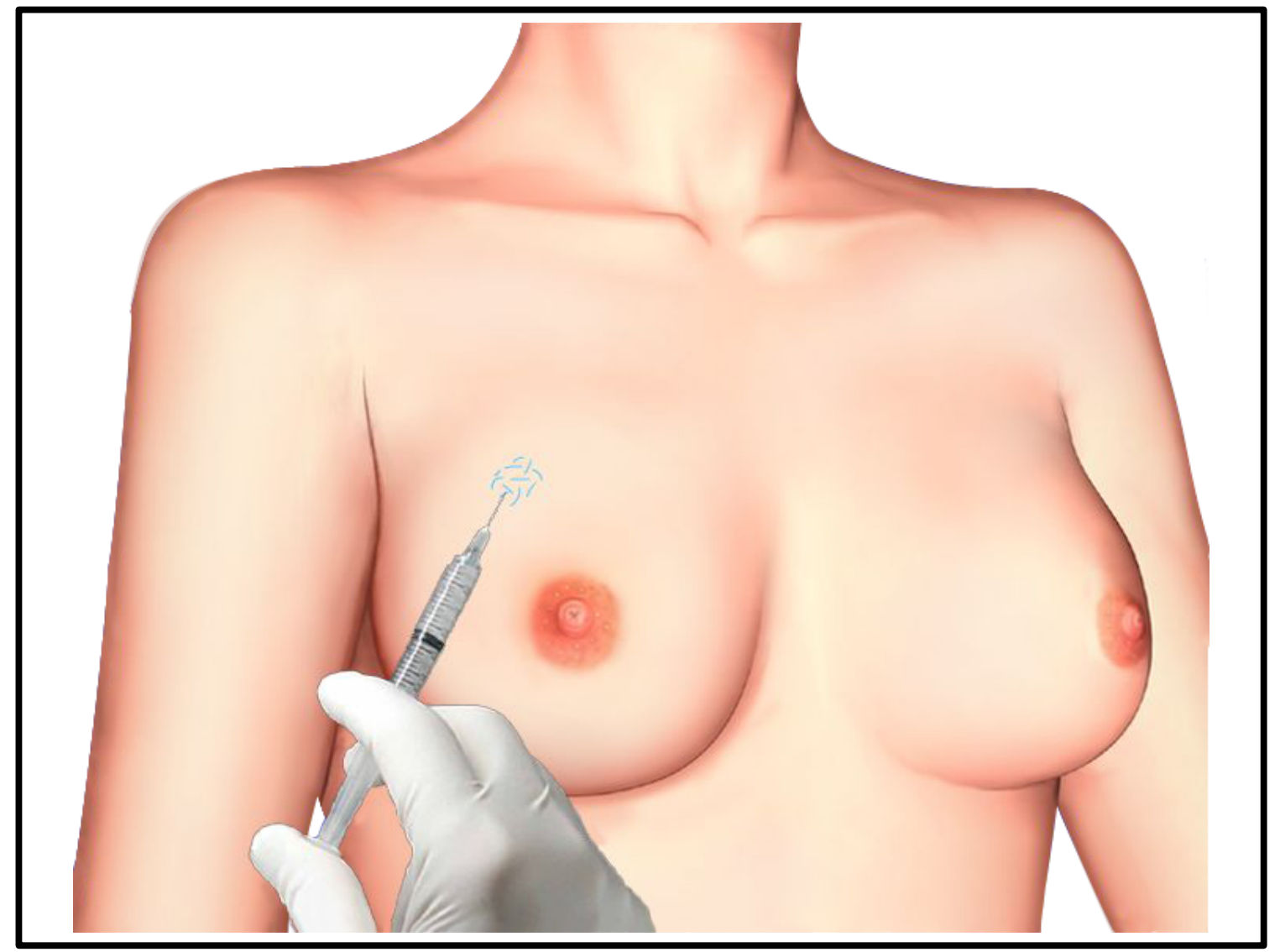

Figura 4 - Injeção peritumoral do radiofármaco tecnécio para marcação do linfonodo sentinela. 


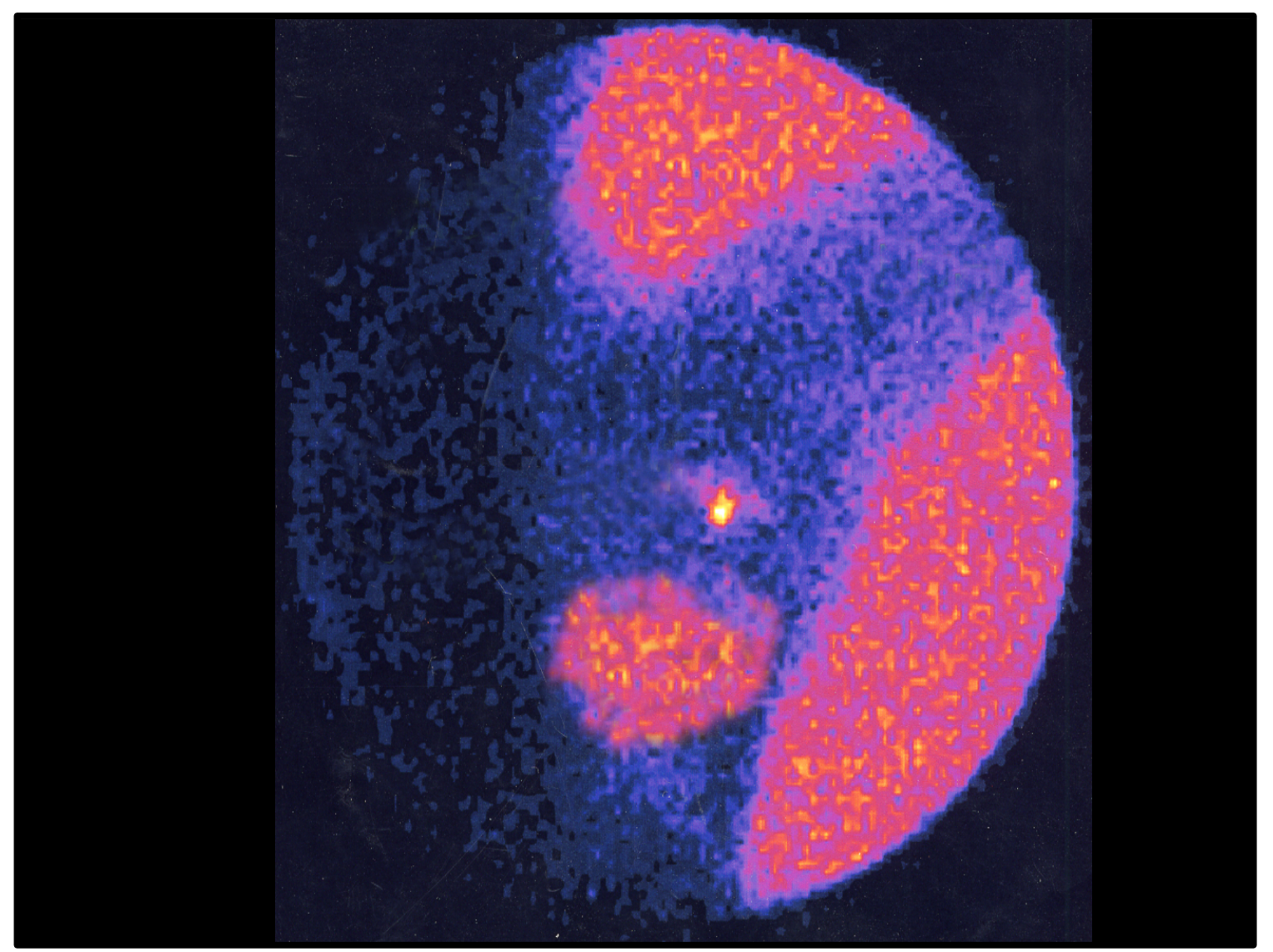

Figura 5 - Linfocintilografia demonstrando captação de radiofármaco em linfonodo axilar. 


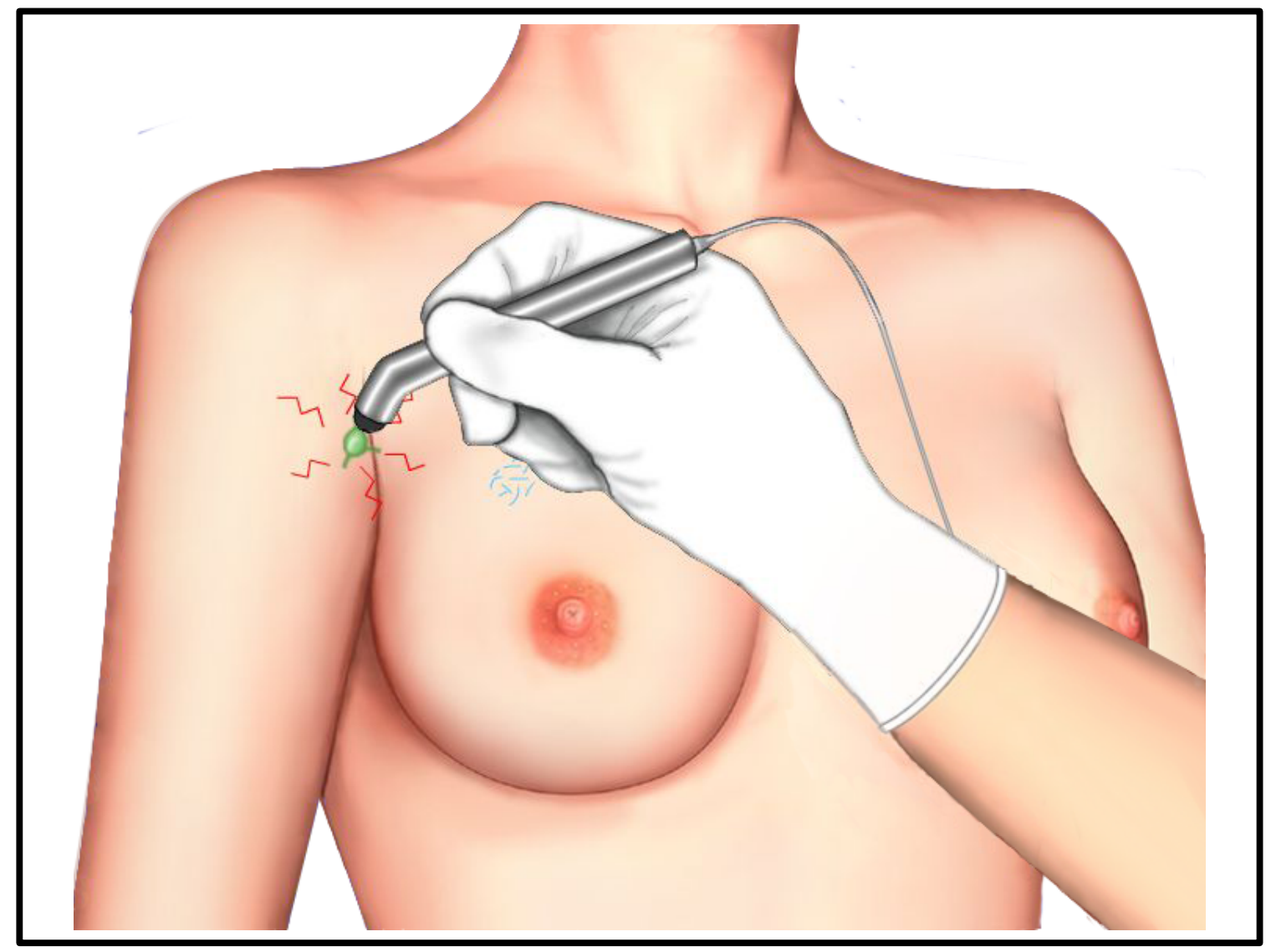

Figura 6 - Identificação do linfonodo sentinela por gama probe. 


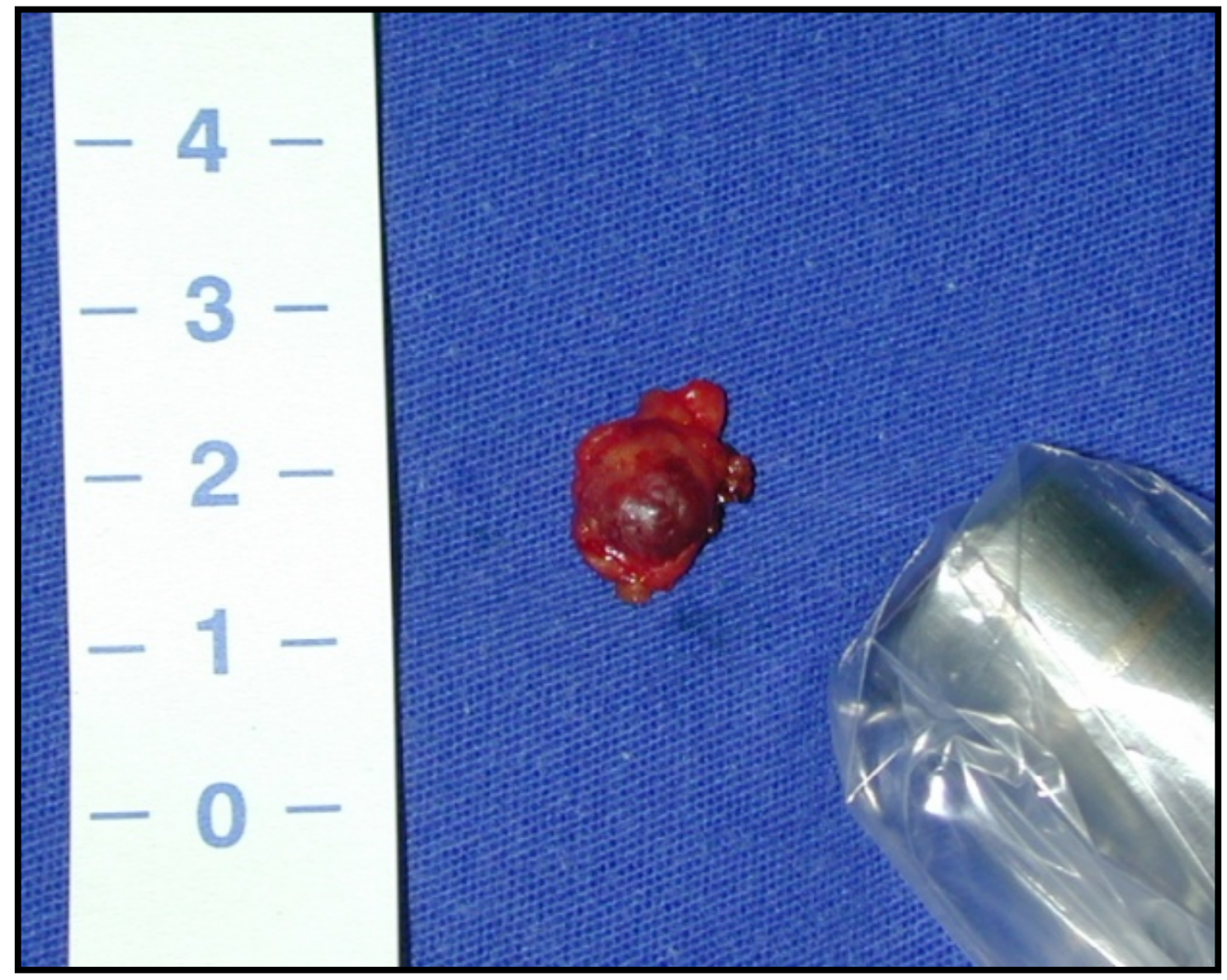

Figura 7 - Mensuração da radiação ex-vivo no linfonodo sentinela. 


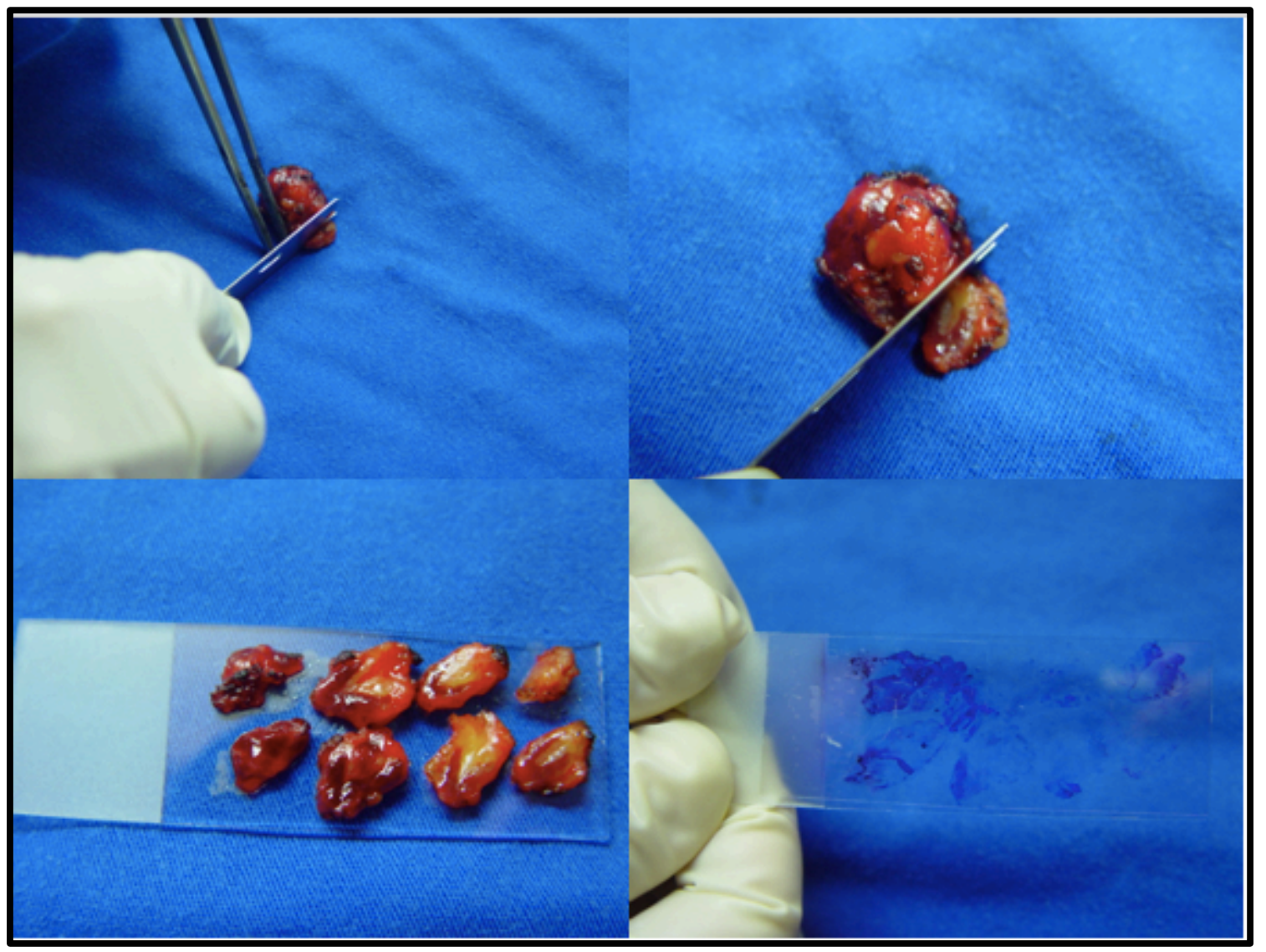

Figura 8 - Exame citológico por contato. 
5. RESULTADOS 
No período de janeiro de 1987 a agosto de 2018, 982 pacientes com carcinomas mamários infiltrativos foram submetidos a tratamento cirúrgico no serviço de onde proveio a casuística. O tratamento cirúrgico foi realizado upfront em 888 casos e em 94 pacientes optou-se por terapia sistêmica neoadjuvante.

A abordagem axilar através da BLS foi praticada a partir de maio de 2001. Do total de 716 pacientes submetidos a tratamento cirúrgico inicial a partir dessa data, foram realizadas BLS em 552 casos com axila clinicamente negativa, sem quimioterapia neoadjuvante.

Foram identificados 138 casos (25\%) de carcinomas mamários infiltrativos iniciais com BLS positiva para malignidade na avaliação anatomopatológica final, sendo que em 38 pacientes a análise intraoperatória foi considerada negativa. Foram dissecados linfonodos regionais axilares (nãosentinelas) em 129 pacientes destes 138 (93,5\%), que efetivamente representam a amostra deste estudo. Em 27 casos (20,9\%) a infiltração do LS/LPS ocorreu através de micrometástases.

Assim, avaliou-se 129 pacientes, dos quais apenas um caso era do sexo masculino e $128(99,2 \%)$ do sexo feminino. A média de idade dos pacientes foi de 53 anos ( \pm 12 anos), 65 mulheres $(50,8 \%)$ se apresentavam no período pós-menopausa e 63 mulheres $(49,2 \%)$ na pré-menopausa. Os procedimentos ocorreram entre julho de 2001 e agosto de 2018, sendo que 46 pacientes $(35,7 \%)$ submeteram à ressecção segmentar da mama, 52 pacientes $(40,3 \%)$ foram submetidos à mastectomia e 31 pacientes $(24 \%)$ à adenectomia mamária. A maioria dos casos eram carcinomas invasivos SOE (106 pacientes, 82,2\%), sendo 13 pacientes com carcinoma lobular invasivo $(10,1 \%)$ e em 10 casos $(7,8 \%)$ identificaram-se outros tipos histológicos. O CLA foi constatado 
em 47 casos (36,4\%; IC95\%: 28,5-45,0). O CLA será considerado como outcome na análise que segue.

A localização dos tumores é exposta na tabela 1. A maioria dos tumores invasivos foi localizada nos quadrantes superolaterais.

As tabelas 2, 3 e 4 apresentam os resultados das diversas variáveis qualitativas analisadas.

A tabela 5 sumariza todas as variáveis quantitativas avaliadas no estudo. Pode-se verificar que a média do número de focos invasivos na mama foi de dois, o tamanho tumoral médio ao exame anatomopatológico foi de 21,2 mm ( $\pm 13,7 \mathrm{~mm})$, a porcentagem média de receptores de estrogênio positivos por paciente foi $75 \%( \pm 32,4 \%)$, a porcentagem média de receptores de progesterona positivos por paciente foi 53\% ( $\pm 38 \%$ ) e Ki-67 26\% ( $\pm 22 \%)$.

A média de LSs e LPSs removidos foi de três, de LSs e LPSs comprometidos foi de um e a taxa de comprometimento dos LSs e LPSs foi de $66 \%$. O tamanho médio das metástases nos LN-S comprometidos foi de 7,7 $\mathrm{mm}( \pm 5,2)$, com mediana de $6,9 \mathrm{~mm}$.

Entre os parâmetros clínicos e tumorais estudados, os fatores qualitativos que tiveram impacto com significância estatística no CLA na análise univariada foram (tabela 6):

a) tamanho tumoral ao exame clínico cT2,

b) tamanho tumoral ao exame anatomopatológico,

c) grau histológico III,

d) embolização vascular peritumoral presente em área focal.

Os parâmetros moleculares não foram relevantes, do ponto de vista estatístico, na análise univariada (tabela 7). 
Na tabela 8 é possível observar os fatores linfonodais qualitativos que tiveram impacto com significância estatística no CLA:

a) mais de um LS ou LPS comprometido,

b) taxa de comprometimento linfonodal de $100 \%$,

c) dois ou mais FNL no mesmo LN ou em LNs distintos,

d) maior metástase superior a 4,0 mm,

e) presença de extensão neoplásica extracapsular,

f) acometimento da gordura perilinfonodal,

g) envolvimento vascular perilinfonodal,

h) vinte ou mais LN-S dissecados.

Os valores da razão de chance para CLA incluindo IC $95 \%$ e os respectivos níveis descritivos estão disponíveis nas tabelas 6, 7 e 8 e ajudam a compreender a intensidade das associações estatísticas entre os fatores e o CLA. O - indica que os parâmetros são redundantes ou impossíveis de calcular.

A mediana do tamanho tumoral ao exame anatomopatológico foi um dos fatores quantitativos significativamente associado ao CLA, com 17,0 mm no grupo sem CLA e 23,0 mm no grupo com CLA, $p>0,001$ (tabela 9 e figura 9). A porcentagem do receptor de estrogênio foi ligeiramente diferente entre os grupos, com $90 \%$ no grupo sem CLA versus $80 \%$ na referência, $p=0,012$. Fenômeno semelhante foi observado na apresentação da mediana do receptor de progesterona em porcentagem, com $50 \%$ no grupo com comprometimento e $77,5 \%$ na referência, $p=0,011$.

A tabela 9 mostra também as diferenças para o número de LSs e LPSs comprometidos, com mediana de 1 versus 2, $p<0,001$; para a taxa de comprometimento dos LSs e LPSs, que foi de $50 \%$ versus $100 \%, p=0,008$; 
para o número de FNL, que foi significativamente maior no grupo com CLA, com mediana de 2, $\mathrm{p}<0,001$; para o tamanho da maior metástase, com mediana de 8,0 mm, $\mathrm{p}<0.001$; e para o número de LN-S dissecados, cuja mediana foi de 23, $p<0,001$.

As variáveis que mostraram significância estatística podem ser visualizadas nas figuras 10 a 17.

Após ajuste do modelo, as variáveis que aumentaram a chance de ocorrência do CLA foram o tamanho tumoral ao exame clínico na categoria cT2, com OR $=9,23$ (IC 95\%: 1,50-57,03), $p=0,017$, a presença de dois ou mais FNL, com OR $=4,11$ (IC 95\%: 1,08-17,70), $p=0,039$ e maior metástase > $4,0 \mathrm{~mm}$, com OR = 15,42 (IC 95\%: 1,57-151,99), $\mathrm{p}=0,019$. As outras variáveis analisadas com significância estatística na análise univariada não se ajustaram ao melhor modelo (tabela 10).

Uma análise de curva ROC (figura 18), produzida a partir dos valores preditos no modelo ajustado de regressão logística para o CLA, apresentou área sob a curva de $81,0 \%$ (IC 95\%: 71,6-90,3) com significância estatística para predição do fenômeno $(p<0,001)$. 
Tabela 1 - Localização dos tumores na mama avaliados pelo exame anatomopatológico em 129 casos de carcinoma mamário infiltrativo.

\begin{tabular}{lcc}
\hline \hline & N & Frequência relativa \\
& & $\%$ \\
\hline \hline Quadrante superolateral & 57 & 44,2 \\
Região retroareolar & 31 & 24,0 \\
Quadrante inferolateral & 17 & 13,2 \\
Quadrante superomedial & 15 & 11,6 \\
Quadrante inferomedial & 9 & 7,0 \\
\hline \hline
\end{tabular}


Tabela 2 - Análise descritiva das características tumorais qualitativas estratificadas de acordo com os grupos incluindo frequência absoluta, relativa, intervalo de confiança de 95\% (IC 95\%).

\begin{tabular}{|c|c|c|c|}
\hline & $\mathbf{n}$ & $\%$ & IC 95\% \\
\hline \multicolumn{4}{|c|}{ Tamanho tumoral ao exame clínico } \\
\hline cTx & 47 & 36,4 & $28,5-45,0$ \\
\hline cT1 & 50 & 38,8 & $30,7-47,3$ \\
\hline cT2 & 32 & 24,8 & $18,0-32,8$ \\
\hline \multicolumn{4}{|l|}{ Multiplicidade } \\
\hline Não & 90 & 69,8 & $61,5-77,2$ \\
\hline \multicolumn{4}{|c|}{ Tamanho tumoral ao exame anatomopatológico } \\
\hline pTmic & 1 & 0,8 & $0,1-3,6$ \\
\hline pT1a & 4 & 3,1 & $1,1-7,2$ \\
\hline pT1b & 17 & 13,2 & $8,2-19,8$ \\
\hline pT1c & 53 & 41,1 & $32,9-49,7$ \\
\hline pT2 & 54 & 41,9 & $33,6-50,5$ \\
\hline \multicolumn{4}{|l|}{ Grau histológico } \\
\hline I & 13 & 10,2 & $5,8-16,3$ \\
\hline II & 72 & 56,3 & $47,6-64,6$ \\
\hline III & 43 & 33,6 & $25,8-42,1$ \\
\hline \multicolumn{4}{|l|}{ Grau nuclear } \\
\hline 1 & 6 & 4,7 & $2,0-9,4$ \\
\hline 2 & 62 & 48,4 & $39,9-57,0$ \\
\hline 3 & 60 & 46,9 & $38,4-55,5$ \\
\hline \multicolumn{4}{|c|}{ Embolização vascular peritumoral } \\
\hline Não identificada & 56 & 43,4 & $35,1-52,0$ \\
\hline Presente em área focal & 47 & 36,4 & $28,5-45,0$ \\
\hline Presente multifocal & 26 & 20,2 & $13,9-27,7$ \\
\hline
\end{tabular}


Tabela 3 - Análise descritiva das características moleculares qualitativas estratificadas de acordo com os grupos incluindo frequência absoluta, relativa, intervalo de confiança de 95\% (IC 95\%).

\begin{tabular}{lccr}
\hline \hline & $\mathbf{n}$ & $\%$ & \multicolumn{1}{c}{ IC 95\% } \\
\hline $\begin{array}{l}\text { Receptor de estrogênio } \\
\text { Negativo }\end{array}$ & 12 & 9,3 & $5,2-15,2$ \\
$\quad$ Positivo & 117 & 90,7 & $84,8-94,8$ \\
Receptor de progesterona & & & \\
$\quad$ Negativo & 24 & 18,6 & $12,6-26,0$ \\
$\quad$ Positivo & 105 & 81,4 & $74,0-87,4$ \\
Status do HER-2 & & & \\
$\quad$ Negativo & 102 & 79,1 & $71,5-85,4$ \\
$\quad$ Positivo & 27 & 20,9 & $14,6-28,5$ \\
\hline \hline
\end{tabular}


Tabela 4- Análise descritiva das características linfonodais qualitativas estratificadas de acordo com os grupos incluindo frequência absoluta, relativa, intervalo de confiança de 95\% (IC 95\%).

\begin{tabular}{lccc}
\hline \hline & $\mathbf{n}$ & $\%$ & IC 95\% \\
\hline Reação fibroinflamatória & 28 & 45,2 & $33,2-57,5$ \\
Ausente & 19 & 30,6 & $20,2-42,8$ \\
Discreta & 11 & 17,7 & $9,8-28,6$ \\
Moderada & 4 & 6,5 & $2,2-14,6$ \\
Intensa & & & \\
Extensão neoplásica extracapsular & 56 & 64,4 & $54,0-73,8$ \\
Não & 31 & 35,6 & $26,2-46,0$ \\
Sim & & & \\
Acometimento da gordura perilinfonodal & 60 & 77,9 & $67,7-86,1$ \\
Não & 62 & 22,1 & $13,9-32,3$ \\
Sim & 17 & & \\
Envolvimento vascular perilinfonodal & & 84,2 & $74,8-91,1$ \\
Não & 64 & 15,8 & $8,9-25,2$ \\
Sim & 12 & 63,6 & $55,0-71,5$ \\
Comprometimento linfonodal adicional & 82 & 36,4 & $28,5-45,0$ \\
Não & 47 & & \\
Sim & & & \\
\hline \hline
\end{tabular}


Tabela 5 - Estatísticas descritivas dos fatores quantitativos incluindo média, desvio padrão (DP), mediana, mínimo e máximo (mín-máx).

\section{Média DP Mediana Mín. Máx.}

Número de focos invasivos na mama

Tamanho tumoral (pT em mm)

Receptor de estrogênio (\%)

Receptor de progesterona (\%)

Ki-67 (\%)

Número de LSs/LPSs removidos

Número de LSs/LPSs comprometidos

Taxa de comprometimento LS/LPS (\%)

Número de FNL

Tamanho da metástase $(\mathrm{mm})$

Área LN ocupada pela metástase (\%)

Extensão extracapsular (mm)

Extracapsular / intraparenquimatoso

Número de LN-S dissecados

Total de LN-S comprometidos

Tamanho das metástases nos LN-S (mm)

\begin{tabular}{ccccc}
2,0 & 2,0 & 1,0 & 1,0 & 16,0 \\
21,2 & 13,7 & 18,0 & 0,5 & 100,0 \\
75,0 & 32,4 & 90,0 & 0,0 & 100,0 \\
52,8 & 37,7 & 60,0 & 0,0 & 100,0 \\
26,4 & 21,5 & 20,0 & 1,0 & 95,0 \\
3,0 & 2,0 & 2,0 & 1,0 & 11,0 \\
1,0 & 1,0 & 1,0 & 1,0 & 5,0 \\
65,6 & 31,3 & 50,0 & 14,0 & 100,0 \\
2,0 & 1,0 & 1,0 & 1,0 & 5,0 \\
6,2 & 6,5 & 4,0 & 0,1 & 33,0 \\
44,1 & 29,2 & 35,0 & 1,0 & 95,0 \\
1,1 & 1,1 & 0,6 & 0,1 & 4,0 \\
0,4 & 0,5 & 0,1 & 0,0 & 1,4 \\
20,0 & 11,0 & 18,0 & 1,0 & 48,0 \\
2,0 & 6,0 & 0,0 & 0,0 & 39,0 \\
7,7 & 5,2 & 6,9 & 0,7 & 18,0 \\
\hline
\end{tabular}


Tabela 6 - Distribuição de parâmetros clínicos e tumorais entre indivíduos com e sem comprometimento linfonodal adicional (CLA), incluindo frequência absoluta, relativa, razão de chances com intervalo de confiança de 95\% (IC 95\%) e nível descritivo.

\begin{tabular}{|c|c|c|c|c|c|c|}
\hline & \multicolumn{3}{|c|}{ CLA } & \multirow{2}{*}{ OR } & \multirow{2}{*}{ IC $95 \%$} & \multirow{2}{*}{$\mathbf{p}$} \\
\hline & $\mathbf{N}$ & $\%$ & Total & & & \\
\hline \multicolumn{7}{|l|}{ Status menopausal } \\
\hline Pré-menopausa & 23 & 36,5 & 63 & - & - & \multirow{2}{*}{0,895} \\
\hline Pós-menopausa & 23 & 35,4 & 65 & 1,05 & $0,51-2,16$ & \\
\hline \multicolumn{7}{|c|}{ Tamanho tumoral ao exame clínico } \\
\hline cTx & 11 & 23,4 & 47 & - & - & \\
\hline cT1 & 17 & 34,0 & 50 & 1,69 & $0,69-4,12$ & 0,252 \\
\hline cT2 & 19 & 59,3 & 32 & 4,78 & $1,80-12,7$ & 0,002 \\
\hline \multicolumn{7}{|l|}{ Multiplicidade } \\
\hline Não & 32 & 35,6 & 90 & - & - & \multirow{2}{*}{0,843} \\
\hline Sim & 15 & 38,5 & 39 & 1,13 & $0,52-2,46$ & \\
\hline \multicolumn{7}{|c|}{ Tamanho tumoral ao exame anatomopatológico } \\
\hline pTmic & 0 & 0,0 & 1 & - & - & \\
\hline pT1a & 1 & 25,0 & 4 & - & - & \\
\hline $\mathrm{pT} 1 \mathrm{~b}$ & 2 & 11,8 & 17 & - & - & 0,001 \\
\hline pT1c & 14 & 26,4 & 53 & - & - & \\
\hline рT2 & 30 & 55,5 & 54 & - & - & \\
\hline \multicolumn{7}{|l|}{ Tipo histológico } \\
\hline Carcinoma invasivo SOE & 37 & 34,9 & 106 & - & - & \\
\hline Carcinoma lobular invasivo & 4 & 30,8 & 13 & 0,83 & $0,24-2,87$ & 0,767 \\
\hline Outros & 6 & 60,0 & 10 & 2,89 & $0,74-10,54$ & 0,129 \\
\hline \multicolumn{7}{|l|}{ Grau histológico } \\
\hline I & 2 & 15,4 & 13 & - & - & \\
\hline II & 22 & 30,6 & 72 & 2,42 & $0,50-11,84$ & 0,275 \\
\hline III & 23 & 53,5 & 43 & 6,33 & $1,25-32,01$ & 0,026 \\
\hline \multicolumn{7}{|l|}{ Grau nuclear } \\
\hline 1 & 1 & 16,7 & 6 & - & - & \\
\hline 2 & 16 & 25,8 & 62 & 1,70 & $0,19-16,03$ & 0,625 \\
\hline 3 & 30 & 50,0 & 60 & 5,00 & $0,55-45,39$ & 0,153 \\
\hline \multicolumn{7}{|c|}{ Embolização vascular peritumoral } \\
\hline Não identificada & 14 & 25,0 & 56 & - & - & \\
\hline Presente em área focal & 21 & 44,7 & 47 & 2,42 & $1,05-5,58$ & 0,038 \\
\hline Presente multifocal & 12 & 46,2 & 26 & 2,60 & $0,97-6,85$ & 0,059 \\
\hline
\end{tabular}


Tabela 7 - Distribuição de parâmetros moleculares entre indivíduos com e sem comprometimento linfonodal adicional (CLA), incluindo frequência absoluta, relativa, razão de chances com intervalo de confiança de 95\% (IC 95\%) e nível descritivo.

\begin{tabular}{|c|c|c|c|c|c|c|}
\hline & & $\overline{\overline{C L A}}$ & & & & \\
\hline & $\mathbf{N}$ & $\%$ & Total & OR & IC 95\% & $\mathbf{p}$ \\
\hline Receptor d & & & & & & \\
\hline Negativo & 6 & 50,0 & 12 & - & - & 252 \\
\hline Positivo & 41 & 35,0 & 117 & 0,50 & $0,16-1,78$ & 0,352 \\
\hline Receptor d & & & & & & \\
\hline Negativo & 10 & 41,7 & 24 & - & - & $0 G 0$ \\
\hline Positivo & 37 & 35,2 & 105 & 0,80 & $0,31-1,88$ & 0,640 \\
\hline Status do & & & & & & \\
\hline Negativo & 36 & 35,3 & 102 & - & - & תחת \\
\hline Positivo & 11 & 40,7 & 27 & 1,31 & $0,53-3,00$ &, 050 \\
\hline
\end{tabular}


Tabela 8 - Distribuição de parâmetros linfonodais entre indivíduos com e sem comprometimento linfonodal adicional não-sentinela (CLA), incluindo frequência absoluta e relativa, razão de chances com intervalo de confiança de 95\% (IC 95\%) e nível descritivo.

\begin{tabular}{|c|c|c|c|c|c|c|}
\hline & & CLA & & חת & inorol & 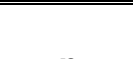 \\
\hline & $\mathbf{n}$ & $\%$ & Total & OR & IC $95 \%$ & p \\
\hline Mais de $1 \mathrm{LS}$ & & & & & & \\
\hline Não & 23 & 26,1 & 88 & 1,00 & - & 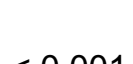 \\
\hline Sim & 24 & 58,5 & 41 & 3,99 & $1,82-8,76$ & $<0,001$ \\
\hline Taxa compre & $0 \%$ & & & & & \\
\hline Não & 19 & 25,3 & 75 & 1,00 & - & $0 \cap 0 ?$ \\
\hline Sim & 28 & 37,8 & 74 & 3,17 & $1,50-6,68$ & 0,003 \\
\hline Dois ou mais & & & & & & \\
\hline Não & 21 & 25,0 & 84 & 1,00 & - & 100001 \\
\hline Sim & 26 & 57,8 & 45 & 4,10 & $1,90-8,87$ & $<0,001$ \\
\hline Maior metás & & & & & & \\
\hline Não & 6 & 13,0 & 46 & 1,00 & - & 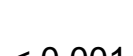 \\
\hline Sim & 25 & 45,5 & 55 & 5,55 & $2,02-15,23$ & $<0,001$ \\
\hline Reação fibro & & & & & & \\
\hline Ausente & 6 & 21,4 & 28 & 1,00 & - & 0,333 \\
\hline Discreto & 9 & 47,4 & 19 & 3,30 & $0,92-11,80$ & 0,066 \\
\hline Moderado & 4 & 36,4 & 11 & 2,09 & $0,45-9,62$ & 0,342 \\
\hline Intenso & 4 & 100,0 & 4 & - & - & 0,999 \\
\hline Extensão ne & & & & & & \\
\hline Não & 16 & 28,6 & 56 & 1,00 & - & 011 \\
\hline Sim & 18 & 58,1 & 31 & 3,46 & $1,38-8,60$ & \\
\hline Acometimen & odal & & & & & \\
\hline Não & 17 & 28,3 & 60 & 1,00 & - & 0.010 \\
\hline Sim & 11 & 64,7 & 17 & 4,63 & $1,48-14,50$ & \\
\hline Envolviment & & & & & & \\
\hline Não & 19 & 29,7 & 64 & 1,00 & - & 021 \\
\hline Sim & 8 & 66,7 & 12 & 4,73 & $1,27-17,60$ & $0,0<1$ \\
\hline Vinte ou mai & elas & & & & & \\
\hline Não & 16 & 22,5 & 71 & 1,00 & - & 0001 \\
\hline Sim & 31 & 53,4 & 58 & 3,94 & $1,84-8,43$ & \\
\hline
\end{tabular}


Tabela 9 - Distribuição das variáveis quantitativas entre indivíduos com e sem comprometimento linfonodal adicional não-sentinela, incluindo mediana e nível descritivo.

\begin{tabular}{lrrrr}
\hline & Sim & Não & \\
\cline { 2 - 3 } & Mediana & Mediana & p \\
\hline \hline Idade (anos) & 52 & 53 & 0,905 \\
Número de focos invasivos na mama & 1 & 1 & 0,732 \\
Tamanho tumoral - anatomopatológico (mm) & 23 & 17 & $<\mathbf{0 , 0 0 1}$ \\
Receptor de estrogênio (\%) & 80,0 & 90,0 & $\mathbf{0 , 0 1 2}$ \\
Receptor de progesterona (\%) & 50,0 & 77,5 & $\mathbf{0 , 0 1 1}$ \\
Ki-67 (\%) & 20,0 & 20,0 & 0,878 \\
Número de LSs e LPSs removidos & 2,0 & 2,0 & 0,813 \\
Número de LSs e LPSs comprometidos & 2,0 & 1,0 & $<\mathbf{0 , 0 0 1}$ \\
Taxa de comprometimento de LSs e LPSs (\%) & 100,0 & 50,0 & $\mathbf{0 , 0 0 8}$ \\
Número de focos neoplásicos nos linfonodos & 2,0 & 1,0 & $<\mathbf{0 , 0 0 1}$ \\
Tamanho da metástase linfonodal (mm) & 8,0 & 3,0 & $<\mathbf{0 , 0 0 1}$ \\
Área do linfonodo ocupada pela metástase (\%) & 50 & 30 & $\mathbf{0 , 0 0 6}$ \\
Extensão neoplásica extracapsular (mm) & 1,4 & 0,5 & 0,314 \\
Componente extracapsular/ intraparenquimatoso & 0,2 & 0,1 & 0,492 \\
Linfonodos regionais não-sentinelas dissecados & 23 & 16 & $<\mathbf{0 , 0 0 1}$ \\
\hline \hline
\end{tabular}


Tabela 10 - Modelo de regressão logística ajustado para comprometimento linfonodal adicional, incluindo frequência absoluta e relativa, odds ratio com intervalo de confiança de $95 \%$ e nível descritivo.

\begin{tabular}{lcccc}
\hline \hline & $\begin{array}{c}\text { CLA } \\
\mathbf{n ~ ( \% )}\end{array}$ & OR & IC 95\% & p \\
\hline cT em categorias & & & & \\
CTx & $11(23,4)$ & ref. & & \\
CT1 & $17(34,0)$ & 1,20 & $0,25-5,71$ & 0,823 \\
CT2 & $18(62,1)$ & 9,23 & $1,50-57,03$ & 0,017 \\
Dois ou mais FNL & & & & \\
Não & $21(25,0)$ & ref. & & \\
Sim & $26(57,0)$ & 4,11 & $1,08-15,70$ & 0,039 \\
Metástase $>$ 4,0 mm no LS & & & & \\
Não & $6(13,0)$ & ref. & & \\
Sim & $25(45,5)$ & 15,42 & $1,57-151,99$ & 0,019 \\
\hline \hline
\end{tabular}




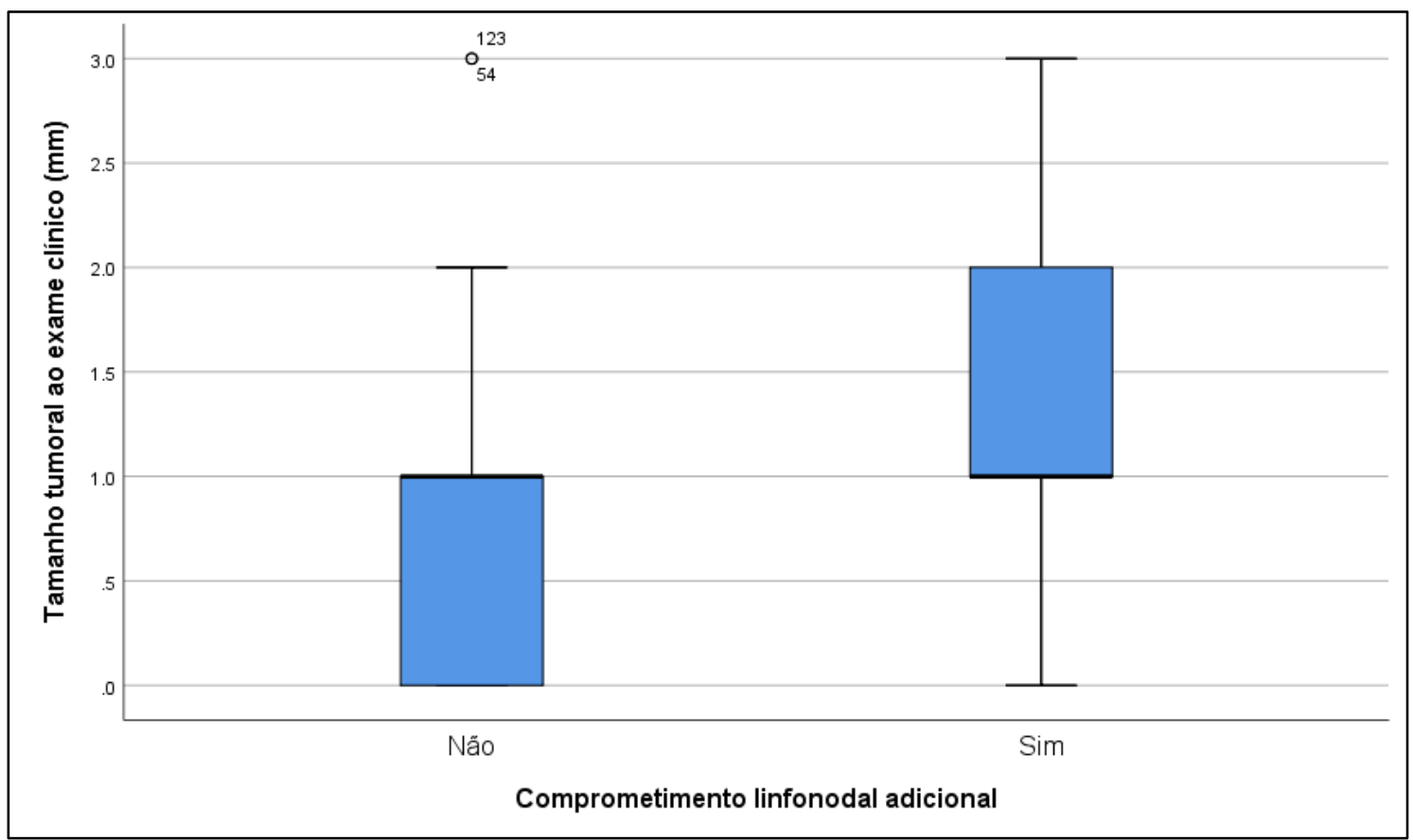

$p<0.001$ (teste $U$ de Mann Whitney de amostras independentes).

Figura 9 - Distribuição do tamanho tumoral ao exame clínico de acordo com o comprometimento linfonodal adicional não-sentinela. 


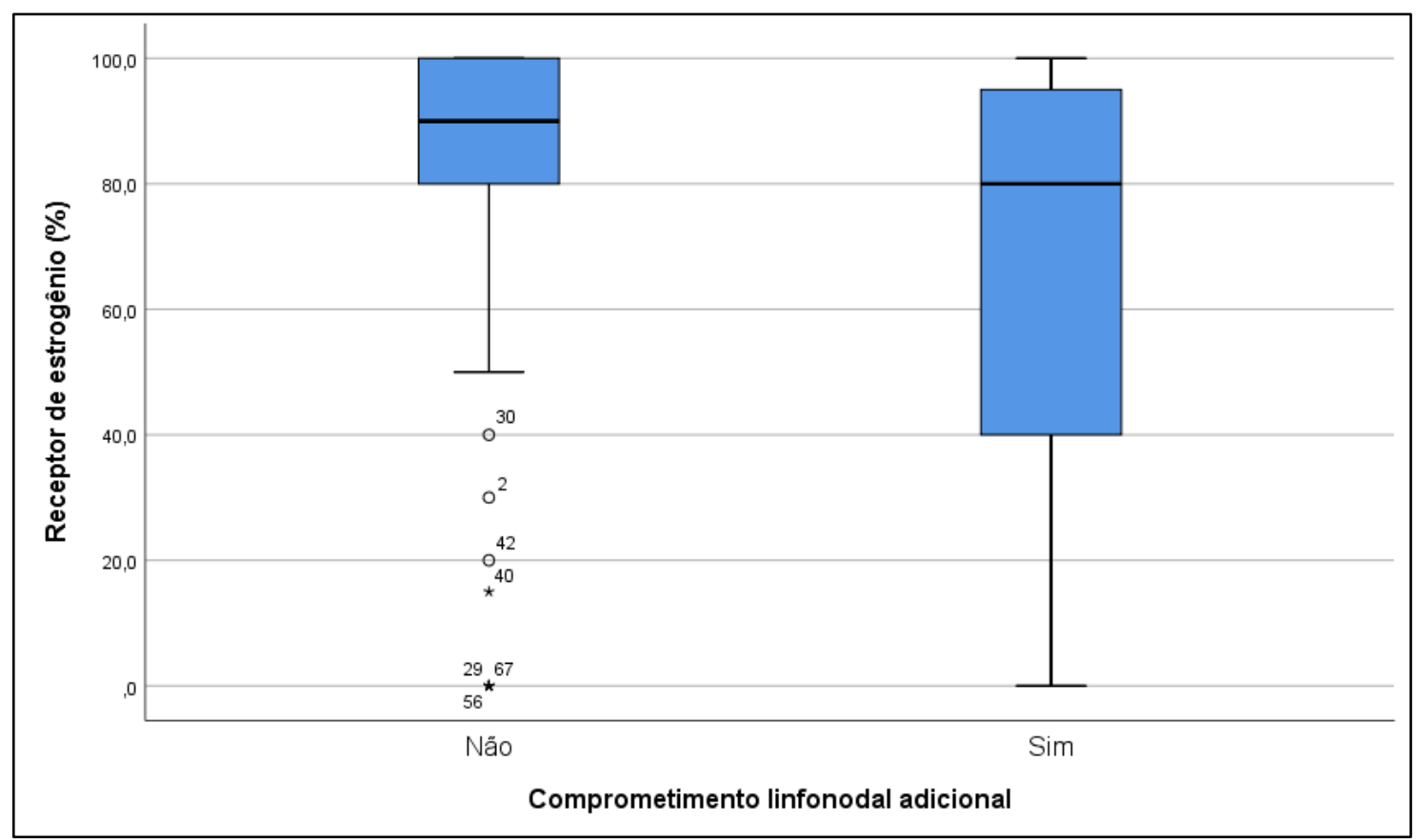

$p=0.012$ (teste $U$ de Mann Whitney de amostras independentes).

Figura 10 - Distribuição do receptor de estrogênio (\%) entre indivíduos com e sem comprometimento linfonodal adicional não-sentinela. 


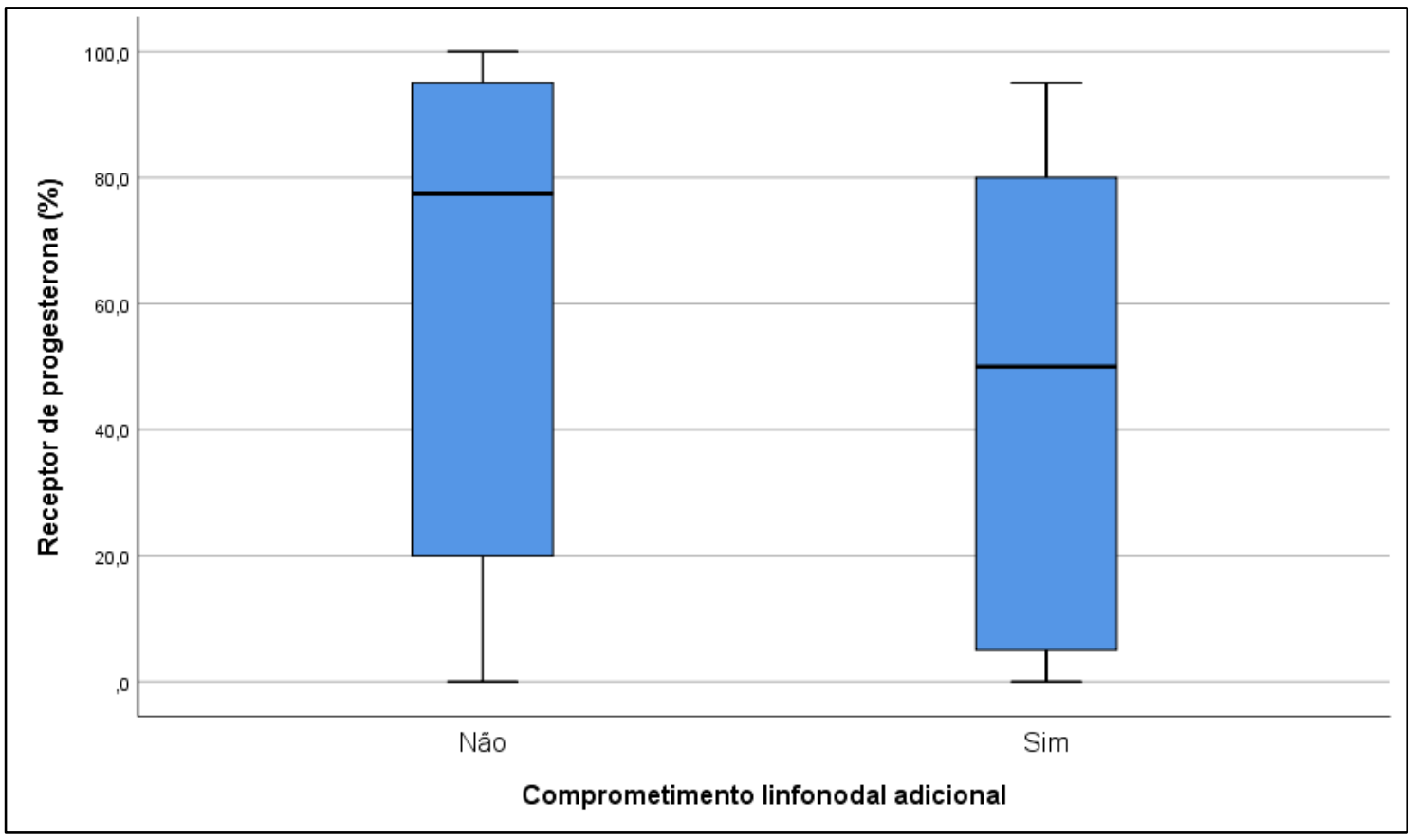

$p=0.011$ (teste $U$ de Mann Whitney de amostras independentes).

Figura 11 - Distribuição do receptor de progesterona (\%) entre indivíduos com e sem comprometimento linfonodal adicional não-sentinela. 


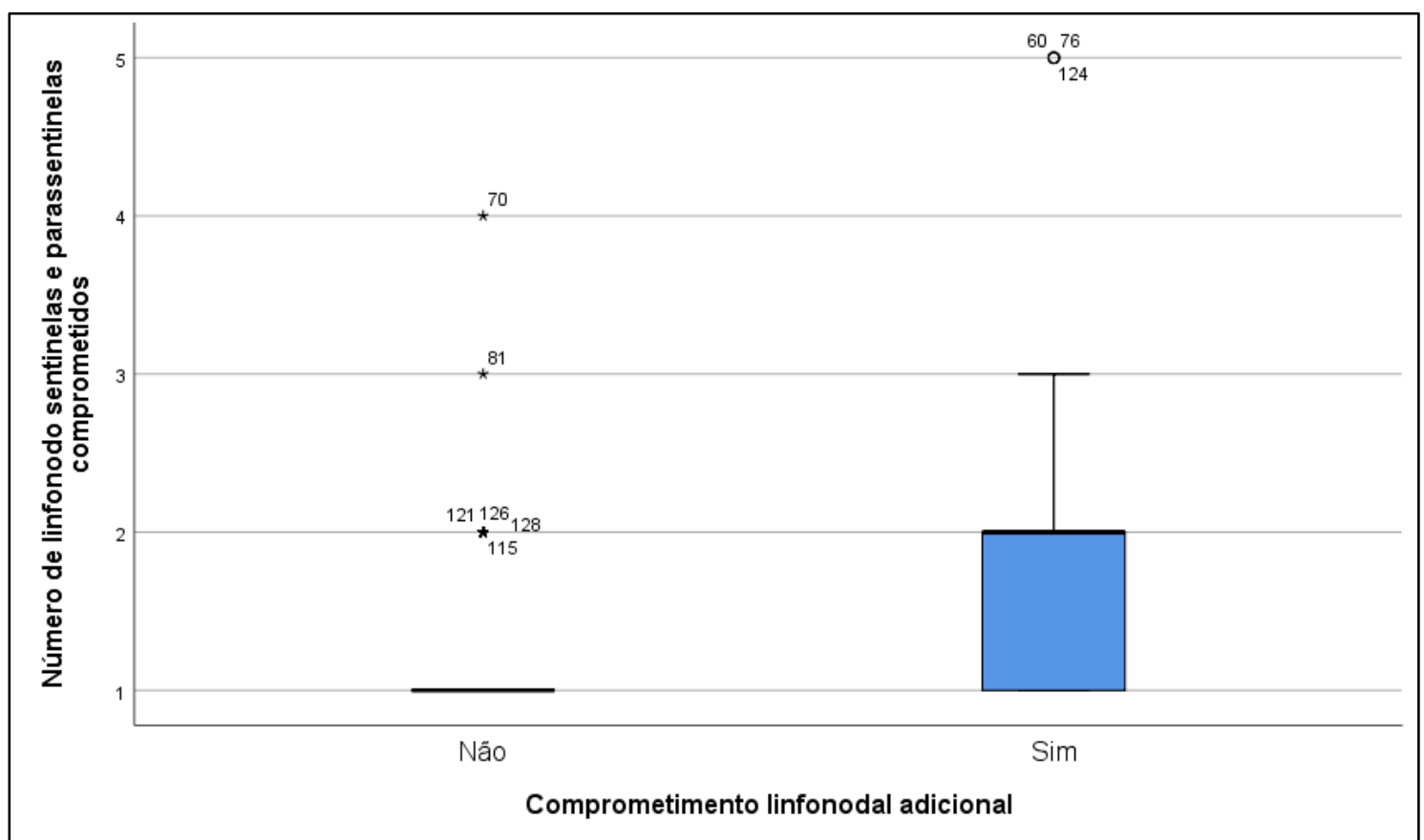

$p<0.001$ (teste $U$ de Mann Whitney de amostras independentes).

Figura 12 - Distribuição do número de linfonodos sentinelas e parassentinelas comprometidos entre indivíduos com e sem comprometimento linfonodal adicional não-sentinela. 


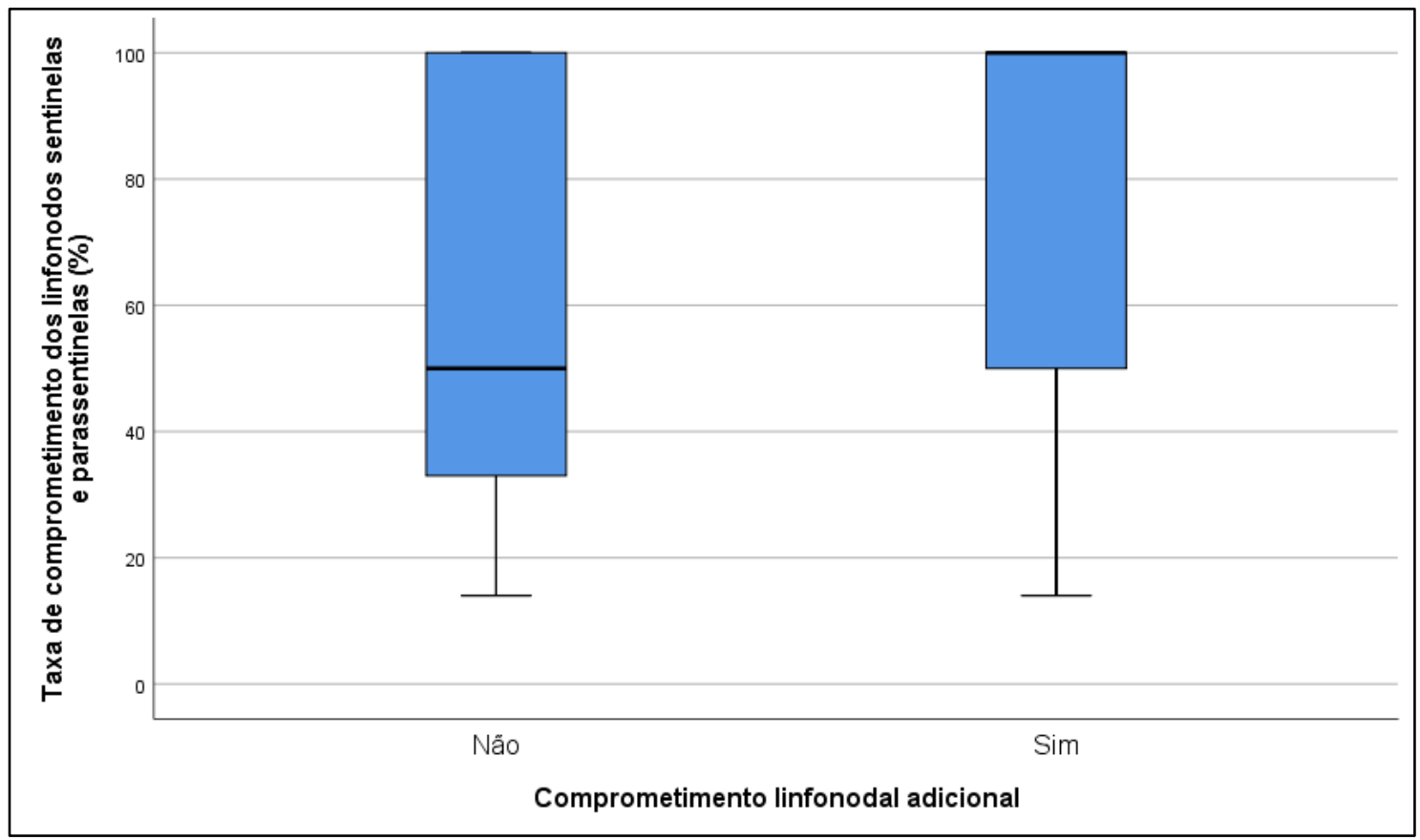

$p=0.008$ (teste $U$ de Mann Whitney de amostras independentes).

Figura 13 - Distribuição da taxa de comprometimento dos linfonodos sentinelas e parassentinelas entre indivíduos com e sem comprometimento linfonodal adicional não-sentinela. 


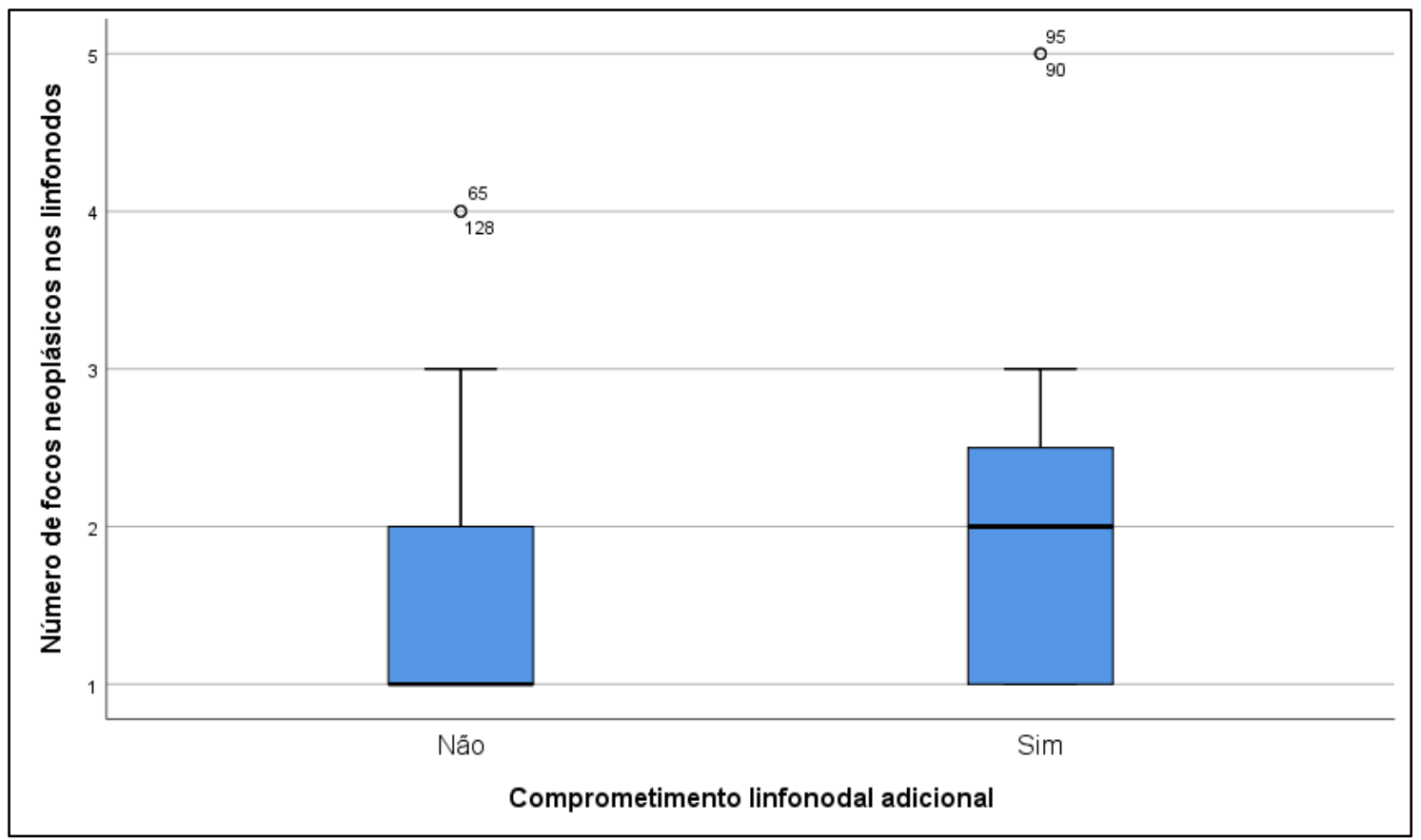

$p<0.001$ (teste $U$ de Mann Whitney de amostras independentes).

Figura 14 - Distribuição do número de focos neoplásicos nos linfonodos entre indivíduos com e sem comprometimento linfonodal adicional não-sentinela. 


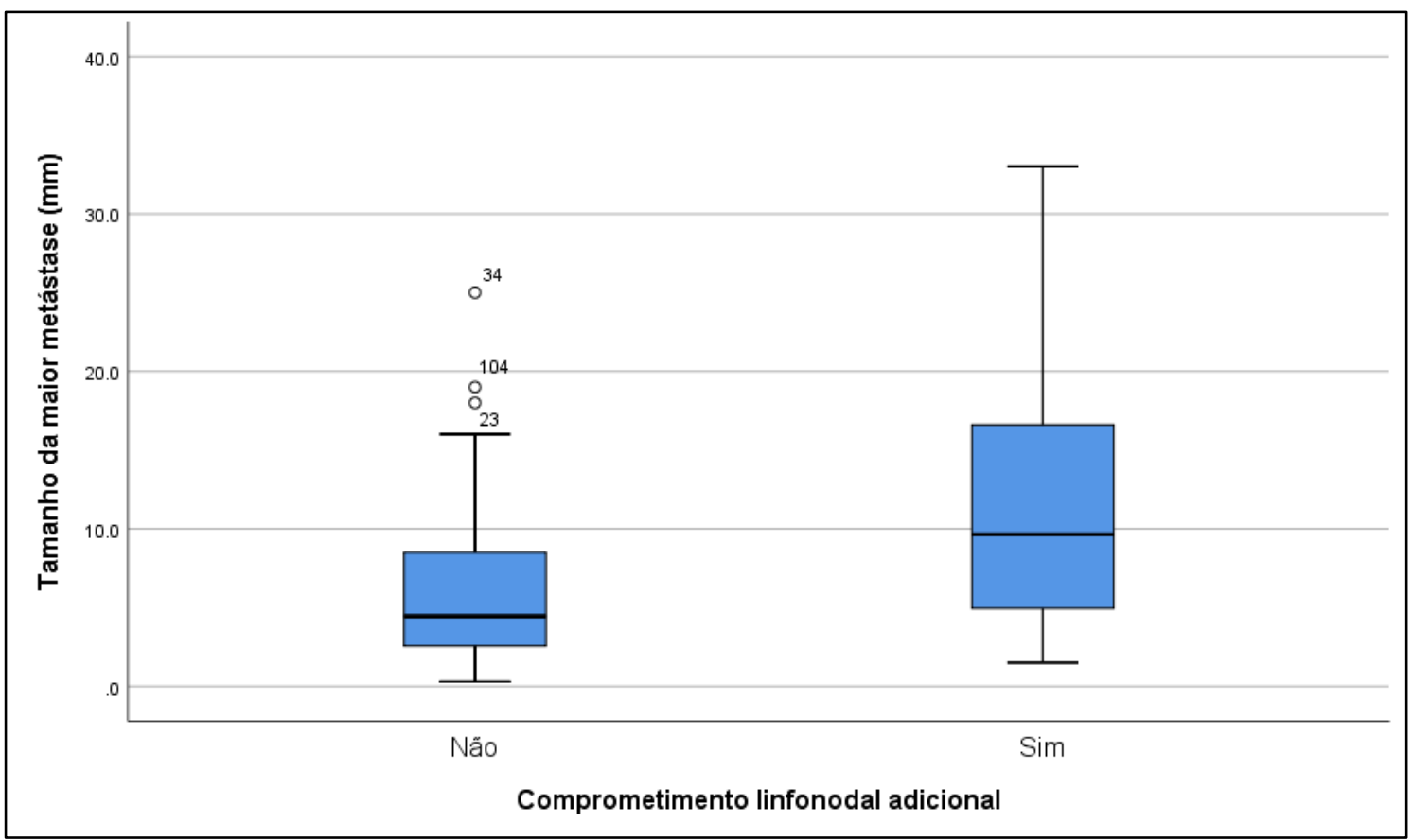

$p<0.001$ (teste $U$ de Mann Whitney de amostras independentes).

Figura 15 - Distribuição do tamanho da maior metástase $(\mathrm{mm})$ entre indivíduos com e sem comprometimento linfonodal adicional não-sentinela. 


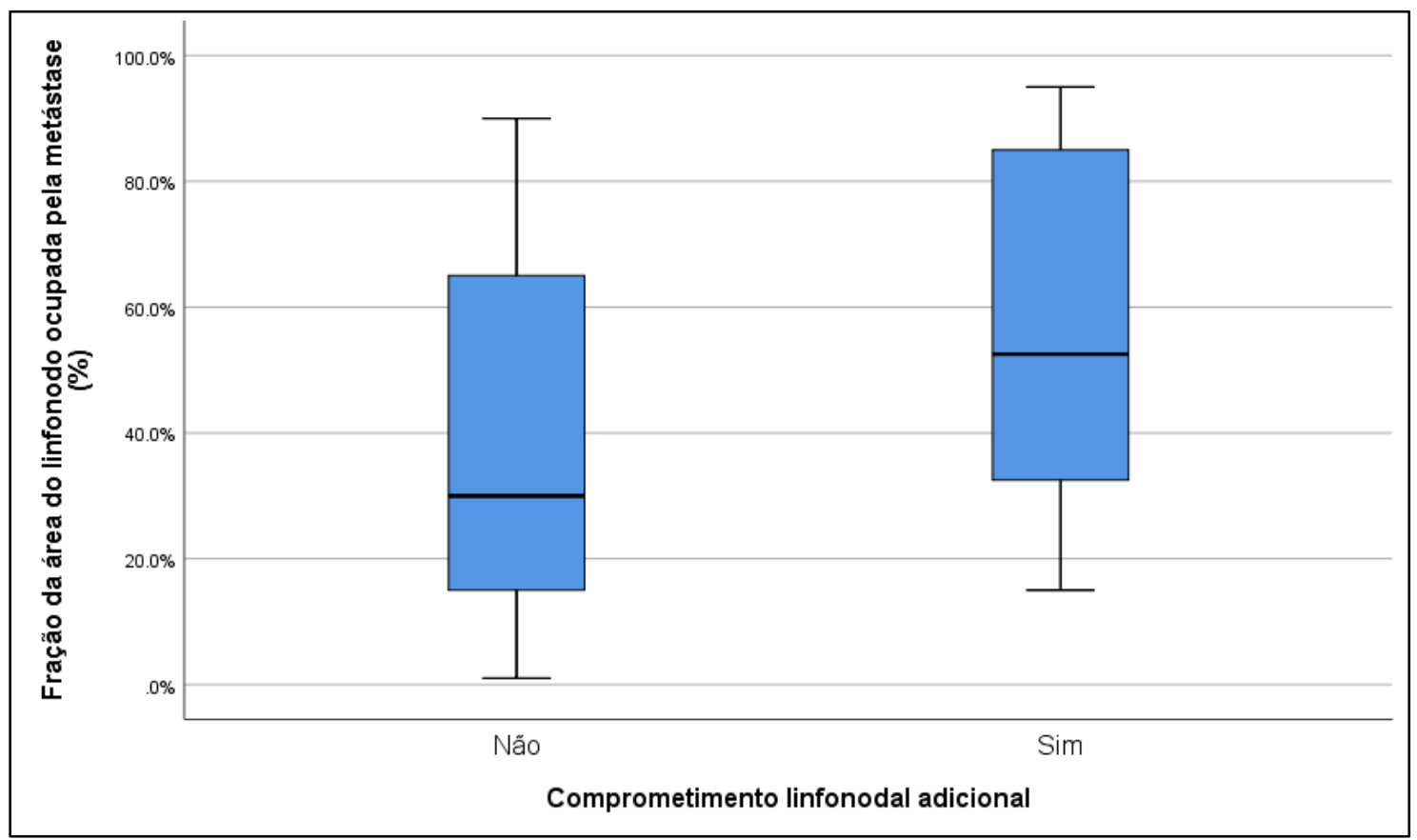

$p=0.006$ (teste $U$ de Mann Whitney de amostras independentes).

Figura 16 - Distribuição da fração da área do linfonodo ocupada pela metástase (\%) entre indivíduos com e sem comprometimento linfonodal adicional não-sentinela. 


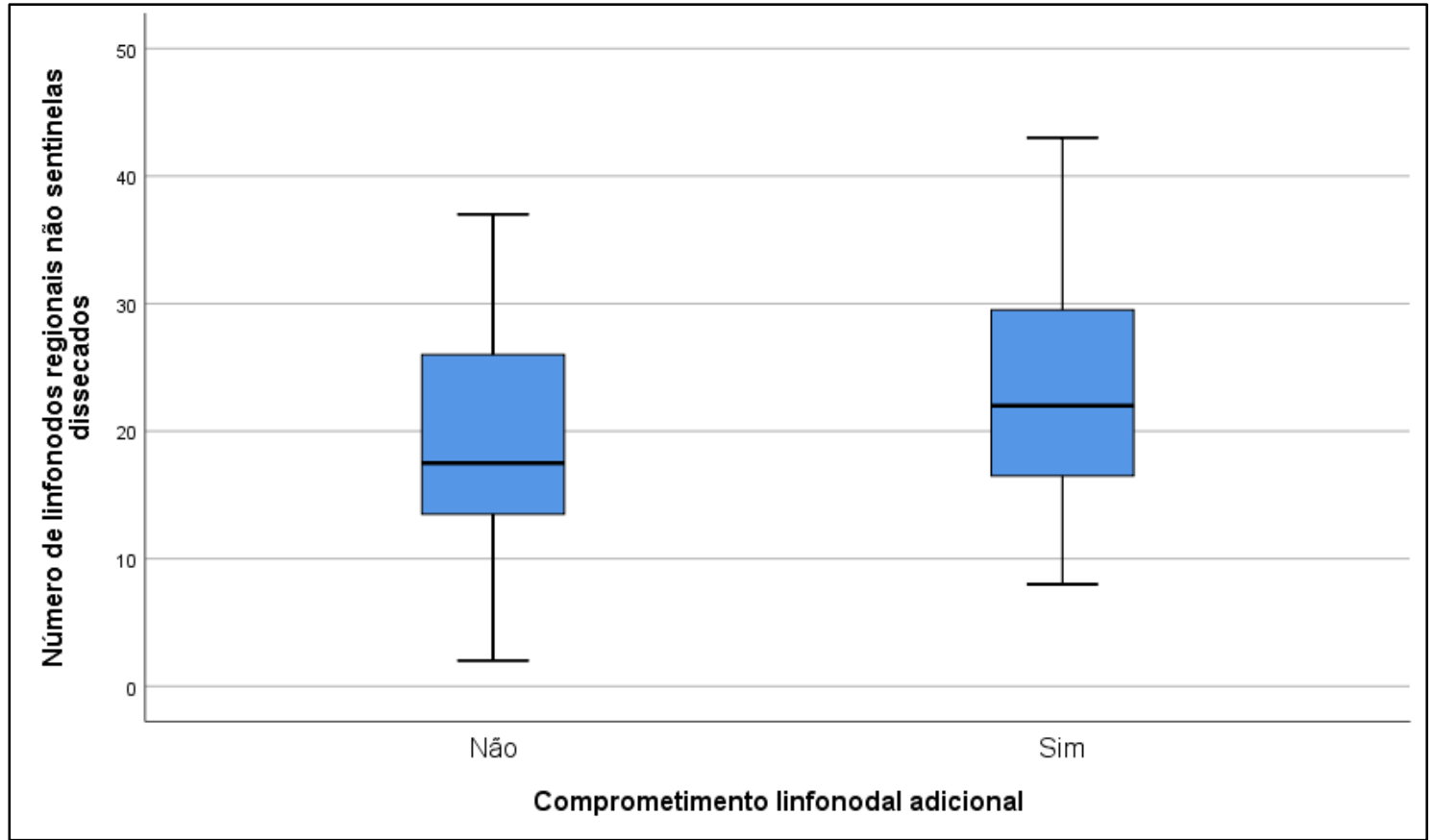

$p<0.001$ (teste $U$ de Mann Whitney de amostras independentes).

Figura 17 - Distribuição do número de linfonodos regionais não-sentinelas dissecados entre indivíduos com e sem comprometimento linfonodal adicional. 


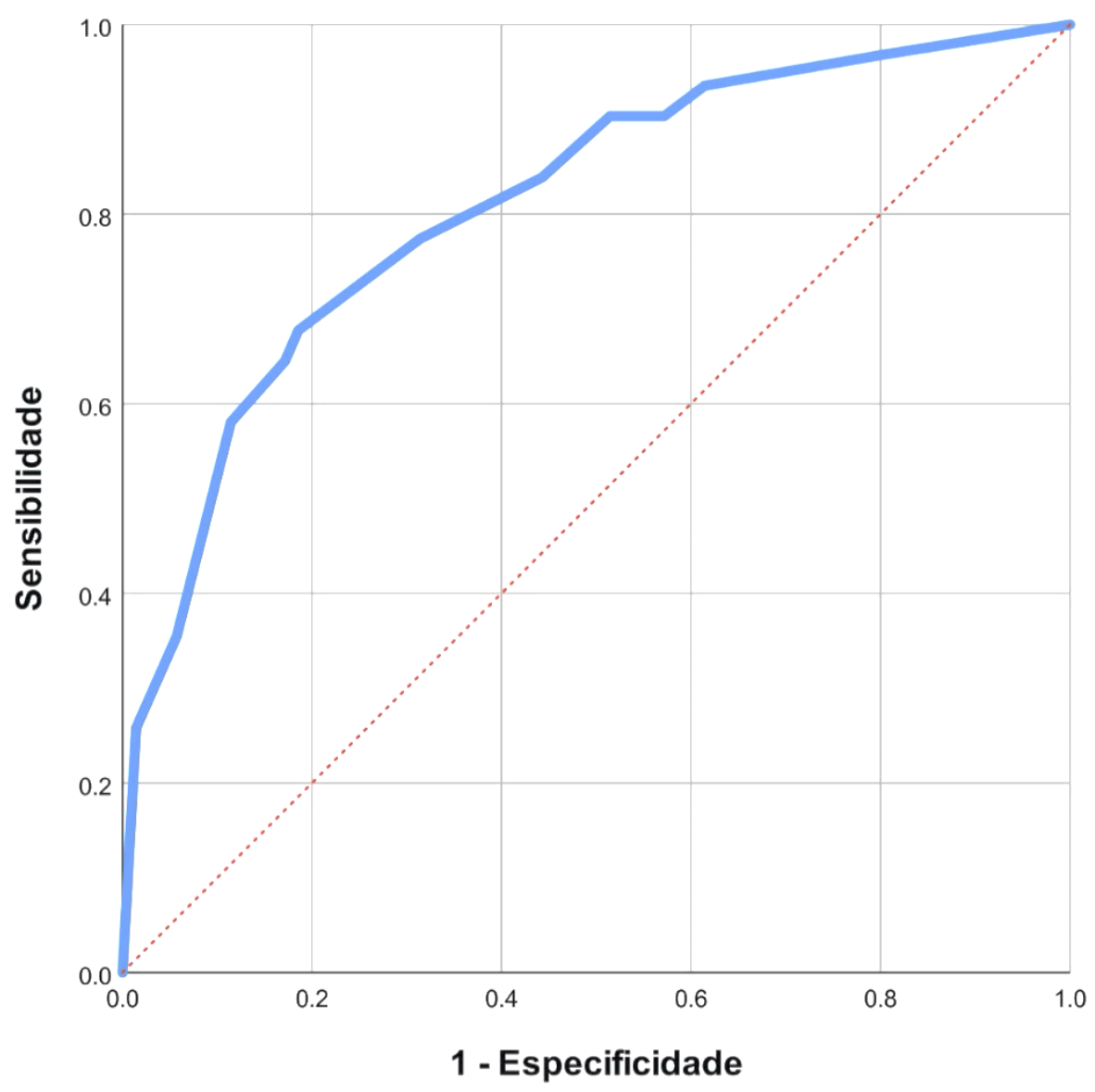

AUC $=0,810($ IC95\%0,716-0,903) p<0,001

AUC = área sob a curva; IC 95\% (intervalo de confiança de 95\%).

Figura 18 - Curva ROC dos valores preditos para o modelo de regressão logística ajustado para comprometimento linfonodal adicional não-sentinela. 
6. DISCUSSÃO 
O que fazer quando o resultado da BLS for positiva? Foi esta pergunta que motivou a escolha do tema da pesquisa realizada. Alguns pontos justificam a reflexão: o LS costuma ser o único comprometido em até $70 \%$ das vezes, as recorrências axilares após BLS são menos frequentes do que o esperado, considerando-se sua taxa de falso-negativo, a indicação da quimioterapia adjuvante geralmente não requer a análise dos outros LNs, e a omissão da DLAC após LS positivo tem se mostrado segura em várias publicações ${ }^{101-104}$.

A BLS diminui a morbidade e protege a qualidade de vida das pacientes operadas de CM. É tentadora a ideia de se evitar a dissecção inclusive quando o LS estiver positivo, pois tradicionalmente se preconiza a linfadenectomia axilar. Porém, por outro lado é preocupante que fiquem remanescentes focos de células neoplásicas em estruturas linfonodais, que possam conter células-tronco de câncer, com possibilidade de resistência à terapêutica sistêmica e de representar fontes para metastatização. Parece lógico que a DLAC possa deixar de ser executada, sem repercussão oncológica negativa em certos casos selecionados, ou ainda que a complementação de tratamento axilar possa ser eficientemente feita por radioterapia. O fato é que não se sabe com exatidão quais seriam estes casos.

Nessa casuística o método radioguiado foi empregado, não requerendo visualização direta do LS, sendo a ressecção orientada por sinal sonoro. A análise do LS no intraoperatório foi realizada inicialmente por metodologia citológica, com alta taxa de sucesso diante da experiência dos patologistas envolvidos e os cortes histológicos por congelação foram utilizados em casos que necessitavam de maior segurança na interpretação (carcinoma lobulares, neoplasias bem diferenciadas ou LNs com macroscopia suspeita). A análise 
anatomopatológica definitiva foi minuciosa, com cortes aprofundados para identificar tanto as macrometástases, quanto as micrometástases, importantes para o balizamento da terapia sistêmica adjuvante.

Os achados mais relevantes foram obtidos pela análise multivariada. $\mathrm{O}$ tamanho tumoral ao exame clínico maior que $2,0 \mathrm{~cm}$ aumentou a chance de CLA não-sentinela em 9,2 vezes; assim como a presença de dois ou mais focos neoplásicos nos LSs/LPSs que aumentaram a chance de metástases em LN-S em 4,1 vezes; e por fim a maior metástase superior a 4,0 $\mathrm{mm}$ aumenta a chance de CLA em 15,4 vezes. Quando essas variáveis foram identificadas em conjunto foi possível predizer a presença de comprometimento dos LN-S com uma acurácia de 81,0\% ( $p<0,001)$.

Achados secundários foram resultantes das análises univariadas e existe uma correlação entre CLA não-sentinela ao considerarmos: tamanho tumoral ao exame anatomopatológico, grau histológico III, embolização vascular peritumoral presente em área focal, mais de um LS/LPS comprometido, taxa de comprometimento linfonodal entre LSs/LPSs de $100 \%$, presença da extensão neoplásica extracapsular, acometimento da gordura perilinfonodal, assim como envolvimento vascular perilinfonodal e número de LN-S dissecados $\geq$ a 20 .

Motivados pelos mesmos objetivos dessa pesquisa, diversos autores enfocaram a questão, e os principais estudos a respeito são comentados a seguir.

Fougo et al. analisaram uma amostra consecutiva de 143 pacientes e identificaram o risco aumentado de metástases em LN-S na ocorrência de tumores T2 e T3, multifocalidade ou invasão linfovascular66. 
Barranger et al. demonstraram por análise univariada a associação significativa entre o envolvimento dos LN-S e o tamanho histológico do tumor primário ( $p=0,0001)$, a presença de macrometástases no LS ( $p=0,01)$, o método usado para detecção da metástase linfonodal (hematoxilina-eosina versus imunoistoquímica; $p=0,03$ ), o número de LSs positivos ( $p=0,049)$, a proporção entre os LSs comprometidos e todos os LSs identificados ( $p=$ $0,0001)$ e a invasão linfovascular peritumoral $(p=0,006)$. O tamanho tumoral $(p$ $=0,006)$, a presença de macrometástases $(p=0,02)$ e a proporção entre os LSs envolvidos pela neoplasia e todos os LSs identificados $(p=0,03)$ permaneceram significativamente associados ao status dos $\mathrm{LN}-\mathrm{S}$ na análise multivariada ${ }^{67}$.

Em estudo com 201 pacientes com LS positivo para malignidade e DLAC, Goyal et al. apontaram que o tamanho tumoral e o grau histológico aumentaram significativamente a frequência de LN-S comprometidos na análise univariada. O aumento da carga tumoral nos LSs (determinado pelo número de LSs acometidos pela neoplasia) foi significativamente associado ao aumento da probabilidade de CLA na análise multivariada. Um subgrupo foi submetido a exame histológico mais detalhado e a análise multivariada revelou que o tamanho da metástase do LS é o mais importante fator preditor do envolvimento de LN-S 68 .

Pesquisa prospectiva com 126 pacientes foi realizada por Friedman et al. para avaliar os fatores preditores de CLA em casos de micrometástases no LS. Observou-se na análise univariada que o tamanho do tumor primário $(p=$ 0,05), o grau histológico ( $p=0,008)$, a invasão linfovascular $(p=0,001)$ e o número de mitoses por $\mathrm{mm}^{2}(p=0,01)$ foram significativamente associados ao 
status dos LN-S. Por análise de regressão logística, o tamanho do tumor ( $p=$ $0,03)$, a invasão linfovascular $(p=0,001)$, o grau histológico $(p=0,003)$ e o número de mitoses por $\mathrm{mm}^{2}(\mathrm{p}=0,01)$ foram as únicas variáveis remanescentes no modelo. Três subconjuntos de pacientes foram identificados: 18,3\% dos pacientes (tumores com até 2,0 cm, grau histológico I e ausência de invasão linfovascular) não apresentavam metástase linfonodal adicional (grupo de baixo risco); $37,3 \%$ dos pacientes (número de mitoses por $\mathrm{mm}^{2}<10$, grau histológico de II a III) tiveram uma taxa inferior a 15\% de CLA (risco intermediário); $44,4 \%$ dos pacientes tiveram uma taxa média de metástases em LN-S de $46 \%$ (alto risco) ${ }^{69}$.

Ao avaliar 157 mulheres com CM e BLS positiva para malignidade, Chu et al. sugeriram que o tamanho da metástase no LS e o tamanho do tumor primário são fatores preditores significativos para CLA. A taxa de envolvimento dos LN-S foi de $7 \%$ quando o LS apresentava uma micrometástases e de $55 \%$ na presença da macrometástases ${ }^{70}$. Em outro estudo realizado pelo mesmo grupo e utilizando a mesma população foram reexaminados os LN-S através da imunoistoquímica. $\mathrm{O}$ uso da imunoistoquímica aumentou a probabilidade de detecção de metástase no LN-S e o risco de metástase detectada pela imunoistoquímica aumentou com o tamanho da metástase no LS e o tamanho do tumor primário ${ }^{71}$.

Abdessalam et al. investigaram 100 pacientes com LS positivo para neoplasia em carcinomas mamários infiltrativos iniciais e evidenciaram $40 \%$ de CLA. As variáveis preditivas do CLA foram invasão linfovascular peritumoral ( $p$ $=0,004)$, extensão extralinfonodal $(p<0,001)$ e aumento do tamanho da metástase no interior do LS $(p=0,011)^{72}$. 
Güven et al. sugeriram que a DLAC deveria ser considerada em pacientes com macrometástases superiores a $10,0 \mathrm{~mm}$, extensão extracapsular, relação entre o número de LSs metastáticos e o número de LSs dissecados superior a $50 \%$ e tumor primário maior que $2,0 \mathrm{~cm}^{73}$.

Metanálise de van la Parra et al. concluiu que os fatores preditores de metástases nos LN-S são: o método de detecção da metástase (hematoxilinaeosina), a presença de metástase em LS maior do que $2,0 \mathrm{~mm}$, a extensão extracapsular da metástase no LS, mais que um LS positivo para malignidade, 1 ou nenhum LS negativo para neoplasia, a taxa de positividade dos LSs superior a $50 \%$, o tamanho do tumor primário superior a $2,0 \mathrm{~cm}$ e a invasão linfovascular tumoral ${ }^{74}$.

Um grupo de 190 pacientes com carcinoma mamário invasivo e BLS positiva para neoplasia foi estudado por Asaga et al., sendo 47 casos tumores múltiplos e 143 casos lesão única. Os fatores preditores para metástase linfonodal adicional nos tumores únicos foram a invasão linfática peritumoral e a presença de macrometástase no LS e nos tumores múltiplos foi o tamanho tumoral ao exame anatomopatológico superior a $2,0 \mathrm{~cm}^{75}$.

Rivers et al. estimaram os fatores preditores de metástases em quatro ou mais LNs acometidos pela neoplasia, após a BLS positiva para malignidade. Foram relevantes tamanho do tumor superior a 2,0 cm, invasão linfovascular peritumoral, aumento da proporção entre o número de LSs positivos pelo número total de LSs dissecados, extensão neoplásica extralinfonodal e o tamanho da metástase no LS (principalmente macrometástases) ${ }^{76}$.

Em pesquisa englobando 541 pacientes, Bolster et al. identificaram três fatores preditores de metástases em LN-S: tamanho da metástase no LS ( $p=$ 
$0,02)$, tamanho do tumor primário $(p=0,01)$ e invasão vascular $(p=0,07)$. O odds ratio (OR) ajustado foi de 3,1 para a presença de micrometástases no LS comparado com a ocorrência de células tumorais isoladas, de 4,0 para macrometástases versus células tumorais isoladas no LS, de 3,1 para o tamanho tumoral $(>3,0 \mathrm{~cm}$ comparado $a \leq 3,0 \mathrm{~cm})$ e de 2,0 para a presença de invasão linfovascular ${ }^{77}$.

Maimaitiaili et al. ao analisarem 296 pacientes com metástases em LS e que foram submetidos à DLAC, confirmaram o CLA em 95 pacientes $(32,1 \%)$. $\mathrm{Na}$ análise univariada, a presença de três ou mais LSs positivos para metástases ( $p<0,01)$, a ocorrência de macrometástases no LS $(p=0,023)$ e a invasão linfovascular $(p=0,04)$ foram os fatores associados ao comprometimento dos LN-S. Na análise multivariada, o número de LSs positivos foi o preditor independente para $\mathrm{CLA}^{78}$.

Casuística de Illyes et al. envolvendo 75 pacientes com LS positivo para malignidade demonstraram que nos casos de metástases nos LSs maiores que $6,0 \mathrm{~mm}, 7,0 \mathrm{~mm}$ e $8,0 \mathrm{~mm}$, a prevalência de envolvimento dos LN$S$ foi significativamente maior $(p=0,046,0,022$ e 0,025). O índice mitótico $\geq 7$ ( $p$ $<0,001)$ e o tamanho do tumor primário acima de 26,0 mm $(\mathrm{p}<0,001)$ também foram determinantes para o envolvimento adicional dos $\mathrm{LN}-\mathrm{S}^{79}$.

Dados publicados por Viale et al. apontaram que a prevalência de metástases adicionais ocorreu em 39,4\% dos casos com LS positivo. Observou-se um acometimento adicional de $14,7 \%$ nos casos de LS contendo células tumorais isoladas, de $21,4 \%$ na presença de micrometástases e de $50,3 \%$ em pacientes com macrometástases. Quando os pacientes com 
micrometástases foram estratificados em grupos com extensão tumoral menor que $1,0 \mathrm{~mm}$ versus 1,0 a $2,0 \mathrm{~mm}$, a prevalência CLA foi de $17 \%$ para $30,2 \%{ }^{80}$.

Foschini et al. concluíram que existe impacto prognóstico em relação ao status axilar com o aumento linear do tamanho das macrometástases observadas em LS e que o risco de doença axilar residual é baixo nas pacientes com tumores até $2,0 \mathrm{~cm}$, quando a metástase linfonodal for menor que $7,0 \mathrm{~mm}^{81}$.

A metanálise de Nottegar et al. ${ }^{82}$ demonstrou que a extensão extracapsular da metástase no LS é um fator de pior prognóstico do carcinoma mamário invasivo e está associado ao comprometimento de LN-S, achado evidenciado por Stitzenberg et al..$^{83}$.

Pesquisa de Orsaria et al. identificaram que a taxa de comprometimento dos LSs (razão entre o número de LSs comprometidos e o número de LSs dissecados) e o subtipo luminal por analogia a imunoistoquímica foram os parâmetros preditores de CLA ${ }^{84}$.

Análise multivariada realizada Changsri et al. em 131 pacientes com LS positivo para malignidade e DLAC, determinou duas variáveis independentes para a predição de doença residual na axila: o tamanho da metástase no LS e a presença de extensão extralinfonodal ${ }^{62}$.

Um estudo com 1114 pacientes foi realizado por Mamtani et al. para avaliar a importância de depósitos tumorais extralinfonodais (êmbolos tumorais intravasculares ou envolvimento metastático da gordura axilar). Cento e treze pacientes (10\%) apresentavam depósitos tumorais extralinfonodais, sendo em $72 \%$ dos casos êmbolos tumorais intravasculares e em $28 \%$ dos pacientes a ocorrência de depósitos neoplásicos na gordura adjacente. Esses pacientes apresentavam tumores maiores (mediana de 2,2 versus $2,1 \mathrm{~cm} ; \mathrm{p}=0,033$ ) e 
mais frequentemente extensão neoplásica extracapsular (83\% versus 44\%; $p<$ 0,001). Na análise univariada, a presença de depósitos tumorais extralinfonodais (OR = 9,66; IC 95\%: 6,36-14,68), tumores maiores $(\mathrm{OR}=1,47$; IC 95\%: 1,25-1,72) e extensão neoplásica extracapsular (OR = 10,73; IC 95\%: $6,86-16,78)$ foram associados a quatro ou mais LN-S positivos $(p<0,001)$. Os depósitos tumorais extralinfonodais permaneceram significativamente associados a quatro ou mais LN-S positivos (OR = 5,67; IC 95\%: 3,53-9,08; $p$ $<0,001)$ em análise multivariada, principalmente entre os pacientes com um a dois LSs positivos (OR = 7,15; IC 95\%: 4,04-12,67). Os autores concluíram que deve se favorecer a DLAC quando existem depósitos tumorais extralinfonodais ${ }^{105}$.

A omissão da dissecção axilar complementar, evita uma reabordagem cirúrgica e apresenta vantagens decorrentes da redução da extensão do procedimento: menor morbidade, menos chance de linfedema e de erisipela no braço, melhor mobilidade do ombro, menos parestesia local e preservação de mecanismos de imunocompetência dependentes de $\mathrm{LNs}^{93,106-108}$.

No estudo clínico britânico ALMANAC foram cotejadas 515 pacientes com BLS e 516 com DLAC. Decorridos 12 meses, nas pacientes tratadas com BLS a frequência de algum grau de linfedema foi de $5 \%$ e de parestesias no braço de $11 \%$, ao passo que no grupo da DLAC os índices foram $13 \%$ e $31 \%$, respectivamente ${ }^{106}$.

A síndrome da cauda axilar com aderências locais causando dor e limitação na abdução do ombro é relativamente frequente após DLAC. Sua incidência é 3-4 vezes menor após cirurgia de BLS. A despeito das vantagens, a BLS não é totalmente isenta das complicações citadas. Estas podem existir, 
mas em menor frequência e intensidade, e tendem a desaparecer dentro de 612 meses $^{109}$.

Certamente existem muitas pacientes com BLS positiva que não necessitam de linfadenectomia axilar complementar; assim como outras para as quais a DLAC ou a RTA sejam necessárias; só que com os dados disponíveis até agora, a escolha é imprecisa. Pode ser, inclusive, que a própria BLS seja supérflua em determinadas situações.

Tanto no estudo ACOSOG Z0011, quanto no AMAROS, ocorreram problemas para se atingir o tamanho amostral calculado e os estudos se encerraram antes do tempo. Isso resultou em poder estatístico baixo e conclusões sem fortes evidências. Sem pretensão dogmática, os achados de ambos os estudos devem ser encarados como preliminares. Parecem ser válidos para pacientes com baixo risco de comprometimento de outros LNs e que recebem tratamento sistêmico adjuvante e radioterapia na mama, contudo, estes achados não foram conclusivos para mulheres com risco maior de envolvimento de outros LNs. Não dá para se ter confiança de que um eventual excesso de recorrências regionais não venha a ocorrer, e que estas recorrências não possam ter importância prognóstica.

Experimentalmente, em camundongos, foi demonstrado que os LNs são também focos de metastatização, não só a partir do fluxo linfático eferente, como é clássico, mas por vasos sanguíneos dentro do próprio $\mathrm{LN}^{41,42}$.

Os resultados verificados em nossa pesquisa, em conjunto com os dados da literatura consubstanciaram parâmetros auxiliares na decisão de se remover ou não os demais LNs axilares quando o LS estiver comprometido. 
São pontos fortes deste trabalho: todos os casos foram tratados pelo mesmo cirurgião, a técnica da BLS e a metodologia de análise anatomopatológica foram homogêneas, as revisões anatomopatológicas foram realizadas por dois patologistas com expertise em patologia mamária, e foi possível estabelecer um cut off para o tamanho da maior metástase de 4,0 mm que aumenta em 15 vezes a chance de envolvimento LN-S, diferente dos demais estudos encontrados na literatura que variam de 7,0 a $10,0 \mathrm{~mm}$, ou que não escalonaram o tamanho da metástase.

As limitações da pesquisa foram relacionadas principalmente a qualidade do material anatomopatológico revisado e às características retrospectivas do estudo empregado. A revisão foi realizada com as análises de novos cortes dos blocos de parafina armazenados, no entanto em alguns casos não foram identificadas lesões residuais no processamento do material. Por se tratar de um estudo retrospectivo, não foi possível parear os grupos com e sem CLA para a análise dos resultados.

Concluímos que é importante se prosseguir com a dissecção dos LNs regionais quando o tumor na mama for maior que $2,0 \mathrm{~cm}$, quando houver dois ou mais focos neoplásicos (juntos ou separados) e quando a maior metástase linfonodal medir mais que 4,0 mm.

Lembrando palavras do filósofo positivista francês Auguste Comte (17981857) "restará sempre muito para se fazer", são necessárias pesquisas prospectivas e randomizadas, para a comparação dos desfechos oncológicos entre os grupos com e sem DLAC, permitindo a identificação dos casos em que complementação cirúrgica poderá ser omitida, visto que os temas da segurança 
oncológica na conduta observadora ou o uso indiscriminado da RTA quando o LS for positivo persistem sem conclusão definitiva. 
7. CONCLUSÕES 
A análise dos resultados de nossa casuística permitiu as seguintes conclusões:

1) A taxa de comprometimento de outros LN-S nesse estudo foi de $36,4 \%$.

2) As características anatomopatológicas das metástases em LSs e LPSs associadas ao acometimento dos demais LN-S são: mais de um LS ou LPS comprometido, taxa de comprometimento linfonodal entre os LSs/LPSs de $100 \%$, dois ou mais focos neoplásicos nos LSs/LPSs, maior metástase superior a $4,0 \mathrm{~mm}$, área do linfonodo ocupada pela neoplasia de $50 \%$, presença de extensão extracapsular, acometimento da gordura perilinfonodal, comprometimento vascular perilinfonodal e dissecção de 20 ou mais LN-S.

3) As características anatomopatológicas do tumor primário associadas ao acometimento linfonodal dos LN-S são: tamanho tumoral ao exame clínico na categoria cT2, tamanho tumoral ao exame anatomopatológico, grau histológico III e presença de embolização vascular peritumoral em área focal.

4) As variáveis preditivas de CLA, através de modelo de regressão logística foram: tamanho tumoral ao exame clínico na categoria cT2, a presença de dois ou mais focos neoplásicos nos LSs/LPSs e a maior metástase superior a $4,0 \mathrm{~mm}$. 
8. REFERÊNCIAS 
1. Siegel RL, Miller KD, Jemal A. Cancer statistics, 2020. CA Cancer J Clin. 2020;70(1):7-30.

2. Instituto Nacional de Câncer José Alencar Gomes da Silva. Estimativa 2020: incidência de câncer no Brasi//Instituto Nacional de Câncer José Alencar Gomes da Silva. Rio de Janeiro: INCA; 2019. Disponível em: https://www.inca.gov.br/sites/ufu.sti.inca.local/files//media/document/lestima tiva-2020-incidencia-de-cancer-no-brasil.pdf. Acessado em 2020 (4 out).

3. Halsted WS. I. The results of operations for the cure of cancer of the breast performed at the Johns Hopkins Hospital from June, 1889, to January, 1894. Ann Surg. 1894;20(5):497-555.

4. Kell MR. Breast cancer: from Halsted to Harney. Ir J Med Sci. 2015;184(1):77-80.

5. Mustakallio S. Conservative treatment of breast carcinoma-review of 25 years follow up. Clin Radiol. 1972;23(1):110-6.

6. Hayward JL. The Guy's trial of treatments of "early" breast cancer. World J Surg. 1977;1(3):314-6.

7. Veronesi U, Cascinelli N, Mariani L, Greco M, Saccozzi R, Luini A, et al. Twenty-year follow-up of a randomized study comparing breastconserving surgery with radical mastectomy for early breast cancer. $N$ Engl J Med. 2002;347(16):1227-32.

8. Fisher B, Anderson S, Bryant J, Margolese RG, Deutsch M, Fisher ER, et al. Twenty-year follow-up of a randomized trial comparing total mastectomy, lumpectomy, and lumpectomy plus irradiation for the treatment of invasive breast cancer. N Engl J Med. 2002;347(16):1233-41.

9. Ashikaga T, Krag DN, Land SR, Julian TB, Anderson SJ, Brown AM, et al. Morbidity results from the NSABP B-32 trial comparing sentinel lymph node dissection versus axillary dissection. $J$ surg Oncol. 2010;102(2):111-8.

10. Cabanas RM. An approach for the treatment of penile carcinoma. Cancer. 1977;39(2):456-66. 
11. Krag DN, Weaver DL, Alex JC, Fairbank JT. Surgical resection and radiolocalization of the sentinel lymph node in breast cancer using a gamma probe. Surg Oncol. 1993;2(6):335-9.

12. Giuliano AE, Kirgan DM, Guenther JM, Morton DL. Lymphatic mapping and sentinel lymphadenectomy for breast cancer. Ann Surg. 1994;220(3):391-8.

13. Van Zee KJ, Manasseh DM, Bevilacqua JLB, Boolbol SK, Fey JV, Tan LK, et al. A nomogram for predicting the likelihood of additional nodal metastases in breast cancer patients with a positive sentinel node biopsy. Ann Surg Oncol. 2003;10(10):1140-51.

14. Hwang RF, Krishnamurthy S, Hunt KK, Mirza N, Ames FC, Feig B, et al. Clinicopathologic factors predicting involvement of nonsentinel axillary nodes in women with breast cancer. Ann Surg Oncol. 2003;10(3):248-54.

15. Unal B, Gur AS, Kayiran O, Johnson R, Ahrendt G, Bonaventura M, et al. Models for predicting non-sentinel lymph node positivity in sentinel node positive breast cancer: the importance of scoring system. Int J Clin Pract. 2008;62(11):1785-91.

16. Kohrt HE, Olshen RA, Bermas HR, Goodson WH, Wood DJ, Henry S, et al. New models and online calculator for predicting non-sentinel lymph node status in sentinel lymph node positive breast cancer patients. BMC Cancer. 2008;8:66.

17. Bartels HS, Carvalho SMT, Osório CABT, Marinho VFZ, Soares FA, Gobbi H. Comparação de três modelos matemáticos para predição de metástases em linfonodos não sentinela em pacientes com câncer de mama e linfonodo sentinela positivo. Rev Bras Mastologia. $2011 ; 21(4): 161-8$.

18. Giuliano AE, Ballman KV, McCall L, Beitsch PD, Brennan MB, Kelemen $\mathrm{PR}$, et al. Effect of axillary dissection vs no axillary dissection on 10-year overall survival among women with invasive breast cancer and sentinel node metastasis: The ACOSOG Z0011 (Alliance) randomized clinical trial. JAMA. 2017;318(10):918-26. 
19. Giuliano AE, Hunt KK, Ballman KV, Beitsch PD, Whitworth PW, Blumencranz PW, et al. Axillary dissection vs no axillary dissection in women with invasive breast cancer and sentinel node metastasis: a randomized clinical trial. JAMA. 2011;305(6):569-75.

20. Donker M, van Tienhoven G, Straver ME, Meijnen P, van de Velde CJH, Mansel RE, et al. Radiotherapy or surgery of the axilla after a positive sentinel node in breast cancer (EORTC 10981-22023 AMAROS): a randomised, multicentre, open-label, phase 3 non-inferiority trial. Lancet Oncol. 2014;15(12):1303-10.

21. Sávolt Á, Péley G, Polgár C, Udvarhelyi N, Rubovsky G, Kovács E, et al. Eight-year follow up result of the OTOASOR trial: the optimal treatment of the axilla - surgery or radiotherapy after positive sentinel lymph node biopsy in early-stage breast cancer: a randomized, single centre, phase III, non-inferiority trial. Eur J Surg Oncol. 2017;43(4):672-9.

22. Giuliano AE, McCall L, Beitsch $P$, Whitworth $P W$, Blumencranz $P$, Leitch AM, et al. Locoregional recurrence after sentinel lymph node dissection with or without axillary dissection in patients with sentinel lymph node metastases: the American College of Surgeons Oncology Group Z0011 randomized trial. Ann Surg. 2010;252(3):426-32.

23. Giuliano AE, Ballman K, McCall L, Beitsch P, Whitworth PW, Blumencranz $\mathrm{P}$, et al. Locoregional recurrence after sentinel lymph node dissection with or without axillary dissection in patients with sentinel lymph node metastases: long-term follow-up from the American College of Surgeons Oncology Group (Alliance) ACOSOG Z0011 randomized trial. Ann Surg. 2016;264(3):413-20.

24. Goyal A, Dodwell D. POSNOC: A randomised trial looking at axillary treatment in women with one or two sentinel nodes with macrometastases. Clin Oncol (R Coll Radiol). 2015;27(12):692-5. 
25. Tinterri C, Canavese G, Bruzzi P, Dozin B. SINODAR ONE, an ongoing randomized clinical trial to assess the role of axillary surgery in breast cancer patients with one or two macrometastatic sentinel nodes. Breast. 2016;30:197-200.

26. van Roozendaal $L M$, de Wilt JHW, van Dalen $T$, van der Hage JA, Strobbe LJA, Boersma LJ, et al. The value of completion axillary treatment in sentinel node positive breast cancer patients undergoing a mastectomy: a Dutch randomized controlled multicentre trial (BOOG 2013-07). BMC Cancer. 2015;15:610.

27. de Boniface J, Frisell J, Andersson Y, Bergkvist L, Ahlgren J, Rudén L, et al. Survival and axillary recurrence following sentinel node-positive breast cancer without completion axillary lymph node dissection: the randomized controlled SENOMAC trial. BMC Cancer. 2017;17(1):379.

28. Houvenaeghel G, Resbeut M, Boher JM. Sentinel node invasion: is it necessary to perform axillary lymph node dissection? Randomized trial SERC. Bull Cancer. 2014;101(4):358-63.

29. Clinical Trials. A prospective randomized multicenter phase III study of axillary lymph node dissection versus no dissection in breast cancer with positive sentinel lymph node - the validation of Z0011 in China. Disponível em: https://clinicaltrials.gov/ct2/show/study/NCT01796444. Acessado em 2020 (4 out).

30. Reimer T, Hartmann S, Stachs A, Gerber B. Local treatment of the axilla in early breast cancer: concepts from the national surgical adjuvant breast and bowel project B-04 to the planned intergroup sentinel mamma trial. Breast Care (Basel). 2014;9(2):87-95.

31. Gentilini O, Veronesi U. Abandoning sentinel lymph node biopsy in early breast cancer? A new trial in progress at the European Institute of Oncology of Milan (SOUND: Sentinel node vs Observation after axillary UltraSouND). Breast. 2012;21(5):678-81.. 
32. Rojas K, Stuckey A. Breast cancer epidemiology and risk factors. Clin Obstet Gynecol. 2016;59(4):651-72.

33. Handley WS. On the mode of spread of breast cancer in relation to its operative treatment. Glasgow Med J. 1905;64(6):401-13.

34. Fisher ER, Fisher B. Relationship of pathologic and some clinical discriminants to the spread of breast cancer. Int $J$ Radiat Oncol Biol Phys. 1977;2(7-8):747-50.

35. Tubiana M, Koscielny S. Natural history of human breast cancer: recent data and clinical implications. Breast Cancer Res Treat. 1991;18(3):125-40.

36. Scallan JP, Zawieja SD, Castorena-Gonzalez JA, Davis MJ. Lymphatic pumping: mechanics, mechanisms and malfunction. $J$ Physiol. 2016;594(20):5749-68.

37. Tanis PJ, Nieweg OE, Valdés Olmos RA, Kroon BB. Anatomy and physiology of lymphatic drainage of the breast from the perspective of sentinel node biopsy. J Am Coll Surg. 2001;192(3):399-409.

38. Turner-Warwick RT. The lymphatics of the breast. $\mathrm{Br} J$ Surg. 1959;46:574-82.

39. Cuadrado GA, Andrade MFC, Jacomo AL. Anatomia do sistema linfático dos membros superiores. In: Brito CJ. Cirurgia Vascular: Cirurgia Endovascular - Angiologia. $4^{a}$ ed. Rio de Janeiro: Thieme Revinter Publicações; 2020. p. 1287-90.

40. Cuadrado GA, Andrade MFC, Akamatsu FE, Jacomo AL. Lymph drainage of the upper limb and mammary region to the axilla: anatomical study in stillborns. Breast Cancer Res Treat. 2018;169(2):251-6.

41. Pereira ER, Kedrin D, Seano G, Gautier O, Meijer EFJ, Jones D, et al. Lymph node metastases can invade local blood vessels, exit the node, and colonize distant organs in mice. Science. 2018;359(6382):1403-7.

42. Brown M, Assen FP, Leithner A, Abe J, Schachner H, Asfour G, et al. Lymph node blood vessels provide exit routes for metastatic tumor cell dissemination in mice. Science. 2018;359(6382):1408-11. 
43. Apud: Breasted JH. The Edwin Smith surgical papyrus. Chicago: University of Chicago Press; 1930.

44. Apud: Sakorafas GH. Breast cancer surgery-historical evolution, current status and future perspectives. Acta Oncol. 2001;40(1):5-18.

45. Apud: Hippocrates. Loeb classical library, vol I-VIII. Harvard: Harvard University Press; 1995.

46. Apud: Moulin D. A short history of breast cancer. Boston: Martinus Nijhoff Publishers; 1983.

47. Apud: Wagner FB. History of breast disease and its treatment. In: Bland KI, Copeland EM, eds. The breast. Philadelphia: WB Saunders Company; 1991. p. 1-16.

48. Apud: Robinson JO. Treatment of breast cancer through the ages. Am J Surg. 1986;151(3):317-33.

49. Apud: Meade RH. An introduction to the history of general surgery. Philadelphia: WB Saunders; 1968.

50. Apud: Kardinal CG, Yarbro JW. A conceptual history of cancer. Semin Oncol. 1979;6(4):396-408.

51. Apud: Roses DF. Development of modern breast cancer treatment. In: Roses DF, ed. Breast cancer. New York: Churchill Livingstone, 1999. p. 289-308.

52. Halsted WS. I. The results of radical operations for the cure of carcinoma of the breast. Ann Surg. 1907;46(1):1-19.

53. Lewis D, Rienhoff WF. Results of operations at the Johns Hopkins Hospital for cancer of the breast: Performed at the Johns Hopkins Hospital from 1889 to 1931. Ann Surg. 1932;95(3):336-400.

54. Gould EA, Winship T, Philbin PH, Kerr HH. Observations on a "sentinel node" in cancer of the parotid. Cancer. 1960;13:77-8.

55. Kett K, Varga G, Lukács L. Direct lymphography of the breast. Lymphology. 1970;3(1):2-12. 
56. Morton DL, Wen DR, Wong JH, Economou JS, Cagle LA, Storm FK, et al. Technical details of intraoperative lymphatic mapping for early stage melanoma. Arch Surg. 1992;127(4):392-9.

57. Veronesi U, Paganelli G, Viale G, Luini A, Zurrida S, Galimberti V, et al. A randomized comparison of sentinel-node biopsy with routine axillary dissection in breast cancer. N Engl J Med. 2003;349(6):546-53.

58. Veronesi U, Viale G, Paganelli G, Zurrida S, Luini A, Galimberti V, et al. Sentinel lymph node biopsy in breast cancer: ten-year results of a randomized controlled study. Ann Surg. 2010;251(4):595-600.

59. Krag DN, Anderson SJ, Julian TB, Brown AM, Harlow SP, Costantino JP, et al. Sentinel-lymph-node resection compared with conventional axillarylymph-node dissection in clinically node-negative patients with breast cancer: overall survival findings from the NSABP B-32 randomised phase 3 trial. Lancet Oncol. 2010;11(10):927-33.

60. Barros A, Cardoso MA, Sheng PY, Costa PA, Pelizon C. Radioguided localisation of non-palpable breast lesions and simultaneous sentinel lymph node mapping. Eur J Nucl Med Mol Imaging. 2002;29(12):1561-5.

61. Barros ACD, Barros MAC, Andrade FE, Mori LJ, Costa PA, Sheng PY, et al. Combined radioguided nonpalpable lesion localization and sentinel lymph node biopsy for early breast carcinoma. Ann Surg Oncol. 2007;14(4):1472-7.

62. Changsri C, Prakash S, Sandweiss L, Bose S. Prediction of additional axillary metastasis of breast cancer following sentinel lymph node surgery. Breast J. 2004;10(5):392-7.

63. Huvos AG, Hutter RV, Berg JW. Significance of axillary macrometastases and micrometastases in mammary cancer. Ann Surg. 1971;173(1):44-6. 
64. Hortobagyi GN, Connolly JL, D'Orsi CJ, Edge SB, Mittendorf EA, Rugo HS, et al. Breast. In: Amin MB, Edge SB, Greene FL, Byrd DR, Brookland RK, Washington MK, et al. AJCC Cancer Staging Manual. 8th edition. Philadelphia: Spring International Publishing; 2018.

65. Viale G, Mastropasqua MG, Maiorano E, Mazzarol G. Pathologic examination of the axillary sentinel lymph nodes in patients with earlystage breast carcinoma: current and resolving controversies on the basis of the European Institute of Oncology experience. Virchows Arch. 2006;448(3):241-7.

66. Fougo JL, Afonso M, Senhorães Senra F, Dias T, Leal C, Araújo C, et al. Predictive factors for non-sentinel lymph node involvement in breast cancer patients with a positive sentinel node: should we consider sentinel node-related factors? Clin Trans/ Oncol. 2009;11(3):165-71.

67. Barranger E, Coutant C, Flahault A, Delpech Y, Darai E, Uzan S. An axilla scoring system to predict non-sentinel lymph node status in breast cancer patients with sentinel lymph node involvement. Breast Cancer Res Treat. 2005;91(2):113-9.

68. Goyal A, Douglas-Jones A, Newcombe RG, Mansel RE, ALMANAC Trialists Group. Predictors of non-sentinel lymph node metastasis in breast cancer patients. Eur J Cancer. 2004;40(11):1731-7.

69. Friedman D, Gipponi M, Murelli F, Meszaros P, Solari N, Massa M, et al. Predictive factors of non-sentinel lymph node involvement in patients with invasive breast cancer and sentinel node micrometastases. Anticancer Res. 2013;33(10):4509-14.

70. Chu KU, Turner RR, Hansen NM, Brennan MB, Bilchik A, Giuliano AE. Do all patients with sentinel node metastasis from breast carcinoma need complete axillary node dissection? Ann Surg. 1999;229(4):536-41. 
71. Chu KU, Turner RR, Hansen NM, Brennan MB, Giuliano AE. Sentinel node metastasis in patients with breast carcinoma accurately predicts immunohistochemically detectable nonsentinel node metastasis. Ann Surg Oncol. 1999;6(8):756-61.

72. Abdessalam SF, Zervos EE, Prasad M, Farrar WB, Yee LD, Walker MJ, et al. Predictors of positive axillary lymph nodes after sentinel lymph node biopsy in breast cancer. Am J Surg. 2001;182(4):316-20.

73. Güven HE, Doğan L, Kültüroğlu MO, Gülçelik MA, Özaslan C. Factors influencing non-sentinel node metastasis in patients with macrometastatic sentinel lymph node involvement and validation of three commonly used nomograms. Eur J Breast Health. 2017;13(4):189-93.

74. van la Parra RFD, Peer PGM, Ernst MF, Bosscha K. Meta-analysis of predictive factors for non-sentinel lymph node metastases in breast cancer patients with a positive SLN. Eur J Surg Oncol. 2011;37(4):290-9.

75. Asaga S, Kinoshita T, Hojo T, Jimbo K, Yoshida M. Predictive factors for non-sentinel lymph node metastasis in patients with clinically nodenegative ipsilateral multiple breast cancer treated with total mastectomy. Clin Breast Cancer. 2015;15(5):362-9.

76. Rivers AK, Griffith KA, Hunt KK, Degnim AC, Sabel MS, Diehl KM, et al. Clinicopathologic features associated with having four or more metastatic axillary nodes in breast cancer patients with a positive sentinel lymph node. Ann Surg Oncol. 2006;13(1):36-44.

77. Bolster MJ, Peer PGM, Bult P, Thunnissen FBJM, Schapers RFM, Meijer JWR, et al. Risk factors for non-sentinel lymph node metastases in patients with breast cancer. The outcome of a multi-institutional study. Ann Surg Oncol. 2007;14(1):181-9.

78. Maimaitiaili A, Wu D, Liu Z, Liu H, Muyiduli X, Fan Z. Analysis of factors related to non-sentinel lymph node metastasis in 296 sentinel lymph node-positive Chinese breast cancer patients. Cancer Biol Med. 2018;15(3):282-9. 
79. Illyes I, Tokes AM, Kovacs A, Szasz AM, Molnar BA, Molnar IA, et al. In breast cancer patients sentinel lymph node metastasis characteristics predict further axillary involvement. Virchows Arch. 2014;465(1):15-24.

80. Viale G, Maiorano E, Pruneri G, Mastropasqua MG, Valentini S, Galimberti V, et al. Predicting the risk for additional axillary metastases in patients with breast carcinoma and positive sentinel lymph node biopsy. Ann Surg. 2005;241(2):319-25.

81. Foschini MP, Miglio R, Quinn C, Belgio B, Regitnig P, Bianchi S, et al. Prognostic impact of macrometastasis linear size in sentinel node biopsy for breast carcinoma. Eur J Surg Oncol. 2017;43(8):1421-7.

82. Nottegar A, Veronese N, Senthil M, Roumen RM, Stubbs B, Choi AH, et al. Extra-nodal extension of sentinel lymph node metastasis is a marker of poor prognosis in breast cancer patients: a systematic review and an exploratory meta-analysis. Eur J Surg Oncol. 2016;42(7):919-25.

83. Stitzenberg KB, Meyer AA, Stern SL, Cance WG, Calvo BF, Klauber-DeMore $\mathrm{N}$, et al. Extracapsular extension of the sentinel lymph node metastasis: a predictor of nonsentinel node tumor burden. Ann Surg. 2003;237(5):607-12; discussion 612-3.

84. Orsaria P, Caredda E, Genova F, Materazzo M, Capuano I, Vanni G, et al. Additional nodal disease prediction in breast cancer with sentinel lymph node metastasis based on clinicopathological features. Anticancer Res. 2018;38(4):2109-17.

85. van den Hoven I, Kuijt GP, Voogd AC, van Beek MWPM, Roumen RMH. Value of Memorial Sloan-Kettering Cancer Center nomogram in clinical decision making for sentinel lymph node-positive breast cancer. $\mathrm{Br} J$ Surg. 2010;97(11):1653-8.

86. Scow JS, Degnim AC, Hoskin TL, Reynolds C, Boughey JC. Assessment of the performance of the Stanford Online Calculator for the prediction of nonsentinel lymph node metastasis in sentinel lymph node-positive breast cancer patients. Cancer. 2009;115(18):4064-70. 
87. Galimberti V, Cole BF, Zurrida S, Viale G, Luini A, Veronesi P, et al. Axillary dissection versus no axillary dissection in patients with sentinelnode micrometastases (IBCSG 23-01): a phase 3 randomised controlled trial. Lancet Oncol. 2013;14(4):297-305.

88. Lyman GH, Temin S, Edge SB, Newman LA, Turner RR, Weaver DL, et al. Sentinel lymph node biopsy for patients with early-stage breast cancer: American Society of Clinical Oncology clinical practice guideline update. J Clin Oncol. 2014;32(13):1365-83.

89. Lyman GH, Somerfield MR, Bosserman LD, Perkins CL, Weaver DL, Giuliano AE. Sentinel lymph node biopsy for patients with early-stage breast cancer: American Society of Clinical Oncology clinical practice guideline update. J Clin Oncol. 2017;35(5):561-4.

90. Morrow M, Van Zee KJ, Patil S, Petruolo O, Mamtani A, Barrio AV, et al. Axillary dissection and nodal irradiation can be avoided for most nodepositive Z0011-eligible breast cancers: a prospective validation study of 793 patients. Ann Surg. 2017;266(3):457-62.

91. Robertson JFR, Herrod PJJ, Matthew J, Kilburn LS, Coles CE, Bradbury I. Treatment of the axilla in patients with primary breast cancer and low burden axillary disease: Limitations of the evidence from randomised controlled trials. Crit Rev Oncol Hematol. 2017;110:74-80.

92. DiSipio T, Rye S, Newman B, Hayes S. Incidence of unilateral arm lymphoedema after breast cancer: a systematic review and metaanalysis. Lancet Oncol. 2013;14(6):500-15.

93. Nguyen TT, Hoskin TL, Habermann EB, Cheville AL, Boughey JC. Breast cancer-related lymphedema risk is related to multidisciplinary treatment and not surgery alone: results from a large cohort study. Ann Surg Oncol. 2017;24(10):2972-80. 
94. Fleissig A, Fallowfield LJ, Langridge CI, Johnson L, Newcombe RG, Dixon JM, et al. Post-operative arm morbidity and quality of life. Results of the ALMANAC randomised trial comparing sentinel node biopsy with standard axillary treatment in the management of patients with early breast cancer. Breast Cancer Res Treat. 2006;95(3):279-93.

95. Öz B, Akcan A, Doğan S, Abdulrezzak Ü, Aslan D, Sözüer E, et al. Prediction of nonsentinel lymph node metastasis in breast cancer patients with one or two positive sentinel lymph nodes. Asian J Surg. 2018;41(1):12-9.

96. Santos GEO. Cálculo amostral: calculadora on-line. Disponível em http://www.calculoamostral.vai.la. Acessado em 2020 (20 out.)

97. Lakhani SR, Elis IO, Schnitt SJ, Tan PH, van de Vijver MJ. WHO classification of tumours of the breast. 5th ed. Lyon: International Agency for Research on Cancer; 2019.

98. Elston CW, Ellis IO. Pathological prognostic factors in breast cancer. I. The value of histological grade in breast cancer: experience from a large study with long-term follow-up. Histopathology. 1991;19(5):403-10

99. Hammond MEH, Hayes DF, Dowsett M, Allred DC, Hagerty KL, Badve S, et al. American Society of Clinical Oncology/College of American Pathologists guideline recommendations for immunohistochemical testing of estrogen and progesterone receptors in breast cancer. Arch Pathol Lab Med. 2010;134(6):907-22.

100. Wolff AC, Hammond MEH, Hicks DG, Dowsett M, McShane LM, Allison $\mathrm{KH}$, et al. Recommendations for human epidermal growth factor receptor 2 testing in breast cancer: American Society of Clinical Oncology/College of American Pathologists clinical practice guideline update. J Clin Oncol. 2013;31(31):3997-4013.

101. Reynolds C, Mick R, Donohue JH, Grant CS, Farley DR, Callans LS, et al. Sentinel lymph node biopsy with metastasis: can axillary dissection be avoided in some patients with breast cancer? J Clin Oncol. 1999;17(6):1720-6. 
102. Bilimoria KY, Bentrem DJ, Hansen NM, Bethke KP, Rademaker AW, Ko $\mathrm{CY}$, et al. Comparison of sentinel lymph node biopsy alone and completion axillary lymph node dissection for node-positive breast cancer. J Clin Oncol. 2009;27(18):2946-53.

103. Grube BJ, Giuliano AE. Observation of the breast cancer patient with a tumor-positive sentinel node: implications of the ACOSOG Z0011 trial. Semin Surg Oncol. 2001;20(3):230-7.

104. Park J, Fey JV, Naik AM, Borgen PI, Van Zee KJ, Cody 3rd HS. A declining rate of completion axillary dissection in sentinel lymph nodepositive breast cancer patients is associated with the use of a multivariate nomogram. Ann Surg. 2007;245(3):462-8.

105. Mamtani A, Barrio AV, Goldman DA, Wen HY, Vincent A, Morrow M. Extranodal tumor deposits in the axillary fat indicate the need for axillary dissection among T1-T2cN0 patients with positive sentinel nodes. Ann Surg Oncol. 2020;27(10):3585-92.

106. Mansel RE, Fallowfield L, Kissin M, Goyal A, Newcombe RG, Dixon JM, et al. Randomized multicenter trial of sentinel node biopsy versus standard axillary treatment in operable breast cancer: the ALMANAC Trial. J Natl Cancer Inst. 2006;98(9):599-609.

107. Camp RL, Rimm EB, Rimm DL. A high number of tumor free axillary lymph nodes from patients with lymph node negative breast carcinoma is associated with poor outcome. Cancer. 2000;88(1):108-13.

108. Favarão KU, Mantese JC, Barros ACSD. Shoulder mobility after axillary sentinel node biopsy for early infiltrating breast cancer treatment. Eur $J$ Gynaecol Oncol. 2010;31(1):23-6.

109. De Groef A, Van Kampen M, Tieto E, Schönweger, Christiaens MR, Neven $P$, et al. Arm lymphoedema and upper limb impairments in sentinel node-negative breast cancer patients: a one year follow-up study. Breast. 2016;29:102-8. 
9. ANEXO 
Anexo. Parecer consubstanciado do Comitê de Ética em Pesquisa.

\section{USP - FACULDADE DE MEDICINA DA UNIVERSIDADE DE SÃO PAULO - FMUSP}

\section{PARECER CONSUBSTANCIADO DO CEP}

\section{DADOS DO PROJETO DE PESQUISA}

Título da Pesquisa: VARIÁVEIS ANATOMOPATOLÓGICAS E MOLECULARES ASSOCIADAS AO ACOMETIMENTO DOS DEMAIS LINFONODOS REGIONAIS QUANDO O LINFONODO SENTINELA É POSITIVO PARA MALIGNIDADE NOS CASOS DE CARCINOMA INFILTRATIVO INICIAL

Pesquisador: Alfredo Luiz Jacomo

Área Temática:

Versão: 1

CAAE: 95570318.9 .0000 .0065

Instituição Proponente: Faculdade de Medicina da Universidade de São Paulo

Patrocinador Principal: Financiamento Próprio

\section{DADOS DO PARECER}

Número do Parecer: 2.839.142

Apresentação do Projeto:

Trata-se de um estudo retrospectivo de prontuários e exames histológicos de linfonodos de pacientes portadoras de tumores de mama atendidas em clínica particular. O responsável pela clínica é o orientador do projeto e os envolvidos garantem o sigilo das informações.

Objetivo da Pesquisa:

VARIÁVEIS ANATOMOPATOLÓGICAS E MOLECULARES ASSOCIADAS AO ACOMETIMENTO DOS DEMAIS LINFONODOS REGIONAIS QUANDO O LINFONODO SENTINELA É POSITIVO PARA MALIGNIDADE NOS CASOS DE CARCINOMA INFILTRATIVO INICIAL

Avaliação dos Riscos e Benefícios:

Não há riscos, por ser um projeto baseado em prontuários. As considerações éticas são apenas a garantia formal do sigilo e anonimato das informações, garantidas por carta formal de anuencia.

Comentários e Considerações sobre a Pesquisa:

É uma pesquisa simples que espero resulte em algum dado novo, já que é uma área com extensas publicações.

Considerações sobre os Termos de apresentação obrigatória:

É solicitada a dispensa de TCLE para os casos retrospectivos e portanto nenhum caso novo poderá

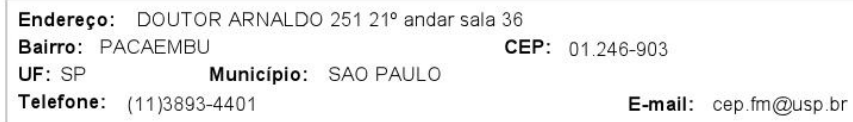




\section{USP - FACULDADE DE \\ MEDICINA DA UNIVERSIDADE Parasil Plarma DE SÃO PAULO - FMUSP}

Continuação do Parecer. 2.839.142

ser incluído. Nesse caso, análise puramente retrospectiva sem novos casos, acho que seria dispensável.

Recomendações:

A população de estudo deve ser composta por casos retrospectivos e seus dados devem ser depositados em banco de dados anonimo, com total garantia de anonimato de individuos envolvidos.

Conclusões ou Pendências e Lista de Inadequações:

Nenhuma

Considerações Finais a critério do CEP:

Este parecer foi elaborado baseado nos documentos abaixo relacionados:

\begin{tabular}{|l|l|c|c|c|}
\hline \multicolumn{1}{|c|}{ Tipo Documento } & \multicolumn{1}{|c|}{ Arquivo } & Postagem & Autor & Situação \\
\hline $\begin{array}{l}\text { Informações Básicas } \\
\text { do Projeto }\end{array}$ & $\begin{array}{l}\text { PB_INFORMAÇÕES_BÁSICAS_DO_P } \\
\text { ROJETO_1161930.pdf }\end{array}$ & $\begin{array}{c}09 / 08 / 2018 \\
11: 54: 56\end{array}$ & & Aceito \\
\hline Folha de Rosto & FOLHA.pdf & $09 / 08 / 2018$ & Alfredo Luiz Jacomo & Aceito \\
\hline Outros & Projeto.pdf & $\begin{array}{c}11: 53: 14 \\
11: 41: 37\end{array}$ & & \\
\hline Outros & custos.pdf & $19 / 06 / 2018$ & Alfredo Luiz Jacomo & Aceito \\
\hline Outros & & $12: 18: 28$ & & Aceito \\
& ANUENCIA.pdf & $19 / 06 / 2018$ & Alfredo Luiz Jacomo & Aceito \\
\hline $\begin{array}{l}\text { Projeto Detalhado / } \\
\text { Brochura }\end{array}$ & Doutorado.pdf & $19 / 06 / 2018$ & Alfredo Luiz Jacomo & Aceito \\
Investigador & & $12: 16: 03$ & & \\
\hline Cronograma & CRONOGRAMA.docx & $19 / 06 / 2018$ & Alfredo Luiz Jacomo & Aceito \\
\hline
\end{tabular}

Situação do Parecer:

Aprovado

Necessita Apreciação da CONEP:

Não

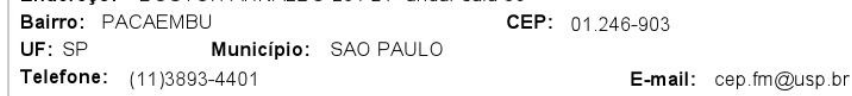




\section{USP - FACULDADE DE MEDICINA DA UNIVERSIDADE Plataforma
DE SÃO PAULO - FMUSP}

Continuação do Parecer. 2.839.142

SAO PAULO, 23 de Agosto de 2018

\section{Assinado por:}

Antonio de Padua Mansur

(Coordenador)

Endereço: DOUTOR ARNALDO $25121^{\circ}$ andar sala 36

Bairro: PACAEMBU CEP: $01.246-903$

UF: SP Municipio: SAO PAULO

Telefone: (11)3893-4401

E-mail:cep.fm@usp.br 